\title{
II. DER NIEDERRHEIN
}

Als die unmittelbaren Nachbarn im Osten waren die niederrheinischen Territorien Kleve, Geldern und Jülich-Berg sowohl die gegebenen Verbündeten als auch die Objekte der Ausdehnungsambitionen der Herzöge von Burgund als Grafen von Holland und Herzöge von Brabant. Als traditionell königsferne Landschaft ${ }^{1}$ bot der Niederrhein bis zur Kölner Stiftsfehde von 1474/1475 nur geringen Widerstand gegen die Usurpation von Reichsrechten ${ }^{2}$, weshalb die burgundischen Herzöge vornehmlich in dieser Region die Toleranzgrenze des Reiches gegenüber derartigen Aneignungen ausloteten. Philipp der Gute war in den Fällen Holland, Seeland, Hennegau und Luxemburg, wenn auch bei letzterem erst nach langwierigen Verhandlungen, faktisch erfolgreich, ohne allerdings die reichsrechtliche Legitimation zu erreichen ${ }^{3}$. Die Verbindungen der Burgunder mit den niederrheinischen Fürsten waren so eng, daß ihre Strukturen zwar nicht unbesehen auf die Beziehungen zu anderen Reichsfürsten übertragen werden können, an ihnen aber Charakteristika der Haltung Karls des Kühnen zum Reich besonders deutlich herausgearbeitet werden können.

Herzog Karl konnte sich Geldern durch eine Kombination aus zweifelhaften Rechtsgründen und Gewalt sichern und seinen Besitz durch die Belehnung vom 6. November 1473 legalisieren. Die Einverleibung Gelderns war nach der Übernahme der Pfandlande am Oberrhein seine zweite erfolgreiche, vertraglich abgesicherte Ausdehnung auf Reichsgebiet. Ihr Verlauf bietet Aufschlüsse über Taktik und Selbstverständnis Karls im Umgang mit dem durch interne Machtkämpfe geschwächten Nachbarn. Zudem schien die Aneignung des Landes das Modell für die Herrschaftsübernahme im Kölner Erzstift zu lie-

${ }^{1}$ HEINIG, Friedrich III., S. 1249, modifizierend die umfassende Darstellung der niederrheinischen Geschichte im Spätmittelalter von Wilhelm JANSSEN, Die niederrheinischen Territorien im Spätmittelalter. Politische Geschichte und Verfassungsentwicklung 1300-1500, in: RhVjbll 64 (2000) S. 45-167, hier S. 49.

$2 \mathrm{Zu}$ dem hohen Grad an administrativer Entwicklung und territorialer Integrität der Fürstentümer schon am Ende des 14. Jahrhunderts siehe Wilhelm JANSSEN, Die niederrheinischen Territorien in der zweiten Hälfte des 14. Jahrhunderts, in: RhVjbll 44 (1980) S. 47-67; DERS., Niederrheinische Territorialbildung. Voraussetzungen, Wege, Probleme, in: Klever Archiv 3 (1981) S. 95-113; DERS., Die niederrheinischen Territorien im Spätmittelalter, S. $127-156$.

${ }^{3}$ Siehe dazu Jörg K. HOENSCH, Kaiser Sigismund, Herrscher an der Schwelle zur Neuzeit, München 1996, S. 271-273, 352; LACAZE, Philippe le Bon et l'Empire, 1, S. 136-146. Sigmund erließ erst 1425 den Befehl, Holland, Seeland und Hennegau als erledigte Reichslehen einzuziehen. Auch in Zukunft beanspruchte er neben den genannten Provinzen Flandern, Brabant, Antwerpen, Mecheln, Limburg und Luxemburg für das Reich und verweigerte Philipp die Bestätigung ihres Besitzes; VAUGHAN, Philip, S. 32-51. 
fern. Weniger spektakulär entwickelte sich das Verhältnis zu Kleve und Jülich-Berg, an denen jedoch Methode der Einflußnahme und persönliche Haltung Karls zu diesen vergleichsweise kleinen, strategisch aber bedeutenden Reichsterritorien studiert werden können.

Aufgrund der engen Verflechtung der burgundischen Politik mit Kleve und Geldern werden diese im Folgenden gemeinsam behandelt. Auf Zusammenstellungen der überlieferten Informationen zu den familiären Bindungen der Fürstenhäuser mit dem burgundischen Hof und eine knappe Darstellung der burgundischen Rolle in den Soester und Münsterschen Fehden folgt eine Untersuchung von Politik und persönlichem Verhältnis Karls des Kühnen zu den Herzögen von Kleve und Geldern. Die gegebenen Eckpunkte sind Vorgeschichte und Ablauf der Eroberung Gelderns mit dem Nachspiel des Tages von Trier und die Belagerung von Neuss. Gleiches gilt für den daran anschlieBenden Abschnitt zu den Herzögen von Jülich-Berg. Besonders instruktiv für die Persönlichkeit Karls und seiner Einschätzung von Reich und Reichsfürsten ist die Korrespondenz mit den Herzögen, allen voran mit Herzog Johann von Kleve. In ihr spiegeln sich auf den unterschiedlichsten Ebenen das Vollgefühl der herzoglichen Macht nach der Eroberung Gelderns und die im Laufe des Neusser Unternehmens und der Konfrontation mit Kaiser und Reich zunehmende Nervosität Karls.

\section{Kleve und Geldern}

\subsection{Die Kontakte zwischen den Höfen}

a) Familienverbindungen: Kleve

Für die Herzöge von Burgund entwickelte sich seit der Wende zum 15. Jahrhundert Kleve zu ihrem wichtigsten Bündnispartner unter den nordwestlichen Reichsfürsten, eine Bindung, die rasch durch Heiraten und kulturellen Austausch gefestigt wurde. Es ist zu prüfen, inwieweit das Verdikt Vaughans, unter Philipp dem Guten seien die Herzöge Adolf und Johann von Kleve zu burgundischen Marionetten degradiert, auch für die Regierungszeit Karls des Kühnen zutrifft, und welcher Handlungsspielraum dem Klever unter diesen Umständen noch verblieb ${ }^{4}$.

4 VAUGHAN, Philip, S. 289-292, Zitat S. 292; vorsichtiger formuliert JANSSEN, Die niederrheinischen Territorien im Spätmittelalter, S.91, der davon spricht, daß sich Kleve zur »Klientel« der »politischen Führungsmacht Burgund « simmer bewußter bekannte«. Werner PARAVICINI, Kleve, Geldern und Burgund, S. 65; DERS., The Court of the Dukes of Burgun- 
Klevische Hilfe für Johann Ohnefurcht gegen die Partei der Orléans/Armagnac stand zunächst im Vordergrund des Bündnisses zwischen Herzog Johann und Graf Adolf von Kleve, das um Ostern 1405 geschlossen wurde 5 . Graf Adolf, seit 1417 Herzog Adolf I. von Kleve6, war in Brüssel am Hof des Herzogs von Brabant erzogen worden. Engere Beziehungen Kleves zum französischen Königshaus hatten sich spätestens seit 1378 ergeben, als Graf Adolf (d. Ä.) dem französischen König gegen ein Geldlehen von 1000 francs huldigte ${ }^{7}$. Nachdem eine weitläufigere Verwandtschaft bereits seit dem Ende des 14. Jahrhunderts über klevische und burgundische Ehen mit dem Haus Wittelsbach-Holland etabliert worden war, wurde das Bündnis dynastisch gefestigt durch den Ehevertrag Graf Adolfs von Kleve mit der Schwester Philipps des Guten, Maria, vom Oktober 1405. Etwa zur selben Zeit stellte Herzog Johann Ohnefurcht dem Grafen eine Pension von 1000 Goldschilden aus ${ }^{8}$. Zum Vollzug der Ehe kam es allerdings erst 1415, als Herzog Johann aufgrund seiner bedrängten Lage in Frankreich gezwungen war, sich klevischer Hilfe zu versichern ${ }^{9}$. Auf dieser Grundlage entwickelte sich Kleve bis $1477 \mathrm{zu}$ dem mit Burgund am engsten und kontinuierlichsten verbundenen reichsfürstlichen Haus. Dynastische Verbindungen und die Anziehungskraft des burgundischen Hofes gingen dabei mit militärischer und diplomatischer Kooperation Hand in Hand.

dy. A Model for Europe?, in: Ronald G. AsCH, Adolf M. BIRKE (Hg.), Princes, Patronage, and the Nobility. The Court at the Beginning of the Modern Age c.1450-1650, Oxford 1991, S. 69-102, hier S. 90-92. Zur administrativen Entwicklung und Residenzenbildung in Kleve siehe Wolf-Rüdiger SCHLEIDGEN, Die Kanzlei der Grafen und Herzöge von Kleve im 14. und 15. Jahrhundert, in: Landesherrliche Kanzleien im Spätmittelalter, München 1984, S. 171-192; Klaus FliNK, Der Klevische Hof und seine Chronisten. Verwaltungsschriftgut als Quelle und Mittel der territorialen Geschichtsschreibung, Kleve 1994; DERS., Territorialbildung und Residenzentwicklung in Kleve, in: Territorium und Residenz, S. 67-96; Wilhelm JANSSEN, Regierungsform und Residenzbildung in Kurköln und anderen niederrheinischen Territorien des 14. und 15. Jahrhunderts, in: Territorium und Residenz, S. 151-169.

5 Franz PETRI, Nordwestdeutschland in der Politik der Burgunderherzöge, in: Westfälische Forschungen 8 (1953-1954) S. 80-100, hier S. 83; JANSSEN, Die niederrheinischen Territorien im Spätmittelalter, S. $90 \mathrm{f}$.

6 Siehe zum Folgenden PARAvicinI, Kleve, Geldern und Burgund, S. 55-57; C.A.J. ARMSTRONG, La politique matrimoniale des ducs de Bourgogne de la maison de Valois, in: DERS., England, France and Burgundy in the Fifteenth Century, London 1983, S. 237-342, hier S. 239, 251-254, H. PREuss, Politische Heiraten in Jülich-Kleve-Berg, in: Land im Mittelpunkt der Mächte, S. 133-146, hier S. 135f.

7 Gregor HÖVELMANN, Die Anfänge der Beziehungen zwischen Kleve und den Herzögen von Burgund, in: AHVN 161 (1959) S. 232-243, hier S. 234f.

${ }^{8}$ HOVVELMANN, Die Anfänge der Beziehungen, S. $238 \mathrm{f}$.

${ }^{9}$ HövelmaNN, Die Anfänge der Beziehungen, S. 24lf. Zum klevischen Sieg in der Schlacht von Kleverhamm, der Kleve hohe Lösegelder einbrachte und es so zu umfangreichem militärischem Engagement auf burgundischer Seite befähigte, siehe JANSSEN, Die niederrheinischen Territorien im Spätmittelalter, S. 97f. 
Zwischen 1420 und 1435 gründete Herzog Adolf den Antoniusorden, der allerdings nicht zwingend auf die Anregung durch den Orden vom Goldenen Vlies zurückgeführt werden muß ${ }^{10}$. Herzog Adolfs jüngerer Sohn, Adolf von Kleve-Ravenstein ${ }^{n}$, widmete sich vollständig dem Dienst am burgundischen Hof, wo er seit seinem 14. Lebensjahr aufgewachsen war, und wurde einer der wichtigsten Ratgeber der Herzöge Philipp und Karl'12. Seine Eheschließung 1453 mit Beatrix von Coimbra, einer Nichte Herzogin Isabellas, verdankte er Herzog Philipp. In zweiter Ehe war er mit Anne de Bourgogne, Bastardtochter Herzog Philipps, verheiratet. Nach dem Tode Karls bekleidete er unter Maria von Burgund den Posten des Generalstatthalters aller burgundischen Lande und wurde zu einem der wichtigsten Ratgeber der Herzogin. Erst seine Rolle während der Aufstände der Genter nach dem Tod Marias entfremdeten ihn von Maximilian. Auch sein Sohn Philipp von Kleve-Ravenstein ${ }^{13}$ bekleidete hohe Ämter und diente den Herzögen in diplomatischen und militärischen Funktionen. Im Mai 1468 stattete Karl ihn mit einer jährlichen Pension von 5000 francs aus für die "grans, loyaux et notables services«, die er dem Haus Burgund geleistet hatte. 1475 ernannte er ihn zum Generalstatthalter der Niederlande während des Feldzuges in Lothringen ${ }^{14}$. Die Töchter des klevischen Herzogspaares wurden von Herzog Philipp, in Ermangelung eigener legitimer weiblicher Nachkommen, zur Festigung politischer Projekte mit erheblichem finanziellem Aufwand nach Geldern, Orléans und Aragon-Navarra verheiratet ${ }^{15}$.

${ }^{10}$ Holger KRUSE, Werner PARAVICINI, Andreas RANFT, Ritterorden und Adelsgesellschaften im spätmittelalterlichen Deutschland. Ein systematisches Verzeichnis, Frankfurt a.M. u.a. 1991, S. 259, zum Orden insgesamt S. 258-266. Leo PETERS, Der jülichsche Hubertus- und der klevische Antonius-Ritterorden, in: Land im Mittelpunkt der Mächte, S. 125-132, hier S. 130.

11 Paul de WIN, Adolphe de Clèves, seigneur de Ravenstein, de Wijnendale et de Dreischor, in: de SMEDT (Hg.), Les Chevaliers de l'Ordre de la Toison d'Or, Nr. 55 S. 131-134; Wim P. BLOCKMANS., „Kleve, Adolf von«, in: LexMA, 5, 1991, Sp. 1213.

12 Siehe zu Adolfs Pensionen und Zuwendungen u.a. HANSEN, Westfalen und Rheinland, 2, Nr. 241, S. 324 (1453), und Nr. 427, S. 501 (1457). Die Einträge in den Rechnungsbüchern schwanken zwischen $4000 \mathrm{lb}$ und $5000 \mathrm{lb}$ im Jahr für Adolfs Pension. 1465: $5000 \mathrm{lb}$, Lille ADN B 2058 f.88r-89r; 1466: 4000 lb, Lille ADN B 2061 f.69r; 1467: 4000 lb, Lille ADN B 2064 f.347r. Seit 1468 erhielt er die oben erwähnten 5000 frs, 1472: Lille ADN B 2093/66 897; 1474: Lille ADN B 2105/67 597.

13 Philipp erhielt spätestens seit dem Jahr 1470 eine jährliche Pension von $1000 \mathrm{lb}$, Lille ADN B 2079, o. Fol.; vgl. auch Lille ADN B 2088/66 597, Quittung über die Pension für 1472 .

14 Pension: Urkunde Brügge, 20.5.1468, STEIN, Catalogue des Actes, Nr. 398; Generalstatthalterschaft: Patent Valenciennes, 21.8.1475, STEIN, Catalogue des Actes, Nr. 2189. Statthalterschaft nach Januar 1477, Lille ADN B 2115 f.38r-v: Pensionen von 12000 frs und 8000 frs.

${ }^{15}$ ARMSTRONG, La politique matrimoniale, S.257f. Monique SOMME, Une mère et son fils: Isabelle de Portugal, après son départ de la cour (1457-1471), et Charles le Téméraire, in: 
Auch Herzog Johann I.16 (1448-1481) wuchs am Hof Philipps des Guten auf und besuchte in Gent die Lateinschule ${ }^{17} .1451$ wurde er Ritter vom Goldenen Vlies, nahm 1454 am Fasanenfest teil und verband sich 1456 dem burgundischen Herzogshaus zusätzlich durch seine Hochzeit mit Elisabeth von Burgund-Étampes ${ }^{18}$. Ebenso wie sein jüngerer Bruder besaß Johann ein großes Haus in Brüssel ${ }^{19}$ und erfüllte als hochrangiger Vertreter oder Begleiter Herzog Philipps diplomatische und repräsentative Aufgaben; so 1459 auf dem Kongreß von Mantua ${ }^{20}$ und 1461 beim Einzug in Paris im Gefolge des neuen Königs Ludwig XI. Das enge Verhältnis Philipps von Burgund zu Johann von Kleve zeigt sich unter anderem in den eigenhändigen Briefen Philipps an Johann aus den Jahren 1451 und 1452. Johann stand Philipp im Alter und wohl auch charakterlich wesentlich näher als Karl21, was diesen aber nicht daran

Geneviève und Philippe CONTAMINE (Hg.), Autour de Marguerite d'Écosse. Reines, princesses et dames du XV $\mathrm{XV}^{\mathrm{e}}$ siècle, Paris 1999, S. 99-121, hier S. 105.

16 Siehe Wilhelm JANSSEN, "Johann I.« in: NDB, 10, 1974, S. 492-493; Paul de WIN, Jean $\mathrm{I}^{\text {er, }}$ duc de Clèves, comte de la Marck, in: de SMEDT (Hg.), Les Chevaliers de l'Ordre de la Toison d'Or, Nr. 47, S. 109-112.

17 Robert SCHOLTEN (Hg.), Gert van der Schuren, Clevische Chronik, Kleve 1884, S. 145147.

18 Eheabredung in: LACOMBLET, Rheinisches Urkundenbuch, 4, 1, Nr. 308, S. 375-379. 1443 hatte Herzog Philipp Kaiser Friedrich III. den Vorschlag zu einer Ehe zwischen Johann und der Schwester des Kaisers, Katharina, unterbreitet, HövELMANN, Die Anfänge der Beziehungen, S. 233.

19 PARAVICINI, Kleve, Geldern und Burgund, S. 57.

20 Frédéric de ReIFFENBERG (Hg.), Jacques du Clercq, Mémoires, 2, S. 347. Siehe auch Agostino SoTTILI, Die Universität Pavia im Rahmen der Mailänder Außenpolitik. Der Italienaufenthalt von Johann I. von Kleve und Jean de Croÿ und andere Anekdoten über die Universität Pavia, in: A. BUCK, T. KLANICZAY (Hg.), Sozialgeschichtliche Fragestellungen in der Renaissanceforschung, Wiesbaden 1992, S. 49-81. Herzog Johann wurde häufig gebeten, Vorschläge für neue Ordensmitglieder zu unterbreiten, vgl. z.B. Karl an Johann vom 21.2.1468 Brüssel, HStA Düsseldorf, Kleve-Mark, Familiensachen 16, J2, Dijon ACO, Papiers Henri STEIN, Briefwechsel Nr. 864. In einem Schreiben Karls vom 29.12.1471 forderte dieser Johann auf, sich wie die anderen Ordensritter ein Kleid passend zu einem von Karl gestellten Mantel anfertigen zu lassen. Karl legte Johann nahe, den Stoff für das Kleid bei Tommaso Portinari zu kaufen, da dieser auch für die Herstellung der Mäntel sorgen werde. Karl an Johann, 29.12.1471 Saint-Omer, HStA Düsseldorf, Kleve-Mark, Beziehungen zu Geldern 31, Dijon ACO, Papiers Henri STEIN, Briefwechsel Nr. 1983; Karl an Johann, 26.2.1472 Male-lès-Bruges, HStA Düsseldorf, Kleve-Mark, Beziehungen zu Geldern 35, Dijon ACO, Papiers Henri STEIN, Briefwechsel Nr. 2010. Vgl. auch Karl an Johann, 12.12.1472 Abbeville, bezüglich der für den 2.5.1473 geplanten Kapitelsitzung, HStA Düsseldorf, Kleve-Mark, Beziehungen zu Geldern 31, Dijon ACO, Papiers Henri STEIN, Briefwechsel Nr. 2174. Auf ein Schreiben Karls vom 11.12.1475 hin schlug Johann unter anderen den Grafen von Virneburg (Vernenbosch) als neuen Ordensritter vor, HStA Düsseldorf, Kleve-Mark, Familien-Sachen 16 Nr. 1 u.2, Dijon ACO, Papiers Henri STEN, Briefwechsel Nr. 3298-3299. Vgl. zum letzten PaRAviCINI, Kleve, Geldern und Burgund, S. 56 u. Anm. 32.

21 Johann bezeichnete Philipp als seinen Vater, den er nächst Gott am meisten ehre: PETRI, Nordwestdeutschland, S. 84. Briefe Philipps an Johann: Armand GRUNZWEIG, Quatre Let- 
hinderte, Johann und seinem Bruder Adolf Ende 1476 die Vormundschaft Marias von Burgund anzuvertrauen ${ }^{22}$.

1469 nahm der Burgunder Johanns ältesten Sohn Johann (II., reg. 14811521) an seinen Hof und beauftragte Pierre de Miraumont, Herrn von La Boutillerie, mit seiner Erziehung23. Um die Jahreswende 1473/74 begleitete Johann II. Karl auf der Reise durch die Pfandlande und in das Herzogtum Burgund $^{24}$. Am 23. Mai 1475 schlug Karl ihn vor Neuss zum Ritter, nachdem er sich in einem Scharmützel mit den Kaiserlichen ausgezeichnet hatte ${ }^{25}$. Einer der Bastarde Johanns I., Adolf, studierte an der Universität von Orléans und wurde am dortigen befreundeten Hof gastlich aufgenommen, so zur Feier kirchlicher Hochfeste, und war gleichzeitig Escuier pannetier am Hofe Karls. 1473 wurde er von Karl mit der jungen und reichen Witwe des Herrn von Helmond verheiratet ${ }^{26}$. Beim Einzug der Särge Philipps des Guten und Isabellas von Portugal in Dijon im Januar 1474 und deren Beisetzung in der Kartause von Champmol bildeten Adolf von Kleve-Ravenstein und Johann (II.) von Kleve das Ehrengeleit, da Karl durch eine Krankheit daran gehindert war ${ }^{27}$. Eine am burgundischen Vorbild orientierte, zunehmend aufwendige Hofhaltung führte gemeinsam mit den zahlreichen von Johann geführten Kriegen zu

tres autographes de Philippe le Bon, in: Revue Belge de Philologie et d'Histoire 4 (1925) S. 431-37. Vgl. PARAVICINI, Kleve, Geldern und Burgund, S. 68. Bezeichnend für das im Folgenden noch näher zu beschreibende gespannte Verhältnis vieler klevischer Untertanen zur Politik Karls ist, daß dieser in der Chronik des Herzog Johann völlig ergebenen Gert van der Schuren nicht vorkommt, obwohl er die Arbeit daran wahrscheinlich 1471 aufnahm und 1478 noch nicht abgeschlossen hatte: Gert van der Schuren, Clevische Chronik, Einleitung, S. X.

22 PETR1, Nordwestdeutschland, S. 85.

${ }^{23}$ Lille ADN B 2079, o. Fol.; Lille ADN B 2086 Nr. 66312, Quittung vom 23.3.1472 für Ausgaben für die Kleidung Johanns.

${ }^{24}$ Knebel, Basler Chroniken, 2, S. 46. Knebel spricht von einem »dux Clivensis«, doch wird es sich um Johann II. gehandelt haben, der sich ständig in der Umgebung Karls aufhielt.

${ }^{25}$ Liste der an diesem Tag von Karl zu Rittern Geschlagenen in: Paris BNF Ms fr 11590, f.128v. Bericht über das Scharmützel von Claude Dupré an Herzog Johann, 23.5.1475, in: Adolf UlRICH, Akten zum Neußer Kriege, 1472-1475, in: AHVNR 49 (1889), Nr. 162, S. 116.

${ }^{26}$ Fragmente aus Rechnungen im Schloß Blois vom 10.11.1470, Februar 1471, u. September 1472, in: Léon de LABORDE, Les ducs de Bourgogne. Études sur les lettres, les arts et l'industrie pendant le $X^{e}$ siècle, et plus particulièrement dans les Pays-Bas et le duché de Bourgogne, Preuves, 3 Bde., Paris 1849-1852, hier: 3, S. 404, 409, 411. Escuier pannetier: Lille ADN B 2079, o. Fol. Zur Heirat siehe Karl an Johann, 20.3.1473 Brüssel, HStA Düsseldorf, Kleve-Mark, Beziehungen zu Geldern 34,4, Dijon ACO, Papiers Henri STEIN, Briefwechsel Nr. 2244. (Diese Verbindung wurde zwischen den Herzögen wiederum durch Johann von Sechtingen ausgehandelt.) Zur Ehe PARAVICINI, Kleve, Geldern und Burgund, S. 57f.

${ }^{27}$ Beschreibung des Einzugs in: Paris BNF Ms fr 5365 f.40v-46r und Paris BNF n. a. fr. 7237 f.316r-323v; gedruckt in: $H$. Chabeuf, L'Entrée de Charles le Téméraire et les funérailles de Philippe le Bon à Dijon en janvier et février 1474, in: Mémoires de la Société bourguignonne de Géographie et d'Histoire 18 (1902) S. 79-349, hier S. 257-336. 
einer hohen Verschuldung des klevischen Hofes ${ }^{28}$. Ebenfalls burgundisch geprägt war die intendierten Grablege der Herzöge von Kleve, die sich auf der Lippeinsel op ter Graven in einer eigens gegründeten, wohl Champmol nachempfundenen, Kartause befand ${ }^{29}$.

\section{b) Pensionen}

In einer Urkunde vom 20. Juli 1469 überschrieb Karl dem Herzog von Kleve eine jährliche Pension von 6000 francs, in Fortführung der Pension, die der Herzog bereits von Philipp dem Guten erhalten hatte ${ }^{30}$. Davon wurden 2000 francs dem ältesten Sohn des Herzogs, Johann (II.), vorbehalten, der zu diesem Zeitpunkt seinen Dienst am burgundischen Hof aufnahm. Bereits nach einem gutem Jahr jedoch, in einem Schreiben an Herzog Johann vom 14. Oktober 1470, wurde der Anteil Johanns (II.) an den 6000 francs von 2000 francs auf 3000 francs erhöht. Dies geschah mit der Begründung, daß Johann (II.), der nun vom Dienst bei Herzogin Margarete in den Dienst Herzog Karls wechseln würde, mit den bisherigen 2000 francs nur mager ausgestattet sei. Karl selbst aber sei in Geldnöten und bat deshalb den Herzog von Kleve, seinem Sohn die weiteren 1000 francs aus der gemeinsamen Pensionssumme zuzugestehen, was offenbar auch geschah ${ }^{31}$. Nicht recht passend war es dann aber, daß sich Karl vor seinem Rat im Februar 1473 über eine angebotene klevische Truppenhilfe von jeweils 100 Reitern und Schützen mokierte mit dem Hinweis, bei einer solch großzügigen Pension erwarte er von ihrem Empfänger ein größeres Engagement ${ }^{32}$.

Vollends willkürlich, aber wohl aus Geldnot, verfuhr Karl mit der klevischen Pension im Januar 1476. Am 31. Januar ließ er Herzog Johann aus Be-

28 Wolf-Rüdiger SCHLEIDGEN, Territorialisierung durch Verwaltung. Anmerkungen zur Geschichte des Herzogtums Kleve-Mark im 15. Jahrhundert, in: RhVjbll 63 (1999) S. 152-186, hier S. 179-180. Klaus FLINK, Die klevischen Hofordnungen. Von der Kostliste zur Regiments-Ordnung, in: Holger KRUSE, Wemer PARAVICINI (Hg.), Höfe und Hofordnungen 1200-1600, Sigmaringen 1999, S. 401-420, bes. S. 414, 418. Zur umfangreichsten Hofordnung von 1470/71 Klaus FLINK, Bernd THISSEN, (Bearb.), Die klevischen Hofordnungen, Köln, Weimar, Wien 1997, S. xxvii u. S. 38-43.

${ }^{29}$ Hans Peter HILGER, Kleve und Burgund, in: Land im Mittelpunkt der Mächte, S. $225 \mathrm{f}$.

$30 \mathrm{Vgl}$. Brüssel AGR CC 1924 f.362r.

31 Überschreibung der Pension vom 20.7.1469 in LACOMBLET, Rheinisches Urkundenbuch, 4, Nr. 351, S. 442; Karl an Johann, 14.10.1470 Hesdin, HStA Düsseldorf, Kleve-Mark, Beziehungen zu Geldern 31, Dijon ACO, Papiers Henri STEIN, Briefwechsel Nr. 1552. Vgl. PARAVICINI, Kleve, Geldern und Burgund, S. 57 Anm. 41 u. S. 73, ohne Berücksichtigung des Briefes vom 14.10.1470.

32 Olivier de la Marche an Johann II. von Kleve, 17.2.1473, in: Henri STEN, Nouveaux Documents sur Olivier de la Marche et sa famille, in: Académie Royale de Belgique, Classe des lettres, Mémoires, $2^{e}$ série, 9, Brüssel 1926, S. 1-69, hier S. 45. 
sançon wissen, da $\beta$ auch die restlichen 3000 francs, die noch an ihn ausgezahlt worden waren, für die kommenden drei Jahre dem Sohn zugute kommen sollten, wegen der "großen Unternehmungen«, die Karl zu der Zeit in Anspruch nahmen ${ }^{33}$. Vermutlich kam auch der Jungherzog nicht mehr in den Genuß seiner Pension, sondern das Geld war in die burgundische Kriegskasse geflossen und längst verbraucht. Doch nicht nur der Herzog selbst, auch seine Amtsträger hatten wenig Hemmungen, mit der Pension des Klevers freizügig zu verfahren. Als sich Goch und Wachtendonk mit Hinweis auf einen Befehl Herzog Johanns weigerten, Entschädigungen an den Herzog von Burgund zu zahlen, drohten die burgundischen Domänenschatzmeister am 8. Dezember 1475, die geschuldete Summe von der Pension Herzog Johanns abzuziehen ${ }^{34}$.

Die engen Bindungen des Hauses Kleve an den burgundischen Hof wurden nicht nur von den Betroffenen selbst wahrgenommen ${ }^{35}$, sondern bestimmten auch das Bild an den auswärtigen Höfen. Gert van der Schuren berichtete es als selbstverständlich, daß 1450 in Neapel der Kardinal von Thérouanne Herzog Johann sein Stadthaus in Rom deshalb als Unterkunft anbot, weil er als der Neffe des Herzogs von Burgund ein "merklicher « Fürst war ${ }^{36}$. Ebenso wurden Bittgesuche und Beglaubigungen, die sich an den Herzog von Burgund richteten, häufig gleichzeitig auch an Herzog Johann gesandt, damit dieser sich für die Anliegen der Absender einsetze ${ }^{37}$. In überregionalen politi-

${ }^{33}$ Karl an Johann, 31.1.1476 Besançon, HStA Düsseldorf, Kleve-Mark, Beziehungen zu Geldern 34, Dijon ACO, Papiers Henri STEIN, Briefwechsel Nr. 3325.

34 PARAVICINI, Kleve, Geldern und Burgund, S. 73. Unter Maria und Maximilian war das Haus Kleve weiter auf der Liste der burgundischen Pensionsempfänger, siehe z. B. Lille ADN B 2115 f.36r-37r: (1477) Pensionen für Jungherzog Johann, für Philipp von Kleve, Sohn Adolfs von Kleve-Ravenstein; ebd. f.38r-v: Pensionen für Adolf von KleveRavenstein.

35 So in einer Denkschrift klevischer Räte vom Mai 1451, in der das Projekt, Herzog Johann durch Philipp die Verweserschaft in Limburg und Valkenburg oder die Statthalterschaft in sämtlichen holländischen Landen übertragen zu lassen, erwogen wurde, u.a. um den Ambitionen Kölns auf Jülich zu begegnen. Das Memorial läßt das von Kleve immer wieder verwandte Argumentationsmuster der engen Verwandtschaft und der besonderen Zuneigung zwischen den fürstlichen Familien gut erkennen. Johanns Liebe zu seinem Onkel, »den he baven alle heren der werlt lief ind weert heft", wurde zum Antrieb der klevischen Politik stilisiert: HANSEN, Westfalen und Rheinland, 2, Nr. 79, S. 126-128, Zitat S. 127. Gegenüber Dritten bediente sich auch Herzog Philipp der verwandtschaftlichen Nähe und der Verbundenheit durch die Zugehörigkeit Johanns zum Goldenen Vlies als Argument für die Vertretung klevischer Interessen, so in seinem Schreiben an Kardinal Nikolaus von Kues, Ende August 1451 Brüssel: "...qua ipse nepos noster tum sanguinis proximo gradu, tum racione ordinis nostri Velleris Aurei nobis indissolubiliter connexus est, unde res suas gerendas tamquam proprias cordintimas semper habemus...«, HANSEN, Westfalen und Rheinland, 2, Nr. 107, S. 182.

36 Van der Schuren, Clevische Chronik, S. 168.

37 Siehe z.B. den Dank der Stadt Köln an Pierre de Goux und Herzog Johann für die Kölner Gesandten am burgundischen Hof erwiesene Unterstützung, 22.8.1469 Köln, HR 2, 6, Nr. 266, S. 238; die Beglaubigung Galeazzo Maria Sforzas für seine Gesandten an Karl, die 
schen Zusammenhängen wurde der Herzog von Kleve je nach dem (westlichen) Blickwinkel des Betrachters also nur noch bedingt als selbständiger Akteur wahrgenommen.

\section{c) Familienverbindungen: Geldern}

Weniger eng mit Burgund verbunden als Kleve, konnte sich Geldern dennoch dem Einfluß des großen Nachbarn nicht entziehen, der die immer wieder aufflammenden Auseinandersetzungen um die Herrschaft geschickt zu nutzen verstand. Nach Franz Petri betrieb Burgund in keinem anderen Territorium seine Politik des divide et impera so konsequent wie in Geldern ${ }^{38}$.

Arnold von Geldern heiratete 1423 Katharina von Kleve ${ }^{39}$, eine Schwester Johanns (I.) von Kleve und Nichte Philipps des Guten. Seine Schwester Maria, geboren 1433, wurde in den 1440er Jahren am burgundischen Hof erzogen und wurde die Gattin Jakobs II. von Schottland ${ }^{40}$. Arnold konnte mit burgundischer Hilfe die Herrschaft über Geldern gegen das Haus Berg behaupten, geriet aber durch den sich fortschleppenden Krieg gegen Berg in immer weitere Abhängigkeit von Philipp dem Guten. 1431 verhängte Sigmund den Reichsbann über Herzogshaus und Land Geldern, um die Anerkennung Herzog Adolfs von Berg als Landesherrn zu erzwingen, dem nach kaiserlicher Meinung die Nachfolge in Geldern zustand. Der Bann wurde von Friedrich III. bestätigt und blieb bis zur Eroberung Gelderns 1473 in Kraft ${ }^{41}$. Letztlich hatte er den Einmarsch der Burgunder erst ermöglicht, da ohne ihn eine ähnliche Reaktion des Reiches wie bei Neuss durchaus denkbar gewesen wäre. Der immer wieder ausbrechende Krieg mit Berg ruinierte die herzoglichen Finanzen und beeinträchtigte das Verhältnis Arnolds zu seinen eigenen Ständen und zu Herzog Adolf von Kleve42.

Die geldrischen Stände, zeitweilig unter der Führung Vinzenz' von Moers, setzten dem burgundischen Einfluß entschiedeneren Widerstand entgegen als die Klever, obwohl sie den bis zur Herrschaftsübernahme burgundfreundlichen Jungherzog Adolf und seine Mutter Herzogin Katharina gegen Herzog

gleichzeitig an Herzog Johann, Bastard Anton, Herzogin Isabella und Philipp von Savoyen gerichtet war, 5.5.1469 Abbiategrasso, SESTAN, Carteggi, 1, Nr. 156, S. 240.

38 PETRI, Nordwestdeutschland, S. 86.

${ }^{39} \mathrm{~W}$. JAPPE ALBERTS, Geschiedenis van Gelderland. Van de vroegste tijden tot het einde der middeleeuwen, 's-Gravenhage 1966, S. 96.

40 Gerard NiJSTEN, Het Hof van Gelre. Cultuur ten tijde van de hertogen uit het Gulikse en Egmondse huis (1371-1473), Kampen 1992, S. 101.

${ }^{41}$ Er wurde beispielsweise von Friedrich III. am 12.8.1468 in Graz bekräftigt, Regesten Friedrich III, 7, bearb. v. Thomas R. KRAUS, Nr. 287, S. 173; JAPPE ALBERTS, Geschiedenis, S. 98.

42 JAPPE ALBERTS, Geschiedenis, S. 99f. 
Arnold unterstützten. Burgundische Hilfe gegen den ungeliebten Arnold schien zumindest einigen Städten durchaus akzeptabe143. In der Münsterschen Stiftsfehde und dem Konflikt um die Besetzung des Utrechter Bischofsstuhles zählte Herzog Arnold zu den Gegnern burgundischer Politik. Philipp der Gute antwortete darauf mit intensivierten Kontakten zu Herzogin Katharina, um eine Absetzung Arnolds und die Regentschaft Adolfs zu betreiben. Der Jungherzog wurde mit burgundischer Vermittlung 1463 Schwager des Grafen von Charolais durch seine Ehe mit Katharina von Bourbon. Wahrscheinlich anläßlich seiner Eheschließung wurde er in den Orden vom Goldenen Vlies aufgenommen. Er selbst gründete 1468 nach seinem Sieg über Herzog Johann von Kleve bei Straelen den Orden Unserer Lieben Frau ${ }^{44}$. Ähnlich wie bei Kleve wurde dem geldrischen Herzogshaus die Nähe zu den Herzögen von Burgund positiv zugerechnet. 1470 nannte man Adolf als möglichen Ehemann einer der Töchter König Ferrantes von Neapel und zählte zu den Vorzügen Adolfs auch seine engen Beziehungen und seine Verwandtschaft zu Herzog Karl, offenbar in Unkenntnis des inzwischen eingetretenen Richtungswechsels in der burgundischen Politik ${ }^{45}$.

Herzog Philipp war 1465 der Taufpate der Tochter Adolfs von Geldern, Philippa. Zur Taufe wurden 12 emaillierte und vergoldete Silbertassen und zwei ebenso verarbeitete Silberschüsseln im Wert von insgesamt $493 \mathrm{lb}$ geschenk ${ }^{46}$. Der 1467 geborene Karl dürfte das Patenkind Herzog Karls gewesen sein. Auch noch nach der Gefangennahme Arnolds, die durchaus die $\mathrm{Zu}-$ stimmung Herzog Philipps und Karls gefunden haben muß, standen Adolf und seine Gattin Katharina in engen Beziehungen zum burgundischen Hof. 1466 war Adolf wenigstens ein Mal, im April, am herzoglichen Hof in Brüssel, 1467 im März/April und noch einmal Ende April ${ }^{47}$. Herzogin Katharina, »madame de Guelres la Josne « hielt sich seit dem Tod ihres Vaters, Herzogs Karl von Bourbon, gemeinsam mit ihrer Mutter Agnes von Burgund, einer Schwester Philipps, und ihren Schwestern am burgundischen Hof in Brüssel auf. Herzog Philipp kam in dieser Zeit für ihren Unterhalt auf. Mit einem Gefolge von 57 Personen brach Katharina am 12. September zu ihrem Gatten

43 JAPPE ALBERTS, Geschiedenis, S. 106f.

${ }^{44}$ KRUSE, PARAVICINI, RANFT, Ritterorden und Adelsgesellschaften, S. 404-406.

45 NIJSTEN, Het Hof van Gelre, S. 282; Brief eines Unbekannten an Raimondo de Marliano, 13.8.1470, SESTAN, Carteggi, 1, Nr. 168, S. 267-268.

46 Zahlungsmandat an den Brüsseler Goldschmied Baudoin Henrixzone, 24.3.1465 Brüssel, Lille ADN B 2054 f.182v-183r. Im Juni war Adolf wieder zu Gast am burgundischen Hof: GODEFROY, Itinerar, Juni 1465.

${ }^{47}$ Itinerar in Gerard NIJSTEN, De ontwikkeling van residenties en het hertogdom Gelre, in: Territorium und Residenz, S. 118-149, hier S. 146f. 
nach Grave auf und wurde auch zu der Reise vollständig von Herzog Philipp ausgestattet ${ }^{48}$.

\subsection{Die Soester Fehde}

Philipp der Gute hatte 1430, im Jahr seines Herrschaftsantritts in Brabant, das traditionelle Bündnis zwischen Köln und dem Herzogtum erneuert und den Besuch Erzbischof Dietrichs von Moers empfangen. Als Philipp sich nach dem Vertrag von Arras 1435 mit verstärktem Engagement den Entwicklungen am Niederrhein zuwenden konnte, wurde der Gegensatz zu dem gleichfalls expansiv ausgerichteten Erzbischof bereits spürbar. Es kam allerdings nie zu einer militärischen Konfrontation, und noch während der Auseinandersetzung um die Besetzung des Bistums Utrecht betrieb Erzbischof Dietrich 1437/37 die Wahl des Herzogs zum römischen König. Den Höhepunkt der Beziehungen Dietrichs zu Philipp markiert der Besuch des Herzogs 1440 bei den Heiligen Drei Königen, der vor dem Hintergrund der burgundischen Bemühungen um die Klärung des lehnrechtlichen Status' der niederländischen Territorien $\mathrm{zu}$ verstehen ist $^{49}$.

Das Haus Moers war dem burgundischen Hof vor allem in der Person Graf Friedrichs von Moers und seines Sohnes Vinzenz verbunden. Graf Friedrich wurde 1431 Ritter vom Goldenen Vlies und betätigte sich in vielfältiger Weise als »Sachwalter der burgundischen Politik im Reich«. Er war entscheidend am Vertrag Herzog Philipps mit Jakobäa von Bayern von 1433 beteiligt, der die Sukzession in Holland, Seeland und Hennegau regelte, sowie an den Verhandlungen des Herzogs mit Kaiser Sigmund von 1434 bis 1437 in der Frage der Reichslehen ${ }^{50}$. Diese Politik wurde von Graf Vinzenz fortgesetzt, der 1454 seine Tochter Walburga Philippe de Croÿ zur Frau gab. Ein Jahr nach der Eheschließung seiner Tochter kam die Verbindung zwischen Jeanne de Croÿ, der Cousine Philippes, mit Pfalzgraf Ludwig von Veldenz zustande, mit dessen Schwester Anna Vinzenz seit 1435 vermählt war ${ }^{51}$.

Das Verhalten Philipps in der Soester Fehde ist vor dem dargelegten Hintergrund freundschaftlicher Beziehungen zu Erzbischof Dietrich, des unbestimm-

${ }^{48}$ ARMSTRONG, La politique matrimoniale, S. 255. Ausgaben für den Unterhalt der Herzogin von Bourbon und ihrer Töchter: Lille ADN B 2058 f.106r-107r; Aufwendungen für die Reise Isabellas: ebd., f.204r-205r.

49 JANSSEN, Das Erzbistum Köln im Spätmittelalter, S. 265f; DERS., Die niederrheinischen Territorien im Spätmittelalter, S. $109 \mathrm{f}$.

${ }^{50}$ Graf Friedrich versuchte nach 1437 noch mehrmals, dem Herzog die römische Krone zu verschaffen: PARAVICINI, Moers, Croy, Burgund, S. 19f; vgl. die Denkschrift des Grafen Vinzenz von Moers von 1473 über die Verdienste seiner Familie für Burgund in: Werner PARAVICINI, Zur Königswahl von 1438, in: RhVjbll 39 (1975) S. 99-115.

51 PARAVICINI, Moers, Croy, Burgund, S. 23-25. 
ten Verhältnisses Burgunds zum Reich, des Ringens Kleves mit Kurköln um die Vorherrschaft in Westfalen und am Niederrhein und der Mittlerstellung der Grafen von Moers zu sehen ${ }^{52}$. Der Übertritt der Stadt Soest aus der erzbischöflichen Herrschaft in die des Jungherzogs Johann von Kleve löste den Konflikt aus. Johann nahm die Erbhuldigung der Stadt im Juni 1444 an, nachdem nur wenige Tage zuvor Verhandlungen zwischen Köln, Soest und Kleve unter Vermittlung des burgundischen Rates Dietrich von Mengersreuth zu einer friedlichen Beilegung der Streitpunkte gescheitert waren ${ }^{53}$. Friedrich III. machte sich den Standpunkt des Erzbischofs zu eigen und verhängte am 15. Januar 1445 die Acht über die Stadt ${ }^{54}$.

In der Zurückweisung der kölnischen Vormachtbestrebungen deckten sich Philipps Ziele mit denen seiner klevischen Verwandten. Philipp beteiligte sich offenbar von Beginn an den Kriegskosten Kleves, während Jungherzog Johann mehrmals jährlich an den burgundischen Hof ritt, um sich mit seinem Onkel über das weitere Vorgehen zu beraten. Trotzdem war Philipp darauf bedacht, in der Rolle des neutralen Vermittlers zu verbleiben und sich nicht mit eigenen Truppen gegen den Erzbischof zu stellen ${ }^{55}$. Er gestattete lediglich im Juli 1446, daß zehn burgundische Adlige, darunter seine Bastardsöhne Cornille und Anton, dem Kölner die Fehde ansagten ${ }^{56}$. Mit der Rolle des Schiedsrichters zwischen zwei Reichsfürsten nahm der Herzog zudem eine Stellung ein, die nur dem König zukam ${ }^{57}$. Die wiederholten burgundischen Vermittlungsversuche stießen auf Seiten der Klever dann auch nicht immer auf vorbehaltlose Zustimmung.

52 Klaus SCHOLz, Das Spätmittelalter, in: Wilhelm KoHL (Hg.), Westfälische Geschichte, 1, Düsseldorf 1983, S. 408-435; Wilhelm JANSSEN, Kleve-Mark-Berg-Ravensberg, in: Land im Mittelpunkt der Mächte, S. 17-40.

$53 \mathrm{Zu}$ Einzelheiten und Vorgeschichte der Soester Fehde siehe JANSSEN, Erzbistum Köln, S. 266-269; Wilfried EHBRECHT, Emanzipation oder Territorialisierung? Die Soester Fehde als Ausdruck des Ringens um staatliche Ordnung des Nordwestens zwischen Reich, Burgund, Erzstift Köln und Hanse, in: F. B. FAHLBUSCH, P. JOHANEK (Hg.), Studia Luxemburgensia, Warendorf 1989, S. 404-432; Wolf-Herbert DEUS, Die Soester Fehde, Soest 1950, S. 11-64; Heinz-Dieter HeIMANN, Die Soester Fehde, in: DERS. (Hg.), Soest. Geschichte der Stadt, 2, Die Welt der Bürger, Soest 1996, S. 173-260. Zuletzt und zusammenfassend JANSSEN, Die niederrheinischen Territorien im Spätmittelalter, S. 110-113.

${ }^{54}$ DEUS, Soester Fehde, S. 78f.

${ }^{55}$ LACAZE, Philippe le Bon et l'Empire, 1, S. 165f; PETRI, Nordwestdeutschland, S. 87.

56 Außerdem Jean de Poitiers, Simon und Jacques de Lalaing, Heinrich van den Thorn, Anton de Rochebaron und Jean de Neufchâtel: HANSEN, Westfalen und Rheinland, 1, S. 95* u. Anm. 1. Von einem direkten Eingreifen der Genannten in die Soester Kämpfe ist nichts bekannt.

57 HANSEN, Westfalen und Rheinland, 1, S. 54*. Heinz-Dieter HEIMANN, Zwischen Böhmen und Burgund. Zum Ost-West-Verhältnis innerhalb des Territorialsystems des Deutschen Reiches im 15. Jahrhundert, Diss. Phil. Bochum 1982, S. 267. 
Im September und November 1446 fanden unter burgundischem Vorsitz Verhandlungen statt, die ohne Ergebnis blieben ${ }^{58}$. Erst eine Zusammenkunft, die vom 8. Januar bis zum 5. Februar 1447 in Moers stattfand, brachte den Entwurf eines Friedens, der allerdings nie ratifiziert wurde ${ }^{59}$. Noch einmal im Frühjahr und Frühsommer 1447 versuchte Philipp, gegen den ausdrücklichen Willen Herzog Adolfs, einen Ausgleich herbei zu führen. Dem Hilfegesuch Jungherzog Johanns, der sich noch am 22. April am burgundischen Hof aufhielt ${ }^{60}$, schien Philipp zunächst nicht nachkommen zu wollen. Am 16. Juni schrieb Dietrich von Mengersreuth aus Köln an Adolf, daß sich der Graf von Moers zwar wie gewohnt bereit finde, in Moers einem gütlichen Tag vorzusitzen, doch daß der Erzbischof bereits mit »veele vremts volcks« nach Westfalen gezogen sei und deswegen einen Tag wohl kaum beschicken werde. Der Erzbischof lehnte tatsächlich ab, und Mengersreuth zog unverrichteter Dinge über Kleve zurück an den burgundischen Hof $^{61}$.

Angesichts der unmittelbaren Bedrohung der eigenen Lande wandelte sich die abwartende und ausgleichende Haltung Herzog Philipps merklich. Verhandlungen mit den Sachsen über eine Einigung hinsichtlich der wettinischen Ansprüche auf das luxemburgische Erbe Elisabeths von Görlitz waren bereits seit geraumer Zeit im Gange62. Eine gegnerische Koalition um Köln, Trier und Karl VII. von Frankreich hatte sich seit 1444 formiert und kam im Februar 1445 unter sächsischer Beteiligung in Trier zusammen. Der sächsische Rat Heinrich Engelhard berichtete, daß Graf Gerhard von Blankenheim im Namen Karls VII. zugesagt habe, den Herzögen von Sachsen das Herzogtum Luxemburg mit Hilfe französischer Söldner innerhalb von drei Monaten zu erobern ${ }^{63}$. Herzog Adolf von Kleve erfuhr durch seinen Schwiegersohn Graf Ulrich von Württemberg um den 10. April 1445 jedoch, daß die »Armejacken« abgezo-

58 Johann von Kleve an die Stadt Soest, 18.9.1446 Wesel, HANSEN, Westfalen und Rheinland, 1, Nr. 239, S. 233; Stadt Soest an Johann von Kleve, 23.9.1446 Soest, HANSEN, Westfalen und Rheinland, 1, Nr. 241, S. 234f. Philipp entsandte Guillaume Fillastre, Bischof von Tournai, Antoine de Croÿ Graf von Porcien, Graf Johann von Nassau und Meister Goswin van der Rijdt Kanzler von Brabant; Rezess des Maaseycker Tages vom 6.10.1446, HANSEN, Westfalen und Rheinland, 1, Nr. 244, S. 240-242.

59 Rezess des Löwener Tages vom 8.1.1447, HANSEN, Westfalen und Rheinland, 1, Nr. 249, S. 245f. Klevische Instruktion für den Tag zu Moers, vor 5.2.1447, HANSEN, Westfalen und Rheinland, 1, Nr. 254, S. 248f; Vorläufiger Abschied des Tages von Moers, 5.2.1447, ebd., Nr. 255, S. 249-252.

${ }^{60}$ HANSEN, Westfalen und Rheinland, 1, Nr. 263, S. 264.

61 Herzog Philipp an den Grafen von Moers, 30.5.1447 Gent, HANSEN, Westfalen und Rheinland, 1, Nr. 271, S. 272; ebd., Nr. 278, S. 275; Mengersreuth an Herzog Adolf, 16.6.1447 Köln, ebd., Nr. 281, S. 280f; Herzog Adolf an Herzog Philipp, 29.6.1477 Kleve, ebd., Nr. 293, S. 288 f.

62 HeImanN, Zwischen Böhmen und Burgund, S. 65-72; VAughan, Philip, S. 274-285.

${ }^{63}$ Heinrich Engelhard an die Herzöge Friedrich und Wilhelm von Sachsen, 15.2.1445 Trier, HANSEN, Westfalen und Rheinland, 1, Nr. 136, S. 127-131; DEUS, Soester Fehde, S. 80; HANSEN, Westfalen und Rheinland, 1, S. 76-79*. 
gen seien. Herzog Wilhelm von Sachsen selbst, bereits 1446 von Kaiser Friedrich III. zum Reichshauptmann gegen Soest ernannt, konnte sich erst Anfang 1447 nach der Beendigung der Kämpfe gegen seinen Bruder Herzog Friedrich der Durchsetzung seiner Ansprüche auf Luxemburg zuwenden ${ }^{64}$.

Ende Mai 1447 einigte sich eine Gesandtschaft Erzbischof Dietrichs in Dresden mit sächsischen Vertretern auf die Modalitäten gegenseitiger Hilfe bei der Eroberung Soests, Kleves und Luxemburgs. Gleichzeitig wurde mit Frankreich über Hilfe für das Unternehmen verhandelt ${ }^{65}$. Von diesen Absichten wurde der Herzog von Kleve bereits um den 20. Mai informiert. Er wurde im Auftrag Herzog Wilhelms von Sachsen gebeten, Herzog Philipp zu einem Tag mit sächsischen Abgeordneten in Marburg zu bewegen. Sollte man sich in der luxemburger Frage einigen, könne Herzog Wilhelm im Gegenzug Jungherzog Johann Truppen gegen den Erzbischof zur Verfügung stellen ${ }^{66}$. Warum Johann diese Informationen nicht an Herzog Philipp weitergab, ist unklar. Lag es doch in seinem unmittelbaren Interesse, Philipp zu einem militärischen Eingreifen gegen das heranrückende Heer zu bewegen und eventuell sogar einen Ausgleich zwischen den Sachsen und dem Herzog zu vermitteln. Herzog Philipp wurde erst Ende Juni oder Anfang Juli durch Dietrich von Mengersreuth und Bernhard von Burscheid davon unterrichtet, daß eine große Anzahl Truppen auf Luxemburg marschierte, woraufhin Bastard Anton mit der Verteidigung des Landes beauftragt wurde ${ }^{67}$.

Das Bündnis des Kölner Erzbischofs mit den Sachsen brachte Adolf und Johann von Kleve im Juli 1447 die lang erwartete Versicherung burgundischer Hilfe durch den klevischen Gesandten am Genter Hof, Dietrich Nederhove ${ }^{68}$. Bemerkenswerterweise wurden die Hilfskontingente in einem Schreiben Philipps an Herzog Adolf vom selben Tag nicht erwähnt. Philipp bat seinen Schwager lediglich in einer Nachschrift, er und sein Sohn Johann möchten in

${ }^{64}$ Vgl. zur Geschichte der sächsischen Ansprüche auf Luxemburg LACAZE, Philipp le Bon et l'Empire, 1, S. 157-175; DEUS, Soester Fehde, S. 92-94; HEIMANN, Zwischen Böhmen und Burgund, S. 73-110.

65 HANSEN, Westfalen und Rheinland, 1, Nr. 267, S. 266-269, Nr. 279, S. 275-279; vgl. DEus, Soester Fehde, S. $117 \mathrm{f}$.

${ }^{66}$ Bericht des Schwarzburgischen Gesandten, um den 20.5.1447: HANSEN, Westfalen und Rheinland, 2, Nr. 5, S. 11-14. Siehe auch den Bericht vom 4.10.1448 zum Einverständnis Herzog Wilhelms, mit Herzog Johann über ein Bündnis zu verhandeln: HANSEN, Westfalen und Rheinland, 1 Nr. 375, S. 365f. Auch in der Folgezeit kamen die Verhandlungen zu keinem Ergebnis. Vgl. HEIMANN, Zwischen Böhmen und Burgund, S. 293f.

67 Dietrich Nederhove an Jungherzog Johann, 2.7.1447 Gent, HANSEN, Westfalen und Rheinland, 1, Nr. 301, S. 296f. Daß Herzog Philipp bereits am 16.6.1447, dem Datum des Schreibens Mengersreuths an Herzog Adolf, (HANSEN, Westfalen und Rheinland, 1, Nr. 281) von der Bedrohung erfuhr, wie HEIMANN, Zwischen Böhmen und Burgund, S. 269 meint, kann m. E. aus den Quellen nicht nachvollzogen werden.

68 Philipp an Dietrich Nederhove, 1.7.1447 Gent, HANSEN, Westfalen und Rheinland, 1, Nr. 300, S. 293-296. Dietrich Nederhove an Jungherzog Johann, 2.7.1447 Gent, ebd., Nr. 301 , S. $296 f$. 
Zukunft mehr Vertrauen in das burgundische Bündnis haben als bisher ${ }^{69}$. Schriftlich wollte sich der Herzog auch jetzt noch nicht festlegen, doch gab er zu verstehen, da $B$ ihm die klevische Unzufriedenheit über den mangelnden burgundischen Eifer bekannt war, und daß hierzu länger kein Grund bestehen sollte. Die Hilfszusage wurde Herzog Adolf zur selben Zeit nur mündlich durch den Propst von Xanten, Ferry de Beauvoir, gemacht ${ }^{70}$.

Die burgundischen Truppen kamen durch die kölnisch-sächsische Niederlage vor Soest nicht zum Einsatz, doch ist aus der Abrechnung über die aufgebotenen »hommes d'armes « ${ }^{71}$ ersichtlich, daß Philipp sehr viel daran gelegen war, das feindliche Heer bereits vor dem Erreichen der eigenen Lande aufzuhalten. Die Rechnung nennt insgesamt mehr als 2000 Gewappnete, wobei allerdings anzunehmen ist, daß die 550 in Luxemburg von Bastard Anton Gemusterten vor allem zur Verteidigung des Herzogtums gedacht waren ${ }^{72}$.

Die nie eingestellten burgundischen Bemühungen um eine gütliche Lösung des Konflikts, die durch die Belagerung Soests und das Beharren des Erzbischofs auf einer Vermittlung durch den Herzog von Geldern gelähmt worden waren, erhielten nach dem Abzug der Sachsen und Böhmen neuen Auftrieb. Man tagte schließlich vom 24. August bis zum 22. September unter dem Vorsitz Antoine Hanerons in Moers. Es wurde die Unterwerfung beider Parteien unter den Spruch Herzog Philipps beschlossen sowie ein Waffenstillstand bis zum 11. November, der dann mehrere Male bis zum 31. März 1448 verlängert wurde ${ }^{73}$. Da Erzbischof Dietrich, gestärkt durch die Aussöhnung mit der Kurie und dem Kaiser, jedes Einlenken verweigerte, konnte aber weiterhin keine Einigung erzielt werden, und die Kampfhandlungen wurden nach Ablauf des Waffenstillstandes wieder aufgenommen ${ }^{74}$.

Die Fronten der Soester Auseinandersetzung spiegelten sich in der Konfrontation zwischen dem Basler Konzil und Papst Eugen IV. Während Burgund und Kleve fest zur römischen Oboedienz standen, hatten sich Erzbischof Dietrich, Herzog Arnold von Geldern und der Erzbischof von Trier, Jakob von Sierck, zu Anhängern des Konzils erklärt. Eugen IV. befreite 1445 die Lande des Herzogs von Kleve von der kurkölnischen Jurisdiktion und enthob Erzbi-

69 Philipp an Adolf, 2.7.1447 Gent, HANSEN, Westfalen und Rheinland, 1, Nr. 302, S. 297f. Vater und Sohn von Kleve hatten ihre Enttäuschung in ihren wiederholten Bitten um Hilfe nicht verborgen. Herzog Adolf äußerte sich schon 1445 in diesem Sinne gegenüber der Stadt Soest, die offenbar die ausbleibenden burgundischen Hilfstruppen angemahnt hatte, Adolf an die Stadt Soest, 18.4.1445 Kleve, HANSEN, Westfalen und Rheinland, 1, Nr. 148, S. 141.

70 Adolf an Johann, 4.7.1447 Kleve, HANSEN, Westfalen und Rheinland, 1, Nr. 305, S. 299f; ders. an dens., 6.7.1447 Gent, ebd., Nr. 307, S. 301-303.

${ }^{7}$ HANSEN, Westfalen und Rheinland, 1, Nr. 321, S. 312f.

72 Dietrich Nederhove an Jungherzog Johann, 2.7.1447 Gent, HANSEN, Westfalen und Rheinland, 1, Nr. 301, S. 297.

${ }^{73}$ Kölnisches Protokoll der Verhandlungen: HANSEN, Westfalen und Rheinland, 1, Nr. 326, S. 318-324; Rezess des Moerser Tages, ebd., Nr. 332, S. 328f.

${ }^{74}$ DEUS, Soester Fehde, S. 130-133. 
schof Dietrich im Januar 1446 seines Amtes, so daß Adolf von Kleve sich Hoffnungen machte, mit burgundischer Hilfe die Provision seines jüngeren Sohnes Adolf auf den Kölner Erzstuhl durchsetzen zu können. Außerdem unternahm er Vorstöße an der Kurie, um die vollständige Exemtion des klevischen Territoriums aus der Kölner Kirchenprovinz zu erreichen und ein eigenes Landesbistum mit Sitz in Xanten zu errichten 75 .

Philipp aber, der vor allem an einer Beruhigung der Lage interessiert war, erkannte schon im Sommer 1446 Dietrich in einem Schreiben, in dem er ihn zur Rückkehr in den päpstlichen Gehorsam aufforderte, die volle erzbischöfliche Titulatur zu und gab damit die Ansprüche Adolfs von Kleve auf ${ }^{76}$. Das Vorgehen Philipps war deshalb bemerkenswert, weil er weder Herzog Adolf noch Johann von Kleve von diesen Entwicklungen informierte, obwohl sie angesichts der Kölner Kandidatur des Sohnes beziehungsweise Bruders unmittelbar davon betroffen waren ${ }^{77}$. Auch hinsichtlich der Rechtsposition im Kampf um Soest war es nicht gleichgültig, ob der feindliche Dietrich von Moers durch den Papst als Häretiker exkommuniziert und seines Amtes enthoben wurde oder als Erzbischof unangefochten seine Herrschaft ausübte. Adolf erfuhr erst durch ein Schreiben aus Rom von der Rehabilitierung des Kölners. In einem bewegten Brief von Mitte März $1447^{78}$ unterrichtete er seinen Sohn davon, der sich am burgundischen Hof befand, aber offenbar ebenfalls nichts von dieser Entwicklung wußte.

1448 schaltete sich die Kurie in den schwelenden Konflikt ein mit der Sendung der Kardinallegaten Nikolaus von Kues und Johann Carvajal, deren Vermittlung Herzog Johann von Kleve angesichts ihrer offenen Parteinahme für den Erzbischof zunächst ablehnte, dann aber auf burgundischen Druck hin annahm ${ }^{79}$. Ein Tag zu Maastricht im April 1449 brachte schließlich die vorläufige Lösung: Carvajal stellte in seinem Schiedsspruch die endgültige Ent-

75 Herzog Adolf von Kleve an die Stadt Soest, 18.4.1445 Kleve, HANSEN, Westfalen und Rheinland, 1, Nr. 148, S. 139-141; DEUS, Soester Fehde, S. 80. Adolf von Kleve-Ravenstein hatte die päpstliche Approbation erhalten, wie aus dem Schreiben Eugens IV. an den Generalprior der Augustinereremiten in der Provinz Trier und Köln vom 10.2.1446 hervorgeht. Eugen IV. befahl die Proklamation der Absetzung der Erzbischöfe Jakob und Dietrich und die Einsetzung Bischof Johanns von Cambrai und Adolfs von Kleve-Ravenstein in Trier und Köln: HANSEN, Westfalen und Rheinland, 1, Nr. 201, S. 194. Zu den Bemühungen um ein klevisches Landesbistum siehe JANSSEN, Erzbistum Köln, S. 268 u. H.-J. BRANDT, Klevisch-märkische Kirchenpolitik im Bündnis mit Burgund in der ersten Hälfte des 15. Jahrhunderts. Magister Dietrich Stock $(\dagger 1470)$ Rat der Herzöge von Kleve-Mark, Burgund-Brabant und Geldern, in: AHVN 178 (1976) S. 42-76. Schon nach Ausbruch des GroBen Schismas hatte Kleve durch den Anschluß an die Avignonesische Oboedienz versucht, aus der Kölner Kirchenprovinz auszubrechen, HövELMANN, Die Anfänge der Beziehungen, S. 236.

${ }^{76}$ HANSEN, Westfalen und Rheinland, 1, S. 97*.

77 Vgl. DEUS, Soester Fehde, S. 114.

${ }^{78}$ HANSEN, Westfalen und Rheinland, 1, Nr. 258, S. 255 f.

${ }^{79}$ HANSEN, Westfalen und Rheinland, 1, S. $129 \mathrm{f}^{*}$. 
scheidung dem Papst anheim, bis zu dessen Urteil der status quo gelten sollte. Da ein päpstlicher Spruch nie erging, verblieben Soest und Xanten bei Kleve. Somit war die organisatorische und finanzielle Schwächung des Kölner Erzstiftes neben dem gefestigten burgundisch-klevischen Bündnis die weittragendste Folge der Soester Fehde ${ }^{80}$.

\subsection{Die Münstersche Stiftsfehde und der Utrechter Nachfolgestreit}

Während die Soester Fehde nach dem vorläufigen Urteil des Kardinallegaten weiter schwelte, entwickelte sich ein neuer Konflikt zwischen Kleve-Burgund und Kurköln um die Nachfolge im Bistum Münster nach dem Tod Bischofs Heinrich von Moers $1450^{81}$. Erzbischof Dietrich betrieb die Wahl seines zweiten Bruders Walram von Moers, um Münster weiter dem Einfluß der Familie zu sichern. Walram wurde von der Mehrheit des Domkapitels gewählt und vom Papst konfirmiert. Auch Geldern, Bischof Rudolf von Utrecht und JülichBerg unterstützten die Kandidatur Walrams. Johann von Kleve dagegen konnte sich gegen das Domkapitel auf die Mehrheit der Münsterschen Stadtbevölkerung stützen. Am 11. Juni 1451 schloß er mit der Stadt einen Vertrag, der ihn zur Unterstützung der Gegenkandidatur Erichs von Hoya verpflichtete, dessen Bruder, Graf Johann von Hoya, in Münster über eine zahlreiche Anhängerschaft verfügte. Am 9. Juli 1451 erklärte Herzog Johann Walram von Moers die Fehde ${ }^{82}$. In Münster setzte man große Hoffnungen auf den Einfluß, den der Klever am burgundischen Hof zu ihren Gunsten nehmen würde, denn einer Intervention Philipps des Guten an der Kurie wurde, vor allem angesichts seiner Kreuzzugspläne, große Wirkung zugetraut ${ }^{83}$.

Tatsächlich sandte Philipp wenige Tage nach der Kapitelfeier des Ordens vom Goldenen Vlies in Mons am 2. Mai 1451, in deren Verlauf Herzog Johann als Ordensritter aufgenommen wurde, eine Gesandtschaft an die Kurie. Sie war unter anderem beauftragt, die burgundische Billigung der Kandidatur Erichs von Hoya darzulegen und um dessen Provision zu bitten und wurde mit Briefen des Herzogs an den Papst und verschiedene Kardinäle ausgestattet ${ }^{84}$.

${ }^{80}$ HANSEN, Westfalen und Rheinland, I, S. 132-135*; DEUS, Soester Fehde, S. 136-141. JANSSEN, Die niederrheinischen Territorien im Spätmittelalter, S. 113.

81 JANSSEN, Die niederrheinischen Territorien im Spätmittelalter, S. $113 f$.

82 HANSEN, Westfalen und Rheinland, 2, S. 39-43*.

83 Johann hatte Philipp wahrscheinlich schon im März 1451 auf der Rückreise von seiner Pilgerfahrt nach Jerusalem und Rom in der münsterschen Angelegenheit um Hilfe gebeten: klevische Räte an Herzog Johann, 28.10.1450 Kleve, HANSEN, Westfalen und Rheinland, 2, Nr. 46, S. 72-74; Herzogin Maria an Herzog Johann, 20.2.1451 Monterberg, ebd., Nr. 59, S. 84; HANSEN, Westfalen und Rheinland, 2, S. 41*.

84 (Nachgesandte) Instruktion Philipps an seine Gesandten in Sachen des Bistums Münster, 19.5.1451 Mons: HANSEN, Westfalen und Rheinland, 2, Nr. 83, S. $131 \mathrm{f}$. 
Im Juni und Juli 1451 erreichte Herzog Johann, daß eine weitere Instruktion an die burgundischen Gesandten nach Rom gesandt wurde. Ihr Inhalt orientierte sich an einem klevischen Memorial, das die Klagepunkte gegen die Familie Moers seit dem Abschluß des Friedens von Maastricht 1449 darlegte ${ }^{85}$.

Eine burgundische Gesandtschaft an die Kurie eigens in der Münsterschen Sache aber hat es nie gegeben, obwohl sie von Herzog Johann wiederholt erbeten wurde. Schon in der Denkschrift vom Mai 1451 hatten die klevischen Räte klar ausgesprochen, daß man das burgundische Prestige an der Kurie benötige: Herzog Philipp solle Vertreter zum dauerhaften Aufenthalt nach Rom entsenden, "want die man veele meer geacht ind ontsyen sijn solde" als ein klevischer Geistlicher ${ }^{86}$. Johann sah sich schließlich sogar veranlaßt, den burgundischen Rat und Propst Ferry de Beauvoir selbst zu bitten, eine Gesandtschaft an die Kurie im Namen Herzog Philipps zu übernehmen. Der Propst ging auf die Bitte Johanns nur sehr zögernd ein mit der Begründung, daß er die Mühen des Weges scheue und die Aufgabe gern an einen anderen abträte ${ }^{87}$. Das Verhalten des Propstes beleuchtet die Stellung Johanns am burgundischen Hof, dessen Wünschen man nur im dem Maß nachkam, wie sie den Vorstellungen Herzog Philipps entsprachen. Beauvoir stimmte dem Vorhaben erst auf die ausdrückliche Befürwortung durch den Burgunder hin zu, trat die Reise nach Rom aber trotzdem nie an ${ }^{88}$.

Mit dem Tod Bischof Rudolfs von Utrecht am 24. März 1455 entstand ein weiterer Konfliktherd, der zu einem direkten Aufeinanderprallen burgundischer und klevischer Interessen führte ${ }^{89}$. Philipp setzte gegen die einmütige Wahl Gisberts von Brederode durch das Domkapitel, die mit der Zustimmung Herzog Johanns erfolgt war, die päpstliche Provision seines Bastardsohnes David, Bischof von Therouanne, durch ${ }^{90}$. Wohl um Johann spüren zu lassen,

85 Instruktion an die Gesandten in Rom, Anfang Juli 1451, und Briefe Philipps an Papst und Kardinäle: HANSEN, Westfalen und Rheinland, 2, Nr. 98, S. 159-165, Nr. 99, S. 165-168, Nr. 100, S. 168-170. Vgl. auch die Instruktion an eine klevische Gesandtschaft an den burgundischen Hof, etwa Oktober 1451, ebd., Nr. 118, S. 192-197, worin die klevischen Standpunkte und Klagen gegen das Haus Moers zusammenfaßt werden.

${ }^{86}$ HANSEN, Westfalen und Rheinland, 2, Nr. 79, S. 127.

${ }^{87}$ Ferry de Beauvoir an Herzog Johann, 23.11.1451 Brüssel: HANSEN, Westfalen und Rheinland, 2, Nr. 121, S. 198. Ferry stellte offenbar sehr detaillierte Forderungen, da Herzog Johann ihn in einem Brief vom 5.1.1452 bat, sich neben dem münsterschen Priester mit 5 Pferden zufriedenzugeben und die Reisekosten in zwei Raten zu akzeptieren, die zweite zahlbar auf einen Wechsel in Rom: Herzog Johann an Beauvoir, 5.1.1452 Kleve, HANSEN, Westfalen und Rheinland, 2, Nr. 133, S. 208f.

88 Johann an die Stadt Münster, 3.12.1451 Kleve; Herzog Johann an Ferry de Beauvoir, 5.1.1452 Kleve: HANSEN, Westfalen und Rheinland, 2, Nr. 125, S. 201f; Nr. 133, S. 208f; vgl. auch S. 69-71*.

${ }^{89}$ Hilfsersuchen der Utrechter Geistlichkeit an Herzog Johann, 8.7.1454 Utrecht: HANSEN, Westfalen und Rheinland, 2, Nr. 265, S. 347f. Die Utrechter baten ausdrücklich auch um die Verwendung Johanns beim Grafen von Charolais: ebd., Nr. 325, S. 403.

${ }^{90}$ HANSEN, Westfalen und Rheinland, 2, S. 118*. 
daß eine eigenständige klevische Politik von burgundischer Seite keinesfalls geduldet würde, führte er dem Klever die Konsequenzen einer burgundischen Parteinahme zugunsten des Erzbischofs von Köln in den immer noch offenen Fragen um Soest, Xanten und Münster vor Augen:

Er teilte Johann im Februar 1456 mit, daß er der Bitte des Erzbischofs um einen gütlichen Tag in Köln nachgekommen sei, obwohl außer Frage steht, daß Philipp die Einwände Johanns gegen Köln als Hauptort seines Feindes kannte ${ }^{91}$. In einem weiteren Schreiben vom März provozierte er seinen Neffen mit der Titulierung Erzbischof Dietrichs als "tresreverend pere en dieu, mon trechier et tresamé cousin larcevesque de Couloingne«. Es sei ihm zudem daran gelegen, den Münsterschen Streit zur Ehre des Heiligen Stuhles zu beenden, wobei es die Pflicht Johanns sei, dazu beizutragen, »au moins pour autant que a vous peult toucher.« Sollte sich Johann weiterhin verweigern, sähe er sich gezwungen, den Bitten des Erzbischofs um Überweisung der Sache an den Papst nachzukommen ${ }^{92}$.

Sehr rasch gab Johann seinem großen Erstaunen über die Forderungen und Formulierungen des Onkels Ausdruck, trat aber gleichzeitig den Rückzug an. Er erklärte sich bereit, in jeder anderen Angelegenheit als der des Streits zwischen ihm und dem Erzbischof seine Gesandten nach Köln zu schicken. Im übrigen verwahrte er sich gegen falsche Darstellungen seiner Position und bat Philipp nachdrücklich, Verleumdungen gegen ihn keinen Glauben zu schenken. Schließlich kündigte er sein persönliches Erscheinen am burgundischen Hof im Mai an, wo er dann durch an Selbstverleugnung grenzende Loyalitätsbekundungen die Gunst des Onkels zurückgewinnen mußte ${ }^{93}$ : Er betätigte sich als Vermittler zwischen Utrecht, Gisbert von Brederode und David von Burgund. Durch seine Bemühungen konnte David im August 1456 im Bistum Utrecht friedlich die Herrschaft antreten. Schließlich beteiligte er sich sogar an der gewaltsamen Unterdrückung der overijsselschen Städte des Bistums gegen den neuen Bischof und wirkte anschließend auch hier vermittelnd ${ }^{94}$.

In dem Balanceakt zwischen der Pflege der Beziehungen zu seinem mächtigen Onkel und der Verfolgung eigener Interessen war Herzog Johann immer wieder auf das eigene diplomatische Talent angewiesen: Von Gent 1454 über Utrecht, Deventer, Lüttich ${ }^{95}$ bis hin zu den geldrischen Städten 1473 betätigte

91 Philipp an Johann, 4.1./7.2.1456 Den Haag: HANSEN, Westfalen und Rheinland, 2, Nr. 366, S. 434f.

92 Philipp an Johann, 14.3.1456 Den Haag: HANSEN, Westfalen und Rheinland, 2, Nr. 369, S. 437-439.

93 Johann an Philipp, 22.5.1456 Kleve: HANSEN, Westfalen und Rheinland, 2, Nr. 370 ,

S. 439-441.

94 HANSEN, Westfalen und Rheinland, 2, S. 122-124*.

95 Herzog Johann: Lille ADN B 2058 f.222r; Lille ADN B 2054 f.235r-236r; siehe auch ebd. f.160r, 165r, 167v, 170v, 172r. Adolf: Lille ADN B 2064 f.484v. 1467 war Herzog Johann nicht persönlich im burgundischen Heer anwesend, und bat Karl durch Johann von Sechtin- 
sich Johann als Vermittler zwischen dem Burgunderherzog und dessen Gegnern. 1454 faßten burgundische Räte anläßlich des Genter Aufstandes den Sachverhalt in einem Schreiben an Johann in die folgenden Worte: "On crye pardeca apres vous, affin que vous venu par votre bon moyen et aide le traicté de ceulx de Gand puisse estre fait « ${ }^{96}$. Als nominell souveräner Fürst mit den besten Beziehungen zum burgundischen Herzog genoß er das Vertrauen beider Seiten, vor allem aber das des Herzogs, der die Loyalität des Klevers selbstverständlich erwartete.

Das Verhältnis Kleve-Burgund war unter Philipp dem Guten ein nach höfischen Maßgaben fast familiäres, in politischer Hinsicht aber eines zwischen Herrn und Vasall. Kleve hatte Anteil am burgundischen Schutz und an Glanz und Prestige des Hofes, büßte aber im Gegenzug seine politische Selbständigkeit weitgehend ein. Karl trat 1465/67 im niederrheinischen Raum ein ausgesprochen günstiges politisches Erbe an. Seit Beginn der 1460er Jahre hatte er auch persönlich ein enges Verhältnis zu Johann gepflegt. 1460 folgte er einer Einladung des Herzogs nach Kleve. Vier Jahre später verband er sich mit Johann in einem Bündnis gegen jedermann ${ }^{97}$. Wie sein Vater erwartete er von Kleve bedingungslose Gefolgschaft, während er in Geldern die Konflikte im Haus Egmond mit einer Mischung aus legalistischem und gewaltsamem Vorgehen ausnutzte, die sein auf lange Sicht verhängnisvolles Bild eines handlungsunfähigen Reiches zu bestätigen schienen.

\subsection{Die Eroberung Gelderns}

a) Burgund, Kleve und Geldern bis 1471

Die Gefangennahme Arnolds von Geldern im Januar 1465 war der Höhepunkt der seit langem angestrengten und von Burgund unterstützten oder zumindest geduldeten Bemühungen, den alten Herzog durch seinen Sohn Adolf zu ersetzen. Bis 1469 enthielten sich Philipp und Karl der offenen Parteinahme, wobei aber die Duldung der Einkerkerung Arnolds praktisch der Zustimmung

gen im Dezember 1467 um Neuigkeiten aus dem Krieg gegen Lüttich, Karl an Johann, 6.12.1467 Huy, HStA Düsseldorf, Kleve-Mark, Beziehungen zu Geldern 31, Dijon ACO, Papiers Henri STEIN, Briefwechsel Nr. 791.

96 Jean Soillot an Herzog Johann, 28.5.1454 Brüssel: HANSEN, Westfalen und Rheinland, 2, Nr. 256, S. 338f.

97 Besuch: Philipp an Karl, vor 24.4.1460; Karl an Herzog Johann, 25.4.1460 Gorinchem, Düsseldorf HStA Kleve-Mark Beziehungen zu Geldern 29, Dijon ACO, Papiers Henri STEN, Briefwechsel Nr. 77 u. 78. Der Besuch wurde von Peter von Hagenbach vorbereitet. Nach BRAUER-GRAMM, Peter von Hagenbach, S. 15f, war Hagenbach 1453 Kammerherr Herzog Johanns und besaß aus dieser Zeit noch Verbindungen nach Kleve. Bündnis: GACHARD, Analectes Historiques, 12, in: BCRH $3^{e}$ sér. 8 (1866) S. 273; VAUGHAN, Philip, S. 377. 
gleichkam. Parallel dazu beteiligten sie sich an den Bemühungen Vinzenz' von Moers um einen Ausgleich zwischen Herzog Adolf und den Anhängern Arnolds unter der Führung des Herzogs von Kleve und Wilhelms von Egmond ${ }^{98}$. Seit dem Regierungsantritt Karls erhöhte sich der burgundische Druck auf Geldern und den gesamten Niederrhein dann stetig und wurde von 1473 bis 1475 schließlich zum hauptsächlichen Schauplatz der Auseinandersetzung Burgunds mit dem Reich 99 .

Johann von Kleve führte im Widerspruch zur burgundischen Position von 1466 bis 1468 erfolglos Krieg gegen Adolf von Geldern zur Befreiung des alten Herzogs ${ }^{100}$. Am 28. November 1465 teilte er den Ständen Gelderns mit, daß er zur Verteidigung der Rechte Adolfs entschlossen sei. Er konnte kaum ahnen, daß er in diesem Fall die Entwicklung der burgundischen Politik vorwegnahm, da noch nichts auf eine Entfremdung zwischen dem stets burgundfreundlichen Adolf und den Herzögen Philipp und Karl hindeutete. Johann wandte sich vielmehr bewußt gegen eine Entwicklung, die auf eine burgundische Beherrschung Gelderns unter der nominellen Regentschaft Adolfs hinzuführen schien ${ }^{101}$. Langfristig mußte er um die territoriale Selbständigkeit seiner eigenen Lande fürchten und suchte deshalb die Integrität Gelderns durch die Unterstützung Arnolds aufrechtzuerhalten. Die Wandlung Adolfs zum Führer der "nationalen«, anti-burgundischen Partei Gelderns verkehrte die Vorzeichen. Arnold wurde zum Schützling Burgunds und überschrieb sein Land Herzog Karl. Diese Entwicklung war von Johann weder abzusehen noch gewünscht. In der Hoffnung, eine burgundische Intervention doch noch überflüssig zu machen, gewährte er Arnold bis in das Jahr 1473 hinein, auch gegen den Willen Herzog Karls, militärische Hilfe.

Im Juli und August 1465 ließ Herzog Philipp durch Antoine Haneron den ersten Vermittlungsversuch zwischen der klevisch-egmondischen Partei und den Anhängern Adolfs unternehmen ${ }^{102}$. Haneron befand sich vom 20. August bis zum 20. September 1465 und vom 25. Oktober bis zum 25. November bei den Herzögen in Kleve und Geldern ${ }^{103}$. Zwischen den Reisen Hanerons sandte Philipp zudem noch seinen Sekretär Jean Stoop, Greffier des Rates von Bra-

98 PARAVICINI, Moers, Croy, Burgund, S. 35f.

99 JANSSEN, Die niederrheinischen Territorien im Spätmittelalter, S. 119.

$100 \mathrm{Zu}$ den verschiedenen Bündnissen im Vorfeld und während des Krieges zwischen Kleve und Adolf von Geldem siehe LACOMBLET, Rheinisches Urkundenbuch, 4, 1, Nr. 330-335 S. 409-418.

101 W. JAPPE ALBERTS, De Staten van Gelre en Zutphen, 2, Groningen 1950-1956, S. 48f. 102 Vom 16.-28.7.1465 wurden drei Boten mit Briefen Philipps an die Herzöge von Kleve und Geldern abgefertigt: Lille ADN B 2054 f.161r-v (16.7.1465); ebd., f.163v (26.7.1465); ebd., f.163v-164r (28.7.1465).

103 Lille ADN B 2054 f.144r-v. Außerdem reiste er nach Köln und Deventer, um Angelegenheiten des Erzbischofs und der Bistumsnachfolge in Münster zu regeln. 
bant, zu Herzog Johann nach Kleve ${ }^{104}$. Nach der erfolglosen Mission Hanerons wurde zu Beginn des Jahres 1466 die Reise des Josse de Halewin, Herrn von Perwez und Bailli von Flandern, nach Kleve und Geldern vorbereitet. Halewin wurde am 10. Februar 1466 zu Philipp nach Brüssel gerufen, reiste Ende Februar 1466 von dort ab und kehrte am 29. März zurück. Begleitet wurde er von Jean Stoop ${ }^{105}$. Im April bat Herzog Philipp die streitenden Parteien, seinen Vergleichsvorschlag anzunehmen, der wahrscheinlich von Halewin und Stoop bereits vorgelegt und während der Verhandlungen modifiziert worden war 106 .

Für den Juni 1466 kann die erste direkte Beteiligung des Grafen von Charolais an den Verhandlungen nachgewiesen werden. Vergleichbar den Gesprächen mit dem Pfalzgrafen und Herzog Ludwig von Bayern, die von Abgesandten des Herzogs und Karls parallel und ergänzend geführt wurden, wurden hier Simon de Lalaing, Josse de Halewin und Jean Stoop von Philipp, Jan van Montfort von Karl mit der Vermittlung beauftragt. Die Gesandten kehrten am 13. Juli 1466 an den Hof zurück ${ }^{107}$. Es handelte sich um eine personell relativ aufwendige Delegation, die darauf hindeutet, daß Philipp und Karl zu dieser Zeit tatsächlich an einer Verhandlungslösung des geldrischen Konflikts interessiert waren und sie auch für möglich hielten.

Karl engagierte sich in den folgenden Monaten zunehmend in der Vermittlung, parallel zu den Bemühungen des Grafen Vinzenz von Moers' ${ }^{108}$. Gemeinsam mit seinem Vater sandte er Simon de Lalaing und Antoine de Montjeu zu Johann und Adolf, die aber ebensowenig wie die Vertreter der vier rheinischen Kurfürsten ${ }^{109}$ eine Lösung herbeiführen konnten. Die kurfürstlichen Gesandten erreichten am 15. September 1466 einen Waffenstillstand, der bis zum 2. Februar 1467 verlängert wurde ${ }^{110}$. Im November und Dezember ließen Phil-

${ }^{104}$ Lille ADN B $2058 \mathrm{f} .111 \mathrm{r}, 112 \mathrm{r}$.

${ }^{105}$ Lille ADN B 2058 f.123v; ebd. f.126r (Brief an Halewin vom 10.2.1466); Lille ADN B $2061 \mathrm{f} .121 \mathrm{r}$ und ebd. f.132v (Zahlungsmandate für Halewin und Stoop).

106 Lille ADN B 2058 f.133r.

${ }^{107}$ Lille ADN B $2061 \mathrm{f} .119 \mathrm{r}$ (Zahlungsmandat für Lalaing); Lille ADN B $2058 \mathrm{f} .141 \mathrm{v}-142 \mathrm{r}$ (Montfort); Lille ADN B 2061 f.91r-v (Halewin und Stoop).

108 GRÜNEISEN, Reichsstände, S. 49. Obwohl Graf Vinzenz als Vermittler an den Kämpfen nicht beteiligt war, wurde seinen Besitzungen von Maastricht aus durch die burgundischen Truppen unter Adolf von Kleve-Ravenstein und Bastard Anton immer wieder Schaden zugefügt, was die Verhandlungen stark beeinträchtigte: Graf Vinzenz, der Propst von Kleve und Ritter Johann van den Loe an Herzog Johann, 6.12.1467 Diedem: H. KEUSSEN (Hg.), Urkundenbuch der Stadt und Herrlichkeit Krefeld und der Grafschaft Mörs, 2, Krefeld 1939, Nr. 3386 u. Nr. 3387, S. 270.

109 JAPPE ALBERTS, De Staten van Gelre en Zutphen, 2, S. 54f. nimmt an, daß die Initiative der Kurfürsten, die unter der Leitung Erzbischof Ruprechts von Köln stand, nicht gegen Burgund gerichtet war. Doch ist angesichts der kurkölnisch-klevischen Feindschaft und der Ambitionen Pfalzgraf Friedrichs, der sicherlich hinter dem Vorstoß seines Bruders stand, nicht auszuschließen, daß der burgundisch-klevische Einfluß zumindest zurückgedrängt werden sollte.

110 GRÜNEISEN, Reichsstände, S. 49. 
ipp und Karl durch Antoine de Montjeu und Johann von Luxemburg einige nicht näher bekannte Bitten an Herzog Johann vortragen, bei deren Erfullung Karl sein persönliches Engagement in der Vermittlung in Aussicht stellte, da ihm sehr an einem ehrenvollen Ausgang der Angelegenheit gelegen sei ${ }^{111}$.

$\mathrm{Zu}$ Beginn des folgenden Jahres zeigte der Vorsto $B$ Karls erste Erfolge: Im Februar erklärten sich Herzog Johann und Wilhelm von Egmond nach nochmaligem Briefwechsel bereit, sich dem Schiedsspruch des Grafen von Charolais bezüglich der Gefangenschaft und der Modalitäten der Freilassung Herzog Amolds zu unterwerfen ${ }^{112}$. Auch Adolf von Geldern erkannte Karl als Schiedsrichter an, doch verzögerte sich die Schlichtung mehrmals. Karl hatte zunächst einen Tag für den 12. April 1467 angesetzt, der aber durch das Fernbleiben Adolfs nicht zustande kam und deshalb auf den 15. Juni verschoben wurde ${ }^{113}$. Aber auch dieser Termin brachte keine Ergebnisse, da zwar der Herzog von Kleve Johann von Sechtingen zu Karl sandte ${ }^{114}$, der auch von Herzog Arnold von Geldern bevollmächtigt war, aber ein Vertreter Adolfs von Geldern ausblieb ${ }^{115}$. Adolf verpflichtete sich eben in dieser Zeit dem Erzbischof von Köln in einer Allianz gegen Kleve und brüskierte damit den Herzog von

111 Karl an Johann, 23.11.1466 Brügge, HStA Düsseldorf, Kleve-Mark, Beziehungen zu Geldern 76b, Dijon ACO, Papiers Henri STEN, Briefwechsel Nr. 467. Karl an Johann, 15.12.1466 Gronichem, HStA Düsseldorf, Kleve-Mark, Beziehungen zu Geldern 3, II, Dijon ACO, Papiers Henri STEIN, Briefwechsel Nr. 471. Im Dezember 1466 wurden Montjeu $60 \mathrm{lb}$ für seine Reise zu den Herzögen von Kleve und Geldern angewiesen, Lille ADN B 2061 f. $123 \mathrm{v}$.

112 Johann von Kleve und Wilhelm von Egmond an Karl, o.O. 5.2.1467, LACOMBLET, Rheinisches Urkundenbuch, 4, 1, Nr. 333, S. 414f. (nicht in Briefwechsel). Zwischen dem 1.1.1467 und dem 16.2.1467 verkehrte ein reitender Bote zweimal zwischen Gorinchem und Kleve, Lille ADN B 2064 f.60r. Karl übernahm die Rolle des Schiedsrichters also nicht erst Mitte 1469, wie PARAVICINI, Moers, Croy, Burgund, S. 35 annimmt, sondern bereits zu Beginn des Jahres 1467. Schließlich ist vor diesem Hintergrund die Vermutung JAPPE ALBERTS, Geschiedenis, S. 115, zweifelhaft, daß Karl Adolf in einem Doppelspiel nominell unterstützt habe, den Herzog von Kleve aber für Arnold eintreten ließ, um die Parteien im Gleichgewicht zu halten, bis sich die Möglichkeit zum Eingreifen ergab.

${ }^{113}$ Karl an Johann, 24.4.1467 Brügge, HStA Düsseldorf, Kleve-Mark, Beziehungen zu Geldern 34, 19, Dijon ACO, Papiers Henri STEIN, Briefwechsel Nr. 504.

114 Johann von Sechtingen, Scholaster von Kranenburg, ist zuerst 1460 als Gesandter des Herzogs von Kleve am burgundischen Hof belegt. Er entwickelte sich in den folgenden Jahren zu einem Spezialisten in den klevisch-burgundischen Beziehungen. Herzog Johann an Herzog Philipp, 27.7.1460 Kleve: HANSEN, Westfalen und Rheinland, 2, Nr. 450, S. 527.

115 B. VollmER, Die Belagerung Arnheims und seine Verpfändung an Kleve (1467-1483), in: Gelre 27 (1924) S. 129-156, hier S. 131; Arnold von Geldern an Karl, 10.6.1467 Breda, HStA Düsseldorf, Kleve-Mark, Beziehungen zu Geldern 80, Dijon ACO, Papiers Henri STEIN. Briefwechsel Nr. 513. Am selben Tag schrieb auch Peter von Hagenbach von Breda aus an Karl. Der Text des Briefes ist verloren, doch scheint Hagenbach im Auftrag Karls im geldrischen Streit verhandelt zu haben, Hagenbach an Karl, 10.6.1467 Breda, Briefwechsel Nr. 512. 
Burgund. Da sich Johann seinerseits mit der Stadt Köln verband, lebten die alten niederrheinischen Gegensätze wieder auf ${ }^{116}$.

Trotz dieser Mißstimmung und des Todes Herzog Philipps wurde die Korrespondenz zwischen Karl und Adolf im Juni und Juli 1467 fortgesetzt ${ }^{117}$. Im August bat Karl, nun in seiner Eigenschaft als Herzog von Brabant, daß Johann die brabantischen Lehen des Herzogs von Geldern schonen möge ${ }^{118}$. Im September 1467 versuchte Karl, wenigstens einen Waffenstillstand zwischen den verfeindeten Parteien herbeizufuihren, da er sich von Herzog Johann und den geldrischen Herzögen militärische Hilfe gegen die aufständischen Lütticher versprach. Am 22. September 1467 beglaubigte Karl Jean d'Enghien bei Johann und Adolf zur Aushandlung einer Waffenruhe, die bis Ostern des kommenden Jahres, aber mindestens 3 Monate dauern sollte. Bei diesem Auftrag, von dem d'Enghien am 9. Oktober 1467 zurückkehrte, wurde er von dem Sekretär François de la Kethulle begleitet ${ }^{119}$. Karl ließ versprechen, für eine Lösung des geldrischen Konfliktes zu sorgen, während Johann und Adolf ihm Truppen zum Kampf gegen Lüttich stellten ${ }^{120}$. Doch die Parteien ließen sich nicht zu einem Waffenstillstand bewegen, und auch die Truppen gegen Lüttich trafen nie ein. Der Scholaster von Kranenburg wird diese Nachricht Karl Ende September im Auftrag Johanns überbracht haben ${ }^{121}$, und Karl sollte sich im Mai des kommenden Jahres in Brügge anläßlich der Kapitelsitzung des Ordens vom Goldenen Vlies wieder an die ausgebliebene militärische Hilfe erinnern.

Im Lauf dieser Sitzung wurde Adolf wegen der Gefangenhaltung seines Vaters und des Krieges gegen den Ordensbruder Herzog Johann angeklagt. Aber

116 LACOMBLET, Rheinisches Urkundenbuch, 4, 1, Nr. 334, S. $415-418$ und Nr. 335, S. 418f.; GRÜNEISEN, Reichsstände, S. 50; JAPPE ALBERTS, De Staten von Gelre en Zutphen, 2, S. 62 .

117 Adolf an Karl, 10.6.1467 Breda, HStA Düsseldorf, Kleve-Mark, Beziehungen zu Geldern 80, Dijon ACO, Papiers Henri STEIN. Briefwechsel Nr. 513; Am 6.6.1467 ging ein reitender Bote mit Briefen Karls an Adolf nach Geldern und kehrte am 21.6.1467 mit der Antwort Adolfs zu Karl nach Brügge zurück. Er brach am 10.7.1467 wieder mit einem Schreiben Karls zu Adolf nach Deventer auf und kehrte am 20.7.1467 zurück, Brüssel AGR CC 2422, nach GRÜNEISEN RTA Material (nicht in Briefwechsel).

$118 \mathrm{Karl}$ an Johann, 13.8.1467 Brüssel, HStA Düsseldorf, Kleve-Mark, Beziehungen zu Geldern 34. Dijon ACO, Papiers Henri STEIN, Briefwechsel Nr. 664. Bei dem von GRÜNEISEN, Reichsstände, S. 50 Anm. 131 erwähnten Briefwechsel handelt es sich hauptsächlich um die Korrespondenz zwischen Herzog Johann und Karl, und nicht Herzog Philipp, der kurz vor seinem Tod offenbar kaum noch an diesen Angelegenheiten Anteil nahm.

119 Karl an Johann, 22.9.1467 Brüssel, HStA Düsseldorf, Kleve-Mark, Beziehungen zu Geldern 3, Dijon ACO, Papiers Henri STEIN, Briefwechsel Nr. 715. Datum der Reise und Begleitung durch de la Kethulle: Lille ADN B 2064 f.287v und 334r.

${ }_{120}$ Karl an Johann, 30.9.1467 Brüssel, HStA Düsseldorf, Kleve-Mark, Beziehungen zu Geldern 31, Dijon ACO, Papiers Henri STEn, Briefwechsel Nr. 724. Lohn für den reitenden Boten, der Schreiben an Herzog Johann, an Herzog Adolf, den Herrn von Kulemburg, Wilhelm von Egmond und d'Enghien überbrachte, Lille ADN B 2064 f.292r.

121 HUB, 9, Nr. 405, S. 265. 
auch Johann wurden die Besetzung von Soest, der Krieg gegen Adolf von Geldern, die Verweigerung militärischer Hilfe für den Grafen von Charolais gegen Lüttich 1467 und die Niederbrennung eines Dorfes in Brabant, das seinem Bruder Adolf von Kleve-Ravenstein gehörte, vorgeworfen. Die Angeklagten sollten vor Karl als ihrem Ordenssouverän oder vor dem nächsten Ordenskapitel erscheinen, um sich zu verantworten. Der Beschluß wurde ihnen von dem greffier des Ordens Martin Steenbergh und von Simon de Lalaing überbracht ${ }^{122}$. Doch weder das Ordenskapitel noch die Vermittlung Graf Vinzenz von Moers konnten den Krieg zwischen Johann und Adolf verhindern. Er endete erst nach dem Sieg Adolfs im Juni in der Schlacht bei Straelen mit einem Frieden, den Graf Vinzenz am 9. Dezember zum Abschluß brachte'23. Von einer burgundischen Beteiligung an diesen Friedensgesprächen ist nichts überliefert, was zu der Vermutung Anlaß gegeben hat, hier habe sich Adolfs endgültige Abkehr von Burgund angekündigt, da der Graf von Moers später zum Führer der burgundfeindlichen Partei Gelderns wurde ${ }^{124}$. Wahrscheinlicher ist, daß Adolf sich bereits seit längerer Zeit von Burgund zu lösen suchte und deswegen die Vermittlung des Grafen Vinzenz vorzog. Der Graf wurde als treuer Anhänger Herzog Adolfs in die erklärte Feindschaft zu Burgund erst durch das Schicksal seines Herrn hineingetrieben ${ }^{125}$.

Karl nahm seit Mitte 1469 die Schiedsrichterrolle zwischen Kleve und Geldern wieder auf und fällte am 11. Juli 1469 in Gent in Anwesenheit Johanns von Kleve, Adolfs von Geldern und des Grafen von Moers seinen Schiedsspruch, in dem er sich alle weiteren Entscheidungen über die Ausführung des Sühnevertrags vom 9. Dezember 1468 vorbehielt und eine Waffenruhe anordnete. Er setzte sich somit gleichsam zum dauernden Schiedsrichter ein und begründete dies mit seinen engen Bindungen $\mathrm{zu}$ beiden verfeindeten Häusern, dem Interesse seiner eigenen Lande an friedlichen Verhältnissen in den Nachbarterritorien und seiner Autorität als Ordenssouverän ${ }^{126}$. Adolf huldigte am 8. Juli Karl für die vom Herzogtum Brabant zu Lehen gehenden geldrischen Besitzungen ${ }^{127}$. Der Burgunder aber wandte sich nur wenig später offen den Gegnern des Jungherzogs zu, was allgemein sichtbar durch das Anschlagen

122 Vaughan, Charles, S. 114f. nach Wien, Archiv des Ordens vom Goldenen Vlies, Reg 2, f.43v-44r, 45v-47r; vgl Lille ADN B 2068 f.369v. Sendung Steenberghs und Lalaings, Brüssel AGR CC 1923 f.89r-v.

123 PARAVICINI, Moers, Croy, Burgund, S. 35.

124 JAPPE ALBERTS, De Staten van Gelre en Zutphen, 2, S. 63.

125 PARAVICINI, Moers, Croy, Burgund, S. 34f.

126 LACOMBLET, Rheinisches Urkundenbuch, 4, 1, Nr. 350, S. 440-442. Die Herzöge von Kleve und Geldern waren im Juni und Juli 1469 fast ununterbrochen am burgundischen Hof anwesend, Johann von Kleve bis in den August: GODEFROY, Itinerar, Juni, Juli und August 1469.

127 I. A. NiJHOFF, Gedenkwaardigheden uit de geschiedenis van Gelderland, 4, Arnheim 1847 , Nr. 479, S. $428 f$. 
des burgundischen Wappens am Hof Wilhelms von Egmond, dem Bruder Herzog Arnolds und Verbündeten Johanns von Kleve in Arnheim demonstriert wurde ${ }^{128}$. Damit war der erste Schritt zur direkten Beeinflussung der geldrischen Verhältnisse von innen heraus getan ${ }^{129}$. Ein knappes Jahr später befahl Karl Herzog Adolf, Wilhelm von Egmond die konfiszierten Güter und Renten zurückzuerstatten; ein bemerkenswerter Vorgang angesichts der Tatsache, da $B$ es sich bei Adolf um einen, wenn auch gebannten und geächteten, Reichsfürsten handelte, der sich reichsrechtlich allein vor dem Kaiser $\mathrm{zu}$ verantworten hatte ${ }^{130}$.

Mitte Oktober 1470 verflocht sich die geldrische Affaire mit den politischen Entwicklungen in England und Frankreich. Karl fürchtete angesichts der Vertreibung Eduards IV. einen Angriff der Engländer unter dem mit den Franzosen verbündeten Grafen von Warwick. Er bat daher Herzog Johann um vorsorgliche Rüstungen, weil die Haltung Adolfs von Geldern in einer solchen Auseinandersetzung ungewiß sei ${ }^{131}$. Auch unter diesem Gesichtspunkt wird Karl den Aufenthalt Adolfs an seinem Hof und unter seiner Kontrolle begrüßt haben. Eine Legitimation zu weiterem Eingreifen erhielt Karl im September durch Paul II., der ihn aufforderte, Adolf zur Freilassung seines Vaters zu bewegen ${ }^{132}$. Adolf seinerseits versuchte unterdessen, zur Festigung seiner Position von Friedrich III. mit Geldern belehnt zu werden. Der vorsichtige Kaiser beauftragte aber zunächst den Erzbischof von Trier mit einer Überprüfung der Verhältnisse und antwortete Adolf ausweichend ${ }^{133}$.

Am 26. Oktober sandte Karl Jean Carondelet zu Herzog Johann ${ }^{134}$. Diese Gesandtschaft bezog sich wahrscheinlich auf die Beschwerden Johanns, Ar-

128 PaRAviCINI, Moers, Croÿ und Burgund, S. 35f. m. Anm. 151.

129 VAUGHAN, Charles, S. 115 möchte in diesem Stadium noch nicht von einem festen Plan zur Annektierung des Landes sprechen. Dagegen JAPPE ALBERTS, De Staten von Gelre en Zutphen, 2, S. 69, der Karls Absichten allein in der Expansion sieht und seine Hinwendung zur egmondschen Partei mit deren Schwäche und Lenkbarkeit begründet.

$130 \mathrm{Karl}$ an Adolf, 8.9.1470 Hesdin, HStA Düsseldorf, Kleve-Mark, Beziehungen zu Geldern 76c, Dijon ACO, Papiers Henri STEIN; STEIN, Catalogue des Actes, Nr. 908.

131 Karl an Johann, nach dem 12.10.1470, HStA Düsseldorf, Kleve-Mark, Beziehungen zu Geldern 34, Dijon ACO, Papiers Henri STEIN, Briefwechsel Nr. 1551.

132 Paul II. an Karl, 12.9.1470 Rom, Regest in: NiJHOFF, Gedenkwaardigheden, 4, Nr. 496, S. 438. Bereits am 9.9.1470 hatte sich der Papst an Adolf selbst gewandt und ihn zu angemessener Behandlung seines Vaters aufgefordert, ebd. Nr. 495, S. 437.

133 Vollmacht vom 29.9.1470: NiJHOFF, Gedenkwaardigheden, 4, Nr. 499, S. 438f. Auftrag Friedrichs III. an den Erzbischof, 15.12.1470 Graz, Regest: NIJHOFF, Gedenkwaardigheden, 4, Nr. 500, S. 440; Antwort an Adolf vom selben Tag, ebd., Nr. 501, S. 440.

134 Beglaubigung, 26.10.1470 Hesdin, HStA Düsseldorf, Kleve-Mark, Beziehungen zu Geldern 34, Dijon ACO, Papiers Henri STEIN, Briefwechsel Nr. 1565. Zu Carondelet siehe JeanMarie CAUCHIES, La professionalisation dans les cours de justice princières des Pays-Bas aux XIV et $X^{e} V^{e}$ siècles, in: Heinz MOHNHAUPT, Dieter SIMON (Hg.), Vorträge zur Justizforschung. Geschichte und Theorie, 1, Frankfurt a. M. 1992, S. 19-44, hier S. 35 m. Anm. 68 . 
nolds und Wilhelms von Egmond, die Adolf den Bruch der von Karl im Juli verkündeten Bestimmungen vorwarfen ${ }^{135}$. Man könnte fast Absprachen zwischen Karl und den Klägern vermuten, so gelegen mußte dem Burgunder der damit gelieferte Anlaß zum erneuten Eingreifen in Geldern kommen. Adolf erreichte am 21. Oktober mit 60 Pferden den Hof Karls in Hesdin, wohin ihn ein Herold für den 26. Oktober bestellt hatte. Dort wurden ihm unter anderem der Herzog von Somerset und der Graf von Romont zum Empfang entgegengesandt. Trotz der Zusage Karls, ihn wie einen Bruder behandeln zu wollen, wurde er offenbar bereits kurze Zeit später an der Abreise gehindert. »He en konde geen orleff krigen«, wie sich lapidar ein Sekretär des am Hofe anwesenden Jungherzogs Wilhelm von Jülich ausdrückte. Nach einiger Zeit ließ Adolf den Großteil seiner Begleitung zurückreiten und behielt nur wenige Vertraute um sich ${ }^{136}$.

Der Verlauf der Verhandlungen zu Hesdin ist aus der Perspektive Karls seinen Briefen an die geldrischen Hauptstädte zu entnehmen. Klevische Gesandte hätten ihn gebeten, für die Freilassung Arnolds zu sorgen, da dieser ein brabantischer Vasall und damit Lehnsmann Burgunds sei. Am 4. Dezember teilte Karl Herzog Johann mit, daß Adolf auf seine, Karls, Vorhaltungen hin sich mit der Überführung seines Vaters nach Hesdin einverstanden erklärt habe. Der Herr von Perwez werde Arnold ehrenvoll an den Hof geleiten. Nach Angaben der Chroniken wurde der alte Herzog am 24. Dezember befreit ${ }^{137}$. Dem Bericht Karls zufolge scheiterten die anschließenden Vermittlungsbemühungen im Januar 1471 an der Unnachgiebigkeit des Sohnes,

135 GRÜNEISEN, Reichsstände, S. 52.

${ }^{136}$ Nach einem 1477 verfaßten Bericht aus dem RA Arnheim, Archief van Hertog Karel vl. nr. 8, nach GRÜNEISEN RTA-Material; SCHILFGAARDE, Archiv Huis Bergh, Inv. Nr. 209. Zum Datum auch VAN BERCHEM, Historia Captivitatis, §2 S. 229. Arnheim schrieb am 9.12.1470 an Wageningen, daß der Herzog von Kleve Herzogin Katharina von Geldern mitgeteilt habe, daß Adolf in Hesdin festgehalten werde: JAPPE ALBERTS, De Staten van Gelre en Zutphen, 2, S. 69.

${ }^{137}$ Karl an Johann, 4.12.1470 Hesdin, HStA Düsseldorf, Kleve-Mark, Beziehungen zu Geldern 34, Dijon ACO, Papiers Henri STEIN; Briefwechsel Nr. 1592. Am 6.12.1467 bat Karl Johann außerdem, Josse de Halewin, Herm von Perwez in seinem Auftrag in jeder Weise zu unterstützen, HStA Düsseldorf, Kleve-Mark, Beziehungen zu Geldern 34, Dijon ACO, Papiers Henri STEIN; Briefwechsel Nr. 1597. Adolf von Geldern hielt sich also spätestens seit dem 4.12.1470 am Hof Karls auf und nicht erst seit dem 25.12.1470, wie PARAVICINI, Moers, Croy, Burgund, S. 36 Anm. 154 mit VANDER LINDEN, Itinéraires de Charles, S. 27f,, annimmt. Andererseits kann nach dem Brief vom 4.12.1470 das Zusammentreffen von Adolf und Arnold nicht schon im November stattgefunden haben, wie GRÜNEISEN, Reichsstände, S. 52, glaubt, sondern erst nach der Ankunft Arnolds im Januar 1471. Vgl. VAUGHAN, Charles, S. 115 f. Zum Datum der Befreiung VAN BERCHEM, Historia Captivitatis, §3 S. 229; Theodoricus Paulus, De Rebus Actis, in: KERVYYN DE LETTENHOVE (Hg.), Chroniques relatives à l'histoire de la Belgique sous la domination des ducs de Bourgogne, 3, Brüssel 1876, Kap. 31, S. 295. 
der den Vorschlag ausschlug, Arnold auf Lebenszeit den Herzogstitel und die Nutzung von Grave mit einer ausreichenden Pension zu belassen ${ }^{138}$.

Am 9. Februar 1471 berichtete Karl an Johann aus Arras von der soeben entdeckten Flucht Adolfs. Noch war die Festsetzung Adolfs in Namur am 10. Februar nicht erfolgt, und aus dem Schreiben Karls spricht die große Besorgnis, Adolf könne - mit französischer Hilfe - einen Krieg gegen Burgund und seine Verbündeten beginnen. Er bat Johann daher darum, sowohl sein eigenes Land zu rüsten als auch die Bischöfe von Utrecht und Münster zu warnen. Er, Karl, wolle Herzog Arnold nach Geldern schicken, um dort Maßnahmen gegen einen möglichen Angriff des Sohnes zu ergreifen. Am 13. Februar wird die Nachricht von der Verhaftung Adolfs bei Karl eingetroffen sein, denn noch an diesem Tag wurde der Befehl an den Rat von Holland in Den Haag verfaßt, dem Herzog von Kleve gegen Adolf im Falle von Feindseligkeiten Hilfe zu leisten, dann aber nicht mehr abgesandt ${ }^{139}$. Karl betrachtete Adolf von Geldern also als ernstzunehmende Gefahr für die territoriale Ordnung an seinen östlichen Grenzen und handelte aus diesem Blickwinkel folgerichtig, als er ihn anschließend gefangensetzen ließ. Entscheidend war in den Augen des Burgunders, daß Adolf bereits vor seiner Flucht Kontakt mit Ludwig XI. aufgenommen hatte, der Mitte Februar eine Gesandtschaft an Adolf abfertigte, die zur Flucht gratulieren, die Gefangennahme Adolfs durch Karl auf das Schärfste verurteilen und ein Bündnisangebot machen sollte. Erst auf den 26. Februar 1471 ist der Bericht eines der Gesandten Ludwigs, Johann von Nyvenheim datiert, der die Falschmeldung von der gelungenen Flucht Adolfs korrigierte ${ }^{140}$. Auch wenn nicht klar ist, ob die Instruktion in Karls Hände fiel, muß er von der Existenz der Gesandtschaft erfahren haben. Dies genügte, den

138 Regesten in NujHOFF, Gedenkwaardigheden, 4, Nr. 502 u. Nr. 503, S. 440f., Nr. 505 , S. 441-446. Vollständige Transkription aus dem RA Arnhem bei GRÜNEISEN RTA Material. Bereits Ende Dezember 1470 mußte sich Karl in einem Schreiben an Nijmegen gegen das Gerücht zur Wehr setzen, er halte Adolf gefangen: Regest in NIJHOFF, Gedenkwaardigheden, 4, Nr. 502 S. 440. Die geldrischen Städte schenkten der burgundischen Darstellung keinen Glauben und berieten über Abwehrmaßnahmen, JAPPE ALBERTS, De Staten van Gelre en Zutphen, 2, S. 70.

139 Karl an Johann, 9.2.1471 Arras, HStA Düsseldorf, Kleve-Mark, Beziehungen zu Geldern 34, Dijon ACO, Papiers Henri STEIN; Briefwechsel Nr. 1766. Nicht bei PARAVICINI, Kleve, Geldern und Burgund. Karl an den Rat von Holland, 13.2.1471 Lager bei Wailly, HStA Düsseldorf, Kleve-Mark, Beziehungen zu Geldern 33, Dijon ACO, Papiers Henri STEIN; Briefwechsel Nr. 1775. Das Schreiben weist weder Siegelspuren noch Karls Unterschrift auf und ist vielleicht noch am 13.2.1471 aufgesetzt, dann aber nach Eintreffen der Nachricht von der Gefangennahme Adolfs nicht mehr abgesandt worden.

${ }^{140}$ Instruktion Ludwigs XI. an seine Gesandten in: Paris BNF Ms fr 3884, f.270r-272r, übersetzt in Vaughan, Charles, S. 116f. Der Bericht Nyvenheims in: Paris BNF Ms fr 5041 f.80r und ebd., Ms fr 6980 f.41r-v. Ludwig nutzte trotz dieses Rückschlags die Anwesenheit Nyvenheims im Reich und instruierte ihn im März 1471, mit den Erzbischöfen von Köln und Trier und gegebenenfalls anderen Fürsten Verbindungen aufzunehmen und sie zu einem Bündnis gegen Karl zu bewegen: Paris BNF Ms fr 6978 f.43r-45v. 
Verdacht verräterischer Verbindungen zwischen Adolf und Frankreich zu bestätigen, den Karl seinem Schreiben an Johann vom 9. Februar zufolge und auch nach Ansicht Van Berchems und Basins bereits vor der Flucht oder spätestens seit ihr hegte ${ }^{141}$.

Ausführlich legte Karl seine Sicht der Geschehnisse noch einmal in einer Instruktion an Guillaume Fillastre, Bischof von Toumai und Vorsitzender des Rates, vom Mai 1471 dar $^{142}$. Fillastre sollte auf die Vorwürfe einer Delegation geldrischer Bannerherren und Städte antworten, Adolf sei unter Bruch des Geleits gefangen genommen worden. Vielmehr sei Adolf aus eigenem Willen nach Hesdin gekommen und nie darum gebeten worden, persönlich zu erscheinen. Nachdem Karl ihn auf Drängen der egmondischen Partei dazu bewegt hatte, seinen Vater freizulassen, habe Karl entgegen dem Willen Arnolds Adolf noch entgegenkommende und günstige Vorschläge zur Beilegung des Streites gemacht. Adolf aber habe alles ausgeschlagen. Schließlich habe er sich heimlich und im Einverständnis mit Ludwig XI. und dem Konnetabel vom Hof entfernt, eine Tat, mit der sich die letzteren sogar gebrüstet hätten. Die Angst vor einem geldrisch-französischen Bündnis, einer Bedrohung an zwei Fronten, spricht auch aus dieser Darstellung Karls als Hauptmotiv für die harte Behandlung des jungen Herzogs. Tatsächlich lassen sich Verbindungen zwischen den aufständischen Geldrern und Ludwig XI. auch noch für die Zeit zwischen September 1472 und September 1473 nachweisen, in der Ludwig »Henry de Quinzebus« als Gesandten des Landes Geldern empfing ${ }^{143}$. Das weitere Schicksal Adolfs ist bekannt, bereits im März äußerte der Burgunder Herzog Johann gegenüber sein Vorhaben, Adolf auf unbestimmte Zeit nicht aus der Gefangenschaft entlassen zu wollen ${ }^{144}$.

\section{b) Die Übertragung Gelderns auf Karl}

Nach der Gefangennahme Adolfs bemühte sich Karl zunächst, von den geldrischen Ständen die Anerkennung Arnolds als Herzog zu erlangen. Schon am 16. Februar, eine knappe Woche nach den Ereignissen in Namur, wurde auch

141 Van Berchem geht davon aus, daß Karl Adolf die Verbindung zu Frankreich durch fingierte Briefe unterschoben habe: Historia Captivitatis, $\S 4$ S. 230; Basin nimmt tatsächliche Bündnisse Adolfs gegen Karl an, auch mit den Friesen und Adligen und Städten in Holland, Basin, Histoire, ed. SAMARAN-GARAND, 2, S. 165-168; Commynes erwähnt derartige Verbindungen nicht; vgl. GRÜNEISEN, Reichsstände, S. 63; VAUGHAN, Charles, S. 117. Klevische Truppen unterstützten Karl 1471 gegen Ludwig in Arras, Karl an Johann, 12.4.1471 Lager vor Corbie, HStA Düsseldorf, Kleve-Mark, Beziehungen zu Geldern 34, Dijon ACO, Papiers Henri STEIN; Briefwechsel Nr. 1839.

$142 \mathrm{Karl}$ an Fillastre, Mai 1471 Péronne, HStA Düsseldorf, Kleve-Mark, Beziehungen zu Geldern 33, Dijon ACO, Papiers Henri STEIN; Briefwechsel Nr. 1851.

${ }^{143}$ Paris BNF Ms fr 20685, S. 20685.

${ }^{144}$ Karl an Johann, 7.3.1471 Lager bei Amiens, HStA Düsseldorf, Kleve-Mark, Beziehungen zu Geldern 34, Dijon ACO, Papiers Henri STEIN; Briefwechsel Nr. 1799. 
der Herzog von Kleve aufgefordert, sich bei den Hauptstädten des Landes dafür zu verwenden ${ }^{145}$. Herzog Johann lag viel an einem Ausgleich zwischen den verfeindeten Parteien, da er die Gefahr des wachsenden burgundischen Einflusses an seinen Grenzen immer deutlicher heraufziehen sah und fürchten mußte, von ihm erdrückt zu werden. Auch die standhafte Treue des überwiegenden Teils des Landes zu Adolf und sein eigenes freundschaftliches Verhältnis zu dem jungen Herzog erschwerten Johann die bedingungslose Übernahme der burgundischen Positionen. So bot er Karl im April an, sich noch einmal um eine Versöhnung zwischen Vater und Sohn zu bemühen. Karl antwortete auf das Angebot durchaus positiv und teilte ihm mit, daß er bereits den Städten von Geldern Geleit gewährt habe, die ihn darum, vielleicht in Absprache mit Johann, gebeten hatten ${ }^{146}$. Die hier angedeutete Verhandlungsbereitschaft Karls erscheint in einem etwas anderen Licht, wenn man seine Versicherung Herzog Arnold gegenüber nur vier Tage zuvor betrachtet, mit den Ständen nichts vereinbaren zu wollen, was den Interessen Arnolds schaden könnte ${ }^{147}$. Karl wird die Möglichkeit, dem schwachen Arnold weitergehende territoriale Konzessionen abzuringen, mit zunehmender Deutlichkeit gesehen und deshalb einer friedlichen Lösung des Problems nur noch mäßiges Interesse entgegengebracht haben.

Die Deputation der Stände Gelderns traf im Mai in Péronne ein und erreichte immerhin, daß sich Karl sowohl an Herzog Arnold wie an Johann mit der Bitte um einen Waffenstillstand wandte, der bis zu einer Entscheidung Karls über die Anliegen der Deputierten dauern sollte. Außerdem verlangte sie das Ende der Übergriffe von Seiten Arnolds ${ }^{148}$. Auch durfte sie mit Adolf und seinem Gefolge in seinem Gefängnis in der Burg Lille sprechen, allerdings nur in Anwesenheit einer Niederdeutsch sprechenden Aufsicht ${ }^{149}$.

${ }^{145}$ Karl an Johann, 16.2.1471 Lager bei Hẻbuterne, HStA Düsseldorf, Kleve-Mark, Beziehungen zu Geldern 34, Dijon ACO, Papiers Henri STEIN; Briefwechsel Nr. 1778. Siehe zusammenfassend JANSSEN, Die niederrheinischen Territorien im Spätmittelalter, S. $119 \mathrm{f}$.

${ }^{146} \mathrm{Karl}$ an Johann, 12.4.1471 Lager vor Corbie, HStA Düsseldorf, Kleve-Mark, Beziehungen zu Geldern 34, Dijon ACO, Papiers Henri STEIN; Briefwechsel Nr. 1839.

$147 \mathrm{Karl}$ an Arnold, 8.4.1471, Lager bei Amiens, HStA Düsseldorf, Kleve-Mark, Beziehungen zu Geldern 30, Dijon ACO, Papiers Henri STEIN; Briefwechsel Nr. 1832.

$148 \mathrm{Karl}$ an Amold, 4.6.1471 Péronne, und Karl an Johann, 6.6.1471 Péronne, beide HStA Düsseldorf, Kleve-Mark, Beziehungen zu Geldern 10 bzw. 34, Dijon ACO, Papiers Henri STEIN; Briefwechsel Nr. 1870 und 1876. Vgl. auch Karl an Nijmegen zur selben Sache, 6.6.1471 Péronne, Regest in: NiJHOFF, Gedenkwaardigheden, 4, Nr. 507, S. 447; Briefwechsel Nr. 1877 .

149 Anweisung Karls an Philippe Pot, Herrn von La Roche, Kapitän der Burg Lille, Mai-Juni 1471, HStA Düsseldorf, Kleve-Mark, Beziehungen zu Geldern 33, Dijon ACO, Papiers Henri STEIN; Briefwechsel Nr. 1771 (hier datiert auf »nach 1471 Febr.10«). Im Juni erging der Befehl Karls an Guillaume Bische, Herrn von Cléry, den Herrn von Fosseux als Bewacher Adolfs in der Burg von Courtrai durch eine andere Standesperson abzulösen: Quittung des reitenden Boten vom 12.6.1472, Lille ADN B 2093/66.940. 
Die oben erwähnte Instruktion Karls an Guillaume Fillastre gehört in diesen Zusammenhang, und sie zeigt bereits im Mai 1471 den Weg auf, der nach Ansicht Karls zur Friedensschaffung der einzig gangbare war. Den Deputierten wurde mitgeteilt, daß er solange die Ordnung in Geldern nicht wiederherstellen könne, wen ayant regart au bien et seurté du pays et aussi dudit beau cousin [Adolf] et ses enfans«, wie Arnold alle Rechte über sein Land innehabe. An deren Ausübung könne er Arnold zwar nicht hindern, doch erst wenn alle interessierten Parteien sich seiner, Karls, "yordonnance $\ll$ in diesem Streit unterwürfen und ihm bei der Durchsetzung des Urteils freie Hand ließen, werde er sich des Landes gerne annehmen ${ }^{150}$. Die Übertragung der Vogtei ist als Ziel schon vorgezeichnet, doch galt es noch den Herrschaftswillen Arnolds selbst zu brechen. Der zeigte sich nicht geneigt, den Anweisungen seines Protektors zu folgen, sondern setzte den Krieg gegen die aufständischen Untertanen eigenständig und erfolglos fort. Dies trug ihm im August ein gereiztes Schreiben Karls ein, der ihn dringend aufforderte, sich der vereinbarten Waffenruhe zu fügen. Auf einen Krieg an zwei Fronten, in Geldern und Frankreich, wollte sich Karl nicht einlassen. Zur Beruhigung des Landes stand er deshalb vom Sommer 1471 bis weit in das Jahr 1472 in regem Kontakt mit den geldrischen Hauptstädten. Die Stände Gelderns gaben ihrerseits bis zum burgundischen Einmarsch die Hoffnung nicht auf, die Freilassung Adolfs doch noch zu erreichen ${ }^{151}$.

Im Frühjahr 1472 trug der Kontakt, den Adolf aus der Gefangenschaft heraus mit seinen Anhängern aufgenommen hatte, diplomatische Früchte. Er hatte mit ihnen genau abgestufte Verhandlungsangebote an Karl ausgearbeitet, die dem Herzog durch die Vermittlung wittelsbachischer Fürsten und ihrer Anhänger nahegebracht werden sollten. In Schreiben Bischof Rudolfs von Würzburg, Graf Ulrichs von Württemberg, Herzog Ludwigs von BayernLandshut, Herzog Albrechts von Bayern-München, Bischof Wilhelms von Eichstätt, Pfalzgraf Friedrichs und Erzbischof Ruprechts von Köln wurde dem Burgunder folgender Plan unterbreitet: a) bei Freilassung verpflichtet sich Adolf, Karl als seinen Herrn und Vater anzuerkennen, b) genügt dies Karl nicht, werden sich die Stände dafür verbürgen, daß Adolf ihm in gewünschter Weise dienen wird, c) verweigert Karl die Freilassung, bittet Adolf darum, gegen Ehrenwort am burgundischen Hof seinen Aufenthalt nehmen zu dürfen ${ }^{152}$.

150 Karl an Fillastre, Mai 1471, HStA Düsseldorf, Kleve-Mark, Beziehungen zu Geldern 33, Dijon ACO, Papiers Henri STEIN; Briefwechsel Nr. 1851.

151 Karl an Arnold, 14.8.1471 Abbeville, Regest in: NisHOFF, Gedenkwaardigheden, 4, Nr. 510, S. 450; Briefwechsel Nr. 1922. Kontakt zu den Städten, JAPPE ALBERTS, De Staten van Gelre en Zutphen, 2, S. 78 Anm. 3, S. 85f. Im September verhängte Karl eine Handelssperre gegen alle abtrünnigen geldrischen Städte: Patent 24.9.1471 Abbeville, STEN, Catalogue des Actes, Nr. 1222.

152 Alle Schreiben in: Lille ADN B 18842, Bischof Rudolf, 13.3.1472: 29 450, Briefwechsel Nr. 2027; Graf Ulrich, 14.3.1472: 29 453, Briefwechsel Nr. 2028; Herzog Ludwig, 
Der Pfalzgraf und Erzbischof Ruprecht setzten sich zusätzlich mit eigenen Gesandtschaften, die für den 17., 25. und 30. April und den 14. und 19. Mai, bzw. den 23., 25. und 30. April und den 2.-4, 7., 12. und 17. Mai an Karls Hof nachgewiesen sind, für die Belange Adolfs ein ${ }^{153}$. Die vollständige Unterwerfung, die Adolf anbot, deutet auf seine richtige Einschätzung der Unnachgiebigkeit Karls. Vom Pochen auf den Reichsfürstenstand war nichts geblieben, lieber wollte er als burgundischer Vasall sein Land regieren oder auch nur am Hof seines Gegners leben, als weiter in der Burg von Lille aushalten zu müssen. Karl allerdings reagierte nicht auf den Vorsto $B$ der wittelsbachischen Gruppe, und er dachte nicht daran, das Los Adolfs zu erleichtern 154 .

Arnold gelang es währenddessen nicht, die Herrschaft in Geldern wiederzugewinnen. Seine Resignation äußerte sich zunächst in der Übertragung der Landesvogtei an Karl am 1. Dezember 1471. Dem Burgunder wurden die hohe Gerichtsbarkeit und die Verfügung über eine erhebliche Anzahl konfiszierter Güter der Gegner Arnolds übertragen ${ }^{155}$. Die geldrischen Stände wählten dagegen zunächst Wilhelm II. von Sombreffe, nach dessen Ablehnung am 29. Juni 1472 Graf Vinzenz von Moers zum Landeshauptmann. Graf Vinzenz, ein Parteigänger Adolfs von Geldern, sah sich gegen seinen Willen zu diesem Schritt gezwungen, um die Unabhängigkeit gegen Burgund zu behaupten ${ }^{156}$.

Die Rolle Herzog Johanns von Kleve ist für die Zeit seit der Gefangennahme Adolfs bis zum Beginn der Eroberung Gelderns schwer zu fassen. Nach den gescheiterten Vermittlungsbemühungen von 1471 begegnet er im Februar 1472 als Fürsprecher einer jülich-bergischen Bitte um Verlängerung des Waf-

19.3.1472: 29 451, Briefwechsel Nr. 2034; Herzog Albrecht, 23.3.1472, 29 452, Briefwechsel Nr. 2036; Bischof Wilhelm, 28.3.1472: 29 454, Briefwechsel Nr. 2039; Pfalzgraf Friedrich, 1.4.1472, 29 448, Briefwechsel Nr. 2043; Erzbischof Ruprecht, 6.4.1472, 29449 , Briefwechsel Nr. 2046. Vgl. GRÜNEISEN, Reichsstände, S. 65.

153 GODEFROY, Itinéraire, unter April und Mai 1472.

154 Durch die Eroberung Nijmegens fielen Karl die Kinder Adolfs, Karl und Philippa, in die Hände, Van Berchem, Historia Captivitatis, $\$ 12$ S. 236. Karl ließ sie durch Jean de Rebreuviette, Herrn von Thubeauville im Artois und vier Bogner in die Burg von Béthune bringen, Lille ADN B 2095/67 013. Auf der Burg standen sie in den folgenden Jahren unter der Aufsicht von Jean du Bois und wurden standesgemäß erzogen unter der Obhut eines Geistlichen, einiger Kinderfrauen, eines Kammerdieners, eines Kochs und eines Rechnungsführers, Vidimus eines Patents Karls vom 26.5.1475, Lille ADN B 2105/67 686. Siehe zu Jean de Rebreuviette Werner PARAVICINI, Georg von Ehingens Reise vollendet, in: PAVIOT, VERGER (Hg.), Guerre, pouvoir et noblesse au Moyen Âge, S. 547-588, hier S. 557.

155 NIJHOFF, Gedenkwaardigheden, 4, Nr. 513, S. 455-458. Auch der päpstliche Befehl an die Stadt Nijmegen, sich Arnold zu unterwerfen, fruchtete nicht: 25.3.1472 Rom, NIJHOFF, Gedenkwaardigheden, 4, Nr. 517, S. 459. Angesichts der prekären Lage Gelderns erinnerte sich auch König Jakob III. von Schottland seiner Ansprüche auf das Land, die er Karl durch einen Gesandten darlegen ließ: 24.5.1472 Edinburgh, Lille ADN B 1427, Regest: IADNB 1, 2, S. 372, Briefwechsel Nr. 2084.

${ }^{156}$ PARAVICINI, Moers, Croy, Burgund, S. 36-47. 
fenstillstandes mit Herzog Arnold ${ }^{157}$. In den kriegerischen Auseinandersetzungen, die Arnold noch immer gegen den Willen Karls fortfuhrte, hatte Johann dem alten Herzog offenbar mehr Hilfe zukommen lassen, als es dem Burgunder lieb war. Im Juni 1472, vor seinem Aufbruch in den Krieg gegen Ludwig XI., bat Karl Johann ausdrücklich, Arnold nicht zu unterstützen, da diese Kriege den burgundischen Interessen sehr schädlich seien. Wenig später mahnte er auch die Parteigänger Adolfs in Geldern, sich zu einer Waffenruhe mit den Herren von Egmond und Kulenburg bereit zu finden ${ }^{158}$. Karl war wie üblich darauf bedacht, die Kriegführung auf einen einzigen, von ihm kontrollierten Schauplatz zu beschränken. Johann entsandte Ende Juni Vertreter nach Lobith zu Verhandlungen mit Ritterschaft und Städten Gelderns, die bis Ende des Jahres fortgesetzt wurden und in eine Waffenruhe mündeten. Graf Vinzenz suchte seinerseits einen vereinten Angriff burgundischer und klevischer Truppen zu verhindern, den er bereits vorausschauend befürchtete ${ }^{159}$.

Am 7. Dezember 1472 schlossen Arnold und Karl den Vertrag über die Verpfändung Gelderns für $300000 \mathrm{fl}$.rh. Karl wurde die Nachfolge im Herzogtum unter Übergehung der Rechte Adolfs übertragen. Der alte Herzog hatte spätestens seit der Wahl des Grafen von Moers zum Landesverweser einsehen müssen, daß ihm die Rückeroberung des Landes nicht mehr gelingen würde. In einem Konvolut von ergänzenden Abmachungen vom 30. Dezember wurde Arnold die Nutzung der überschriebenen Länder auf Lebenszeit garantiert. Zusätzlich zur Pfandsumme erhielt er eine Zuwendung von 92000 fl.rh., während Karl in dieser Zeit nur Anspruch auf vier Burgen, je eine in jedem Quartier, erhielt ${ }^{160}$. Außerdem wurde nach burgundischem Vorbild eine Sondersteuer für den rebellierenden Teil des Landes vereinbart, sowie die Privilegien der Anhänger Arnolds bestätigt. Gleichzeitig aber blieben die Bestimmungen des Vogteivertrages in Kraft, so daß Karl neben den Steuern auch die

157 Johann an Herzog und Herzogin von Jülich-Berg, 28.2.1472 Kleve, HStA Düsseldorf, Jülich-Berg I 320 f.7r, nach GRÜNEISEN RTA Material (nicht in Briefwechsel).

${ }^{158} \mathrm{Karl}$ an Johann, 4.6.1472 Arras: HStA Düsseldorf, Kleve-Mark, Beziehungen zu Geldern 32, Dijon ACO, Papiers Henri STEIN, Briefwechsel Nr. 2092. Karl an Anhänger Adolfs, 29.7.1472 Eu: NiJHOFF, Gedenkwaardigheden, 4, Nr. 525, S. 469, Briefwechsel Nr. 2122. Zu Hilfszahlungen an Arnold sah sich Karl allerdings verpflichtet. Im April und Mai 1472 quittierte Arnold dem Argentier Nicolas de Gondeval über $400 \mathrm{lb}$ bzw. $200 \mathrm{lb}$ und erwähnt auBerdem, seit November 1471 insgesamt $1200 \mathrm{lb}$ erhalten zu haben. Lille ADN B 2092/66 809 (29.4.1472); Lille ADN B 2086/66 510 (5.5.1472).

159 JAPPE ALBERTS, De Staten van Gelre en Zutphen, 2, S. 85f.

160 Am 12.3.1473 quittierten die Testamentsvollstrecker Amolds, u.a. Wilhelm von Egmond und Heinrich von Gemen, den Empfang einer Rate von 8000 fl.rh. auf die Pfandsumme und von $750 \mathrm{lb}$ für 100 Mark in Silbergeschirr, das Karl Arnold versprochen hatte: Lille ADN B 2085/66 086-66 087, (falsch eingeordnet in das Jahr 1472.) 
Gerichtsbarkeit in seinen Händen hielt und der Weg zur Herrschaftsübernahme vorgezeichnet war ${ }^{161}$.

Die übergangenen Stände des Landes erklärten dagegen den Vertrag für ungültig. Ähnlich wie wenig später im Fall Kölns schloß Karl Vereinbarungen mit einem benachbarten Fürsten ohne Rücksicht auf die Landstände, die unter diesem Eindruck den Widerstand organisierten. Trotz der vergleichbaren Ausgangssituation aber konnten sich die ganz auf ihre eigenen Kräfte zurückgeworfenen Geldrer der burgundischen Übermacht nicht erwehren. Anders als den Neussern und Kölnern war es ihnen nicht gelungen, auswärtige Mächte zu ihrer Unterstützung zu verpflichten. Dabei spielte nicht zuletzt der Standpunkt des Kaisers eine bedeutende Rolle, der sich nicht zur Hilfe für das gebannte Geldern bereit fand, wohl aber, auch auf Druck der Reichsstädte, zur Rettung des Erzstiftes den Reichskrieg ausrief ${ }^{162}$.

\section{c) Der Feldzug in Geldern}

Die Eroberung Gelderns war seit der Verpfändung des Landes beschlossene Sache, da nun die rechtliche Grundlage für die politische Handlungsfreiheit Karls geschaffen war, die er zuvor immer verlangt hatte. Im Juni, während sich das Heer bereits in Marsch gesetzt hatte, sicherte er sich zusätzlich noch durch den Kauf der jülich-bergischen Ansprüche $a b^{163}$. Bei Hof wurde der bevorstehende Feldzug wohl recht offen diskutiert, denn Ende Februar schrieb der mailändische Gesandte aus Brügge an Herzog Galeazzo Maria, daß Karl nur noch die Verlängerung des Waffenstillstands mit Frankreich erwarte, um im Frühjahr gegen Geldern zu marschieren. König Ludwig werde diese Waffenruhe noch bereuen. Tatsächlich sah sich Ludwig von dem geldrischen Unternehmen Karls überrascht und versäumte es, etwa den Widerstand Dänemarks zusammen mit den Friesen, Bischof Heinrich von Münster und den norddeutschen Reichsfürsten zu organisieren. Er wandte sich einzig mit einem Schreiben an den Kaiser, um diesen zum Schutz Gelderns und der Ansprüche des rechtmäßigen Erben, Adolfs Sohn Karl, aufzufordern ${ }^{164}$.

161 Vertrag vom 7.12.1472: Lille ADN B 1427/16 235, ebd. 16269, in Kopien die weiterführenden Abmachungen vom 30.12.1472, Regesten und Druck in NIJHOFF, Gedenkwaardigheden, 4, Nr. 532-540, S. 477-483. Das Kopialheft in Lille ADN B $1427 / 16269$ enthält beglaubigte Kopien aller Zusatzverträge, sämtlich kollationiert und unterfertigt durch den Sekretär Martin Steenbergh. Zu ihm siehe unten S. 257f. Unklar ist, ob und in welchem Maß Steenbergh, der häufig als Gesandter Karls in den niederrheinischen Bereich eingesetzt wurde, an der Aushandlung der Verpfändung, die von Arnold am 7.12.1472 in Roermond beurkundet wurde, beteiligt war.

162 GRÜNEISEN, Reichsstände, S. 66, 69. Friedrich III. betrachtete das Haus Berg als rechtmäßigen Erben Gelderns, nicht das Haus Egmond, das nie von ihm belehnt worden war. $163 \mathrm{Vgl}$. S. 79.

164 Pietro Aliprando an Galeazzo Maria, 22.2.1473 Brügge: SESTAN, Carteggi, 1, Nr. 188, S. 315f. BITTMANN, Ludwig XI., 2, 1, S. 98-101. Ludwig an Friedrich III., 11.6.1473 Am- 
Die Vereinbarungen Karls mit Johann von Kleve über klevische Waffenhilfe und die dafür zu erwartenden Entschädigungen datieren bereits auf den Dezember 1472. Eine Urkunde Karls vom 31. Juli 1473 erwähnt, daß nach der Übertragung Gelderns an Karl am 7. Dezember 1472 »il eust esté convenu et accordé entre nous et nostre treschier et tresamé cousin le duc de Cleves conte de la Marke qu'il nous aideroit de son pouvoir a avoir la possession desdits duchié et conté...«, und daß er dafür das Amt Goch und andere Belohnungen erhalten werde ${ }^{165}$. Auch Herzog Arnold hatte Johann im burgundischen Exil Kompensationen aus den geldrischen Territorien für seine Aufwendungen im Krieg gegen Adolf zugesagt ${ }^{166}$. Einen Monat vor dem Tod des alten Herzogs, am 22. Januar 1473, teilte Karl Herzog Johann in offizieller, die Legalität des Vorgehens durch die lateinische Ausfertigung betonender Form seine Absicht mit, das ungehorsame Land in die Botmäßigkeit Arnolds zurückzuzwingen und bat Johann, dabei zu helfen ${ }^{167}$. Im März begannen Gespräche über Einzelheiten des Feldzugs, auf seiten Herzog Johanns geführt von Johann von Sechtingen, dessen Gesandtschaft Karl durch seinen Rat und Kammerherrn Augustin von Borchoven beantwortete. Karl drückte seine Zufriedenheit über die gute Freundschaft Herzog Johanns aus ${ }^{168}$. Im März und April wurden Abwehrmaßnahmen gegen feindliche Übergriffe auf die Anhänger der Egmonds in Geldern verabredet, wobei wieder Sechtingen als Unterhändler fungierte ${ }^{169}$. Im Mai begab sich Pierre de Miraumont zu Herzog Johann und Bischof Hein-

boise: J. Vaesen, E. CharavaY (Hg.), Lettres de Louis XI roi de France, Bde.1-12, Paris 1883-1909, hier Bd. 5, Nr. 733, S. 143.

165 Zitiert in PaRAviCINI, Kleve, Geldern und Burgund, S. 59.

166 Am 16.8.1471 überschrieb Arnold Johann die Pfandschaft an der Düffel und das Schloß Calbeck an der Niers für 6000 Gulden in Pfandbesitz, sowie das Schloß Nergena und Stadt und Land Wachtendonk: LACOMBLET, Rheinisches Urkundenbuch, 4, 1, Nr. 354, S. 444. Bestätigt von Karl am 24.7.1473 zu Nijmegen: NIJHOFF, Gedenkwaardigheeden, 5, Nr. 10. $\mathrm{Zu}$ weiteren Schenkungen Karls an Johann in Geldern siehe ebd., S. 446f., 462f., 464f. Die Anschuldigung Van Berchems, Historia Captivitatis, \$15 S. 241, Johann habe Karl zur Einmischung am ganzen Rhein angestachelt, entbehrt wohl der Grundlage.

${ }^{167} \mathrm{Karl}$ an Johann, 22.1.1473 Brügge, HStA Düsseldorf, Kleve-Mark, Beziehungen zu Geldern 32, Dijon ACO, Papiers Henri STEN; Briefwechsel Nr. 2211. Arnold starb am 23.2.1473. Erst vom 31.8.1473 datiert die Quittung des Kammerdieners und Malers Jean Hannequart über $40 \mathrm{lb}$ für die Herstellung von Wimpeln und Fahnen mit dem Wappen Arnolds für die Feier seines Leichenbegängnisses, Lille ADN B 2096/67 245.

${ }^{168}$ Karl an Johann, 4.3.1473 Brüssel, HStA Düsseldorf, Kleve-Mark, Beziehungen zu Geldern 32, Dijon ACO, Papiers Henri STEIN, Briefwechsel Nr 2230; ders. an dens., 17.3. und 24.3.1473 Brüssel, ebd., Briefwechsel Nr. 2238 u. 2247; siehe PARAVICINI, Kleve, Geldern und Burgund, S. 59. Miraumont ging als Gesandter Karls zunächst zu Johann, um von dort mit dem Bischof von Münster, Heinrich von Schwarzburg, ein Bündnis oder zumindest die Neutralität zu vereinbaren. (Brief, Instruktion und Beglaubigung vom 4., 7. und 10. Mai 1473 aus Valenciennes).

169 Karl an Johann, 31.3.1473 Namur, HStA Düsseldorf, Kleve-Mark, Beziehungen zu Geldern 32, Dijon ACO, Papiers Henri STEnN; Briefwechsel Nr. 2256. Ders. an dens., 11.4.1473 Antwerpen, ebd.; Briefwechsel Nr. 2261. PARAVICINI, Kleve, Geldern und Burgund, S. 59f. 
rich von Münster, um mit letzterem mit Hilfe Johanns ein Bündnis zu schlieBen. Die Mission scheiterte an der Abwesenheit des Bischofs, aber auch Johann suchte ihren Erfolg zu hintertreiben, indem er den Gesandten bei sich festhielt und den direkten Kontakt mit dem Bischof verhinderte ${ }^{170}$.

Miraumont war von Valenciennes aus gereist, wo Karl zu dieser Zeit eine Kapitelsitzung des Ordens feierte. Auch die Autorität des Ordenssouveräns nutzte Karl zur Legitimation seines Vorgehens gegen Adolf. Noch einmal ließ er die Angelegenheit Gelderns verhandeln und Adolf von den Ordensrittern zu ewigem Gefängnis verurteilen. Angesichts der sich bereits in vollem Schwung befindlichen Kriegsvorbereitungen und der Gefangenschaft Adolfs handelte es sich bei der Sendung Simon de Lalaings und Martin Steenberghs an Adolf von Geldern und Johann von Kleve, die den Fürsten im Auftrag des Ordens die Aufforderung zur Unterwerfung unter den Schiedsspruch Karls überbrachten, um einen Akt reiner Formalität ${ }^{171}$.

Wie schnell der Widerstand gegen die burgundische Übermacht innerhalb des geldrischen Adels nach dem Tod Herzog Arnolds zusammenbrach, illustriert der Briefwechsel zwischen Graf Vinzenz und seinem Schwiegersohn Philippe de Croÿ aus den Jahren 1472 und 1473. Vinzenz sah sich nicht in der Lage, der burgundischen Armee entgegenzutreten und versuchte die Lage auf dem Verhandlungsweg zu entschärfen. In einem Schreiben an die Stände des Landes vom 12. Februar 1473 erwähnte er einen Vorschlag Herzog Karls zur Befriedung Gelderns in vier Punkten ${ }^{172}$. Frieden wollte der Herzog aber nur zu den eigenen Bedingungen akzeptieren, worunter die Einstellung der feindlichen Handlungen seiner Gegner und die Vollmacht zählten, über alle anhängenden Streitigkeiten im Lande allein zu befinden. Noch im April 1473 war von Mitteln und Wegen die Rede, sich mit Karl auszusöhnen ${ }^{173}$. Vinzenz mußte sich dem Herzog aber schließlich weitgehend bedingungslos unterwerfen, da auch vom Herzog von Kleve, der von der Eroberung Gelderns reich profitierte, keine Hilfe zu erlangen war. Der Graf von Moers verlor alle seine Pfandschaften und mußte bis zum Tod Herzog Karls in äußerst eingeschränkten Verhältnissen leben ${ }^{174}$. Der Kaiser setzte sich wiederholt, zum ersten Mal

170 Siehe die Nachweise bei PARAVICINI, Kleve, Geldern und Burgund, S. 60f. m. Anm. 6772.

${ }^{171}$ Frédéric de REIFFEnBERG, Histoire de l'Ordre de la Toison d'Or, S. 64f., S. 86f. Zur gleichen Zeit unternahm Ludwig XI. einen letzten vergeblichen Versuch, in Geldern und beim Kaiser gegen Karl zu wirken. Am 1 1.6.1473 wandte er sich an Friedrich III. mit der Bitte, sich für die Interessen des minderjährigen Sohnes Adolfs, Karl, einzusetzen: CHMEL, Aktenstücke, 1, 1, Nr. 96, S. 299f. Im Juli war der écuier Jacques Lidol im Auftrag Ludwigs in Geldern und erhielt dafür $100 \mathrm{lb}$ : Paris BNF Ms fr 20685 f.587r.

172 PARAVICINI, Moers, Croy, Burgund, Anhang 2, Nr. 2.

173 PARAVICINI, Moers, Croy, Burgund, S. 40f.

174 Die Gründe für die andauernde Ungnade des Herzogs sind bisher nicht geklärt. Weder die Croÿ noch andere Anhänger Adolfs, wie Oswald van den Bergh, hatten unter solch dauerhaftem herzoglichem Unwillen zu leiden. PARAVICINI, Moers, Croy, Burgund, S. 44-47. 
am 24. November 1473 in Trier, für die Belange Vinzenz' ein, wurde aber von Karl abgewiesen. Ebenso erging es dem König von Dänemark im Januar 1475 während seiner Vermittlungsbemühungen zwischen Herzog und Kaiser ${ }^{175}$.

Karl und Johann trafen sich zum ersten Mal nach Beginn des Feldzugs ${ }^{176}$ am 27. und 28. Juni in Kleve. Am 1. August empfing Karl in der Abtei Elten den Bischof von Münster, Heinrich von Schwarzburg, und verhandelte mit ihm, wie schon 1471, die umstrittenen Ansprüche auf Friesland ${ }^{177}$. In Zutphen hielt sich Karl vom 4. bis zum 10. August 1473 auf und traf dort mit den Oberhirten von Köln und Utrecht zusammen ${ }^{178}$. Im Verlauf des Feldzuges kreuzten sich die Wege Karls und Johanns wiederholt, und wie im Utrechter Konflikt in den 50er Jahren und der Unterwerfung Lüttichs betätigte sich Johann zur Vorbereitung der Kapitulation als Vermittler zwischen den geldrischen Städten und Herzog Karl ${ }^{179}$. Die Belohnung Johanns für seine Teilnahme am Feldzug war wie erwähnt im Vorfeld festgelegt worden ${ }^{180}$. Auf dem Papier handelte es sich um einen beträchtlichen Zugewinn an Land und Einkünften, doch traten bei der Herrschaftsübernahme und der Eintreibung des von den geldrischen Städten zu zahlenden Geldes teilweise erhebliche Schwierigkeiten auf, wie an Oswald van den Bergh als dem prominentesten Beispiel deutlich wird.

Oswald war es sehr schnell gelungen, die Gnade Karls wieder zu erlangen ${ }^{181}$ und seine erneute Belehnung in Nijmegen zwischen dem 24. und 28. Juli 1473 zu erreichen. Herzog Johann, dem die Besitzungen Oswalds als Teil seiner Entschädigung am 4. April übertragen worden war, war allerdings nicht gewillt, diesen Affront widerstandslos zu akzeptieren ${ }^{182}$. Zu Beginn des Jahres 1475 wurde der Briefwechsel zwischen Karl und Johann von diesen Streitigkeiten bestimmt. Karl wandte sich im Januar 1475 an Johann mit der Bitte, da-

175 Bericht des Carlo Visconti an den Herzog von Mailand aus Köln vom 21.12.1473 in: CuSIN, Impero, Borgogna, 2, S. 51; vgl. PaRAviCINI, Moers, Croy, Burgund, S. 48. BACHMANN, Urkundliche Nachträge, S. 365, Anm. 2.

176 Zum Verlauf der Eroberung siehe PARAVICINI, Kleve, Geldem und Burgund, S. 61-68, mit Nachweisen. Zur burgundischen Verwaltung Gelderns W. JAPPE ALBERTS, De Eerste Bourgondische Bezetting van Gelre (1473/1477), in: Nederrijnse Studien XIIle - XVe eeuw, Groningen 1954, S. 49-81

177 PARAVICINI, Kleve, Geldern und Burgund, S. 85f; PETRI, Nordwestdeutschland, S. 96.

178 VAUGHAN, Charles, S. 120.

179 PARAVICINI, Kleve, Geldern und Burgund, S. $62 \mathrm{f}$.

${ }^{180}$ Zum genauen Hergang siehe PARAVICINI, Kleve, Geldern und Burgund, S. 68-72.

181 A. J. MARIS, Belening van Heer Oswald van den Bergh in 1473, in: Gelre 58 (1959) S. 156. Die Begnadigung van den Berghs wurde am 7.12.1473 wiederholt, und die Rückgabe der konfiszierten Güter versprochen: SCHILFGAARDE, Archief van huis Bergh, 1, Nr. $1018 \mathrm{u}$. Nr. 1023. Oswald wurde in der burgundischen Hofordnung vom 13.2.1474 als Pensionsempfänger geführt: PARAVICINI, Brimeu, S. 409. Oswald pflegte vergleichsweise intensive Kontakte zu Friedrich III.: HEINIG, Friedrich III., S. 1250. Angesichts des bevorstehenden Treffens mit dem Kaiser könnte Karl diesem zu Gefallen die schnelle Begnadigung vorgenommen haben.

${ }^{182}$ LACOMBLET, Rheinisches Urkundenbuch, 4, 1, Nr. 357, S. $446 \mathrm{f}$. 
für zu sorgen, daß dem burgundischen Rat und Arzt Karls, Meister Simon de l'Escluse, Dompropst zu Utrecht, die Einkünfte aus dem Zehnten in der Pfarrei Weel wieder ausgezahlt würden, was ein gewisser Walram von Lennep mit Hilfe des Johann van Loe, Drossart Herzog Johanns, verhindere. Dies geschah, um Ansprüche Walrams gegen Oswald van den Bergh, an den der Zehnt verliehen war, durchzusetzen ${ }^{183}$. Die Auseinandersetzungen um die Berghschen Güter spielten sich also auch auf der Ebene der Anhänger Herzog Johanns, Karls und van den Berghs ab ${ }^{184}$, die ihre Forderungen an Dritten zu befriedigen suchten. Herzog Johann willigte entgegen allen Aufforderungen Karls ${ }^{185}$ erst 1479 in die Rückgabe an Oswald gegen eine ansehnliche Entschädigung. Johann konnte sich sicher sein, daß Karl die Allianz mit Kleve nicht zugunsten des letztlich unbedeutenden Oswald opfern würde ${ }^{186}$.

Die Geldernpolitik Karls verdeutlichte ein letztes Mal die gewohnte Schwäche der Reichsgewalt am Niederrhein. Karl, der als Schiedsrichter in seiner Funktion des Ordenssouveräns auftrat, erfüllte gleichsam kaiserliche Aufgaben als Gerichtsherr auf Reichsgebiet. Diese Anmaßung war möglich auf der Grundlage seiner tatsächlichen militärisch-politischen Vormacht und der Akzeptanz der kulturellen burgundischen Vorherrschaft in der Region. Symptomatisch dafür war nicht zuletzt die Duldung durch den Kaiser, der sich nicht zur Hilfe für Land und Herzog von Geldern aufgerufen sah, die ja seit den Zeiten Sigmunds geächtet waren. Das Verhalten Adolfs gegen seinen Vater tat ein Übriges. Solange also ein Konsens der betroffenen Reichsglieder herrschte, wurde die Legitimität burgundischer Machtausübung nicht thematisiert. $\mathrm{DaB}$

183 Brief Karls an Johann vom Januar 1475 aus dem Lager vor Neuss, HStA Düsseldorf, Kleve-Mark, Beziehungen zu Geldern 30, Dijon ACO, Papiers Henri STEIN; Briefwechsel Nr. 2860.

184 Ähnliche Probleme ergaben sich im Streit um die Berghsche Herrschaft Pannerden zwischen van den Bergh und dem Kapitel von St. Martin zu Emmerich: SCHILFGAARDE, Archief van Huis Bergh, 1, Nr. 1043-1047 (Dezember 1474 bis Januar 1475) und ebd. Nr. 1059, 1.11.1475. Im Oktober 1475 kam es zu einem Vergleich, bei dem Guy de Brimeu zum Schiedsrichter bestellt und schnell von Oswald mit 8000 fl.rh. geneigt gestimmt wurde. Herzog Johann zeigte sich allerdings den Vorstellungen Brimeus unzugänglich, PARAVICINI, Brimeu, S. 362f., $410 \mathrm{f}$.

185 Siehe z. B. das Schreiben Karls an den ersten Türhüter des Rates von Geldern, 13.11.1475 Mecheln: SCHILFGAARDE, Archief van Huis Bergh, 1, Nr. 1061.

186 PARAVICINI, Brimeu, S. 412. Schwierigkeiten ergaben sich auch bei den Reparationszahlungen, die Nijmegen Herzog Johann in Höhe von $20000 \mathrm{fl}$.rh. schuldete. Karl verwandte sich für die Bürger der Stadt in einem Schreiben an Johann vom 25.9.1473, Luxemburg, HStA Düsseldorf, Kleve-Mark, Beziehungen zu Geldern 34, Dijon ACO, Papiers Henri STEIN; Briefwechsel Nr. 2406. Vgl. PARAVICINI, Kleve, Geldern und Burgund, S. 72. Zur Finanzverwaltung Gelderns unter burgundischer Herrschaft siehe A. J. MARIS, De raadkamers of hoven van Karel den Stoute in Gelre en Zutphen, 1473-1477, in: Gelre 56 (1957) S. 45-123; J.A.E. KUYS, De financiele instellingen van het hertogdom Gelre. Een inventarisierend overzicht, in: F. KEVERLING BUISMAN u.a. (Hg.), Van Hertogdom Gelre tot Provincie Gelderland, Nijmegen 1990, S. 46-48. 
dabei die vorgebliche Legalität in Form der Übertragung durch Herzog Arnold zweitrangig war, zeigt sich an den Reaktionen auf den Vogteivertrag mit Erzbischof Ruprecht. Waren der Kaiser und mit ihm eine ausreichende Anzahl der Reichsstände der Ansicht, daß Reichsinteressen und Reichsrecht gefährdet waren, galten derartige Verträge nichts.

Adolf hatte am Hofe Karls stets darauf bestanden, da $B$ er als Reichsfürst nur dem Kaiser verantwortlich sei ${ }^{187}$. Unter den wittelsbachischen Fürsten, die sich für die Freilassung Adolfs 1472 einsetzten, ging Bischof Rudolf von Würzburg eigens auf Adolfs reichsfürstliche Stellung ein und betonte dessen Blutsverwandtschaft mit vielen der regierenden Reichsfürsten ${ }^{188}$. Ein gewisses Unbehagen angesichts der Behandlung Adolfs durch den Herzog von Burgund war also vorhanden, doch spielten neben der Ächtung Gelderns auch reichsinterne Parteiinteressen noch eine zu große Rolle, als daß sich der Kaiser zum Eingreifen hätte bewegen lassen. Denn Hilfe für das wittelsbachfreundliche Geldern kam nicht in Betracht. In den unmittelbar betroffenen Regionen und auch schon in einigen Städten des Reiches empfand man die Überschreitung der »bestehenden Rechtsgrenzen« hingegen als bedrohlich. Karl mag durch diese Erkenntnis in seinem strikt legalistischen Vorgehen bestärkt worden sein, das er nach Geldern wiederum in Köln anzuwenden gedachte ${ }^{189}$.

\subsection{Der Tag von Trier}

Briefe Karls an Johann, die sich auf sein Treffen mit Kaiser Friedrich III. in Trier beziehen, sind nicht überliefert. Wenn sie nicht verloren gegangen sind, mag dies seinen Grund darin haben, daß Johann (II.) und Philipp von KleveRavenstein ihrem Vater bzw. Onkel Bericht aus Trier erstatteten ${ }^{190}$, und Karl selbst wenig Lust verspürte, Einzelheiten der komplizierten Verhandlungen mitzuteilen. Im Gefolge Karls befand sich in Trier neben Johann II. von Kleve und Philipp von Kleve-Ravenstein noch ein "petit bastard de Cleves«, so daß das Haus Kleve vielfältig vertreten und wahrscheinlich besser informiert war als die meisten in Trier Anwesenden 191 .

Das Schweigen der Quellen zu den klevisch-burgundischen Beziehungen während des Trierer Tages weist darüber hinaus auf den Tiefpunkt hin, an dem

187 VAUGHAN, Charles, S. $115 f$.

188 Lille ADN B 18842/29 450.

${ }^{189}$ GRÜNEISEN, Reichsstände, S. 63.

$190 \mathrm{DaB}$ ein Briefwechsel zwischen Adolf von Kleve-Ravenstein und Herzog Johann I. von 1464-1476 existiert haben muß, wird aus dem handschriftlichen Inventar Steins deutlich: PARAVICINI, Kleve, Geldern, Burgund, S. 55 Anm. 12.

191 Paris BNF Ms fr 11590 f.117r: die beiden Herzogskinder von Kleve und Ravenstein. Lille ADN B 2098, Ausgaben für Kleiderstoffe: f.1r: Jehan monseigneur de Cleves, Philippe monseigneur de Ravenstein, f.3v: le petit bastard de Cleves. 
die klevische Eigenständigkeit gegenüber Burgund zu dieser Zeit angelangt war. Die Belehnung mit Geldern bildete den Abschluß und die reichsrechtliche Sanktion jenes Eroberungsfeldzuges, der Burgund für Kleve zu einem direkten übermächtigen Nachbarn im Westen gemacht hatte. Herzog Karl verhandelte mit dem Kaiser über ein Königtum, das höchstwahrscheinlich den Klever in eine Mediatstellung herabgedrückt hätte'. Das Scheitern der Trierer Verhandlungen war für Johann, wenn er an seiner weiteren Selbständigkeit interessiert war, ein Glück, und Ähnliches gilt auch für den Mißerfolg des Kölner Stiftskrieg.

\subsection{Der Kölner Stiftskrieg}

Bisher nicht untersucht sind die Schreiben des Herzogs von Burgund an Johann von Kleve im Zusammenhang der Belagerung von Neuss 1474 und 1475. Die Mehrzahl dieser Briefe handelte von Versorgungsproblemen des burgundischen Heeres und den sich häufenden Desertionen. In zwei weiteren Schreiben wird das Verhältnis klevischer Untertanen zu den Burgundern beleuchtet. Im übrigen bat Karl um Geleit durch Kleve für Besucher des Lagers $^{2}$ und ein einziges $\mathrm{Mal}$ auch um militärische Hilfe. Von besonderem Interesse aber sind die Darlegungen Karls zu den Treuepflichten Johanns gegenüber dem Reich und Burgund, die hinsichtlich der Selbsteinschätzung Karls und seiner Sicht des Reichs höchst erhellend sind.

\section{a) Kaiser und Reich}

Vergleichbar den Herzögen von Jülich-Berg, stand Herzog Johann als enger Verbündeter Burgunds und Reichsfürst unversehens vor dem Dilemma, nicht zwei Herren gleichzeitig dienen zu können. Zwar ließen die Kräfteverhältnisse am Niederrhein keinen Zweifel daran aufkommen, daß die burgundische Loyalität die weit drängendere war, andererseits aber widersprachen die klevischen Interessen im Verhältnis zum Kölner Erzstift prinzipiell einer Unterstïtzung der burgundischen Politik.

${ }^{1}$ Siehe unten S. 172-174.

2 Ende 1474 wandte sich Karl an Johann mit der Bitte um Geleit für Graf Gerhard von Oldenburg (3.11.1474) und den Grafen von der Lippe (19.11.1474), die im Namen Christians von Dänemark und des Bischofs von Münster zu Verhandlungen anreisten. Am 4.2.1475 bat Karl um Verlängerung des Geleits für Graf Gerhard. Karl an Johann, 3.11.1474 u. 19.11.1474 Lager vor Neuss, HStA Düsseldorf, Kleve-Mark, Beziehungen zu Geldern 30, Dijon ACO, Papiers Henri STEIN; Briefwechsel Nr. 2781 u. 2795. Bitte um Verlängerung: 4.2.1475 Lager vor Neuss, HStA Düsseldorf, Kleve-Mark, Beziehungen zu Geldern 30, Dijon ACO, Papiers Henri STEIN; Briefwechsel Nr. 2909. 
Nach der Wahl Erzbischof Ruprechts 1463 hatte Johann sich zunächst mit diesem zur Wahrung des territorialen status quo verbunden, sich dann aber schnell auf die traditionellen klevischen Positionen zurückgezogen und war zuerst mit Graf Vinzenz von Moers, dann auch mit anderen Herren der Region, vor allem den kölnischen Pfandherren, gegen den Erzbischof Verträge eingegangen ${ }^{194}$. Nach wie vor war Johann vor allem an der Sicherung von Soest und Xanten gelegen, ein Ziel, das er durchaus gegen die Politik seines burgundischen Verbündeten zu erreichen gedachte. Herzog Philipp ging bereits 1465 ein Bündnis mit Ruprecht ein ${ }^{195}$, doch der Antagonismus zwischen Kleve und dem Erzbischof wuchs während des Krieges in Geldern. Herzog Adolf verband sich 1467 mit Ruprecht, während sich Neuss in Opposition gegen seinen Landesherrn dem Herzog von Kleve anschloß. Hatte Karl im Streit zwischen Erzbischof und Stift zunächst noch seine Vermittlung angeboten, trat er mit der Eroberung Gelderns das Erbe der pro-erzbischöflichen Politik der Herzöge von Geldern an. Wenige Wochen nach Ende des Trierer Tages übernahm Karl die Vogtei über das Erzstift und entschloß sich gut ein halbes Jahr darauf, nach gescheiterten Vermittlungsversuchen, zum Marsch auf das rebellierende Neuss ${ }^{196}$. Ungeachtet der klar zutage liegenden klevischen Interessen forderte Karl Johann schon im März 1473 auf, im eskalierenden Stiftsstreit keine der Parteien zu unterstützen, da er einen gütlichen Tag anberaumen wolle ${ }^{197}$.

Dagegen unternahm Herzog Johann zumindest den Versuch, seine Eigenständigkeit unter Beweis zu stellen und verband sich 1473 mit dem Haupt der Opposition gegen Ruprecht, dem von den Ständen bestellten Stiftsverweser Landgraf Hermann von Hessen. Auch in diesem Vertrag wurde die Einhaltung der Bestimmungen betreffend Soest und Xanten ausdrücklich festgelegt ${ }^{198}$. Karl wird von diesen Verpflichtungen seines Verbündeten gewußt haben, eine Anpassung des Klevers an die burgundischen Ziele wurde aber stillschweigend als selbstverständlich vorausgesetzt: am 14. Juni 1474 wies er Johann an, alle Getreuen Erzbischof Ruprechts auch in seinen Landen gut aufzunehmen und seine eigenen Untertanen, die sich Landgraf Hermann von Hessen und anderen Feinden des Erzbischofs angeschlossen hatten, zurückzurufen und solche Verhältnisse zu verbieten ${ }^{199}$.

Den Klevern blieb nichts anderes übrig, als sich den Wünschen Karls zu beugen. Jungherzog Johann (II.) von Kleve war während der gesamten Bela-

194 Bündnis Johanns mit Wilhelm Graf von Virneburg und anderen Herren, 6.3.1468, LACOMBLET, Rheinisches Urkundenbuch, 4, 1, Nr. 340, S. 425-427.

195 Commines, ed. LENGLET, 2, S. 496-499.

196 VAUGHAN, Charles, S. 316-319.

197 Karl an Johann, 18.3.1473 Brüssel, HStA Düsseldorf, Kleve-Mark, Beziehungen zu Geldern 30, Dijon ACO, Papiers Henri STEN; Briefwechsel Nr. 2240.

1981473 o. Tag und Monat, LACOMBLET, Rheinisches Urkundenbuch, 4, 1 Nr. 371, S. $465 f$.

199 Karl an Johann, 14.6.1474 Luxemburg, HStA Düsseldorf, Kleve-Mark, Beziehungen zu Geldern 30, Dijon ACO, Papiers Henri STEN; Briefwechsel Nr. 2609. 
gerung im Gefolge des Burgunders, und die klevischen Länder dienten als Basis zur Verproviantierung des Heeres. Herzog Johann beteiligte sich nicht an der Kampagne, obwohl er offenbar zuvor versprochen hatte, in eigener Person an einem Krieg gegen den Kaiser teilzunehmen. Es wird ihm äußerst unangenehm gewesen sein, da $B$ ihn Karl im August 1474 daran erinnerte ${ }^{200}$. Zusammen mit den Herzögen von Jülich-Berg regte Herzog Johann Ende August 1474 eine Vermittlung zwischen dem Stift und dem Erzbischof und Burgund an ${ }^{201}$. Nach außen hin mochte Kleve also, wie Vaughan formulierte, als "staunch ally « Karls erscheinen ${ }^{202}$, mit innerer Überzeugung wurde die Hilfe nicht geleistet. Ein mit burgundischer Macht errungener Sieg des Erzbischofs über seine Stände konnte Kleve nur Ungutes für die eigene territoriale Stellung befürchten lassen.

Der Konflikt mit dem Kaiser und seinen Forderungen, dem Reichsaufgebot gegen Karl und Ruprecht Folge zu leisten, war unausweichlich. Noch Ende Juni 1474 hatte Friedrich III. Herzog Johann zum kaiserlichen Kommissar für das Erzbistum Bremen und die Bistümer Münster und Utrecht ernannt, um für die Ausführung des auf dem Reichstag zu Augsburg beschlossenen Anschlags gegen die Türken zu sorgen ${ }^{203}$. Im August versuchten Landgraf Hermann und die kölnischen Landstände, durch die Übersendung der Abschrift eines päpstlichen Briefes Johann von der Unrechtmäßigkeit des burgundischen Vorgehens zu überzeugen ${ }^{204}$. Im Juli dann muß Johann kaiserliche »lettres et mandemens « erhalten haben, die er in einem Schreiben an Karl von Anfang August erwähnte und die ihm ohne Zweifel die Erfüllung seiner Pflichten als Reichsfürst befohlen hatten ${ }^{205}$. Johann hatte daraufhin Karl um Rat gefragt, wie er sich Friedrich III. gegenüber dafür rechtfertigen könne, daß er gegen den ausdrücklichen kaiserlichen Befehl Burgund unterstützte.

Karls Antwort vom 11. August 1474206 bietet Aufschlüsse von größtem Interesse über seine Haltung zu Reich und Kaiser wie auch über seine Einschätzung der Beziehung zwischen Kleve und Burgund: Er sehe eigentlich gar keinen Grund, so schreibt er, auf die Anmahnungen des Kaisers überhaupt zu antworten. "Toutes voies se la chose vous est en si grande estimacion que de

${ }^{200}$ Karl an Johann, 11.8.1474 Lager vor Neuss, HStA Düsseldorf, Kleve-Mark, Beziehungen zu Geldern 30, Dijon ACO, Papiers Henri STEIN; Briefwechsel Nr. 2676.

201 Stadt Köln an den Erzbischof von Trier, 26.8.1474, ULRICH, Acten, Nr. 38, S. 23.

202 VAUGHAN, Charles, S. 320.

203 Friedrich III. an Johann, 27.6.1474 Augsburg, JANSSEN, Reichskorrespondenz, 2 Nr. 484, S. 349.

204 11.8.1474, UlRICH, Acten, Nr. 33, S. 19.

205 Auch Oswald van den Bergh erhielt die kaiserliche Aufforderung, sich mit 200 Bewaffneten am 3. bzw. 10.10.1474 zum Zug gegen Karl in Köln einzufinden: SCHILFGAARDE, Archief van Huis Bergh, 2, Nr. 266f., S. 63.

206 Karl an Johann, 11.8.1474 Lager vor Neuss, HStA Düsseldorf, Kleve-Mark, Beziehungen zu Geldern 30, Dijon ACO, Papiers Henri STEIN; Briefwechsel Nr. 2676. Der verlorene Brief Johanns an Karl, vor 11.8.1474: Briefwechsel Nr. 2675. 
la vouloir faire «, rufe er Johann ins Gedächtnis zurück, daß dieser wiederholt erklärt habe, Karl auch in einem Konflikt mit dem Kaiser persönlich dienen und nicht nur neutral bleiben zu wollen. Die Antwort an den Kaiser sei daher klar: In jedem Fall müsse Johann auf der Seite Burgunds stehen. Begründen "colorer" - könne Johann dies damit, daß er über seine Mutter aus dem Haus Burgund stamme und zudem neben der Blutsverwandtschaft "aliances especialles« zwischen ihnen bestünden. Mit drohendem Unterton erinnerte er Johann schließlich noch daran, daß die klevischen Länder von den burgundischen eingeschlossen seien, so daß auch der Kaiser einsehen müsse, daß Johann keine andere Wahl bleibe.

Das Verhältnis von Lehnsherrn zu Lehnsmann, Fürst zu Getreuem, das zwischen ihm und Johann von Kleve bestand, betonte Karl auch noch einmal in einem Schreiben vom 25. August. Er forderte Johann dringend auf, die Versorgung der Neusser und Kölner mit Lebensmitteln und anderen Gütern durch klevische Untertanen zu unterbinden, was er ihm als Blutsverwandter, wféal et vassal« und aufgrund der »loyaulté et fidélité que me devez« schuldig sei ${ }^{207}$.

Wie sein Vater zwanzig Jahre zuvor im Fall des Bistums Utrecht führte Karl dem Herzog von Kleve unverhüllt und herablassend seine Abhängigkeit von burgundischer Gunst vor Augen. Eine Allianz mit dem Haus Burgund brach in seinen Augen allemal Reichsrecht, das vor der schieren militärischen Übermacht ohnehin verblaßte. Selbst wenn Karl ein Bewußtsein für die reichsrechtlichen Probleme besessen haben sollte, die sich für Johann aus dem Bündnis ergaben, hielt er sie angesichts des eigenen, vermeintlich gewissen Erfolges und der Machtlosigkeit des Kaisers für zweitrangig. Die Erfahrungen von Trier hatten dem Herzog keinen Respekt gegenüber Person und Macht Friedrichs III. nahegelegt, und beleidigter Stolz angesichts der dort erfahrenen Düpierung tat ein übriges. Entscheidender noch für die Beurteilung der weiteren Politik Karls ist seine Fehleinschätzung des der Reichsverfassung inhärenten Beharrungsvermögens und der militärischen Stärke, die das Reich unter akuter Bedrohung aufzubringen vermochte. Das Reichsrecht, in der Form von Acht und Reichsaufgebot durch den Kaiser, glaubte Karl nach wie vor faktisch nicht berücksichtigen zu müssen, obwohl ihn die Abwehr fremder Herrschaftsansprüche durch die Kurfürsten in Trier hätten vorsichtig machen sollen ${ }^{208}$. Im Unterschied zu dem mitsamt seinen Herzögen in der Reichsacht stehenden Geldern sahen die Gegner Ruprechts und Karls das Reichsrecht auf ihrer Seite. Die Situation hatte sich in dieser Hinsicht in ihr Gegenteil verkehrt und ermöglichte so die Aufbietung des Reichsheeres.

Ebenso wie die Herzöge von Jülich-Berg befand sich Johann gegenüber dem Kaiser in einem Rechtfertigungsnotstand. Noch im April 1475 wandte er sich

${ }^{207}$ Karl an Johann, 25.8.1474 Lager vor Neuss, HStA Düsseldorf, Kleve-Mark, Beziehungen zu Geldern 30, Dijon ACO, Papiers Henri STEIN; Briefwechsel Nr. 2688.

208 Siehe unten S. 174-185. 
an Herzog Albrecht von Sachsen mit der Bitte um Fürsprache bei Friedrich III., da jede Handlung gegen Burgund für Kleve fatale Folgen hätte ${ }^{209}$. Mit eben dieser Argumentation hatten die Jülicher ihre Neutralität vor dem Kaiser in Köln verteidigt. Erst aus dem Juni 1475 allerdings ist die Absicht des Kaisers überliefert, auch dem Herzog von Kleve seine Lehen zu entziehen ${ }^{210}$. Es ist bezeichnend, daß von einem Prozeß, der dem gegen die Herzöge von Jülich-Berg vergleichbar war, nichts bekannt ist. Der Kaiser mag in pragmatischer Einschätzung der Machtverhältnisse am Niederrhein von der Aussichtslosigkeit eines derartigen Vorgehens gegen Kleve ausgegangen sein, das im Gegensatz zu Jülich-Berg unauflöslich an Burgund gekettet schien.

\section{b) Proviant und Kriegsmaterial}

Die meisten Briefe Karls an Johann aus Neuss enthielten Bitten um Verpflegung und Material, da Kleve als Versorgungsbasis für die burgundische Armee ideal gelegen war. Von Maastricht aus verlangte Karl am 23. Juli 1474 im Befehlston, mit der knappen Anrede »Beau Cousin«, Johann möge dafür sorgen, daß die Verproviantierung der burgundischen Armee vor Neuss so weit wie möglich aus den klevischen Landen erfolgen könne, die zu diesem Zweck wesentlich günstiger lägen als jene des Herzogs. Sollten sich die klevischen Untertanen weigern - eine Möglichkeit, die Karl hier immerhin bereits ins Auge faßte - seien Zwangsmaßnahmen zu ergreifen. Von Bezahlung ist nicht die Rede, auch wenn man im Licht der späteren Briefe davon ausgehen kann, daß sie erfolgte ${ }^{211}$. Am 28. Juli 1474 wandte sich Karl an Johann mit der Bitte um die Leihe von Kanonen mitsamt ihrem Personal. Johann leistete dem rasch Folge, denn bereits am 3 . August gab Karl an $\gg n o z$ très chiers et bons amis les cannoniers et autres conduisans la bombarde que nous envoie présentement nostre cousin le duc de Clèves« schriftlich Anweisungen für den Transport. Eine Woche später bedankte sich Karl bei Johann für die Lieferung der »bombarde«, die er sorgsam zu behandeln versprach ${ }^{212}$. Die weitere Vergrößerung

209 Johann an Herzog Albrecht, 20.4.1475 Kleve, PRIEBATSCH, Politische Correspondenz, 2, Nr. 100, S. 141.

${ }^{210}$ Herzog Wilhelm von Sachsen an Herzog Albrecht von Sachsen, Juni 1475, PRIEBATSCH, Politische Correspondenz, 2, Nr. 128, S. 163.

211 Karl an Johann, 23.7.1474 Maastricht, HStA Düsseldorf, Kleve-Mark, Beziehungen zu Geldern 30, Dijon ACO, Papiers Henri STEIN; Briefwechsel Nr. 2640. Schon am 25.7.1474 erhielt der Herold Brabant, Ernoulet de Louvain, $4 \mathrm{lb}$ 16s für den Transport des Briefes an Johann, Lille ADN B 2105/67 598.

212 Brief Karls an Johann vom 28.7.1474 aus dem Lager bei Erklentz, HStA Düsseldorf, Kleve-Mark, Beziehungen zu Geldern 30, Dijon ACO, Papiers Henri STEIN; Briefwechsel Nr. 2649; gekürzter Druck UlRICH, Acten, Nr. 22, S. 15f. Karl an die Transporteure der Kanone, 3.8.1474 Lager vor Neuss, HStA Düsseldorf, Kleve-Mark, Beziehungen zu Geldern 30, Dijon ACO, Papiers Henri STEN; Briefwechsel Nr. 2669. Karl an Johann, 11.8.1474 La- 
der schon beachtlichen Artillerie überforderte jedoch die logistischen Möglichkeiten der burgundischen Länder, denn bereits am 31. August mußte der Herzog sich wieder an Johann mit der Bitte um die Lieferung von Pulver wenden. Er habe um Neuss eine Artillerie aufgefahren "plus que l'en vit pièca affusté devant une seulle ville«, doch erhalte er aus Lille nicht das angeforderte Pulver. Johann solle ihm daher so viel Pulver wie möglich senden, das er bis zum kommenden Fest Allerheiligen in Kleve zurückgeben werde ${ }^{213}$.

Im März 1475 mußte Karl seine Bitte um Lebensmittel aus Kleve wiederholen, da ihm zugetragen worden war, daß der Kaiser sämtliche Versorgungswege zu Wasser sperren wollte. Johann solle seine Untertanen zu größten Anstrengungen anhalten, und dieses Mal kündigte Karl sogar angemessene Bezahlung und sicheres Geleit der Fuhrwerke ab Uerdingen an ${ }^{214}$. Sehr dringend bat er Johann noch einmal am 13. Juni des Jahres um Proviant ${ }^{215}$.

\section{c) Pferde}

Erste Schwierigkeiten mit den klevischen Untertanen ergaben sich im Mai 1475, als klevische Wirte die Herausgabe untergestellter burgundischer Pferde verweigerten, solange für den Unterhalt keine Barzahlung geleistet worden war. Folgt man Knebel, so hatten die Burgunder an die 2000 Pferde auf bergischem und klevischem Gebiet, in Holt und Dinslaken zur Versorgung zurückgelassen ${ }^{216}$. Die Wirte wollten Verschreibungen auf den Namen des burgundischen Einnehmers von Nijmegen nicht akzeptieren. Bereits vier Tage später verschärfte sich die Lage noch, als gemeldet wurde, daß die Klever die burgundischen Pferde sogar bereits verkauft hatten, da sie nicht nach ihren Wünschen entlohnt worden waren. Karl reagierte auf diese wassez chose estrange«

ger vor Neuss, HStA Düsseldorf, Kleve-Mark, Beziehungen zu Geldern 30, Dijon ACO, Papiers Henri STEIN; Briefwechsel Nr. 2676.

${ }^{213}$ Karl an Johann, 31.8.1474 Lager vor Neuss, HStA Düsseldorf, Kleve-Mark, Beziehungen zu Geldern 30, Dijon ACO, Papiers Henri STEIN; Briefwechsel Nr. 2695. Am selben Tag erhielt der Ritter und Rat Karls Bernard Velon $12 \mathrm{lb}$ für seine Reise zu Herzog Johann, um das Schreiben zu überbringen: Lille ADN B 2105/67 597. Der Brief ist identisch mit dem im Briefwechsel unter Nr. 2670 aufgefuihrten und falsch auf den 3. August datierten Schreiben Karls an Johann.

214 Brief Karls an Johann vom 28.3.1475 aus dem Lager vor Neuss, HStA Düsseldorf, Kleve-Mark, Beziehungen zu Geldern 30, Dijon ACO, Papiers Henri STEIN; Briefwechsel Nr. 3002.

${ }^{215} \mathrm{Karl}$ an Johann, 13.6.1475 Lager vor Gemelingen, HStA Düsseldorf, Kleve-Mark, Beziehungen zu Geldern 30, Dijon ACO, Papiers Henri STEIN; Briefwechsel Nr. 3115.

216 Knebel, Diarium, Basler Chroniken, 2, S. 135, 168. Eine gewisse Renitenz klevischer Untertanen auch gegen die burgundische Herrschaft in Geldern durch Verweigerung des Lehnseides ist bereits für 1474 überliefert: PARAVICINI, Kleve, Geldern und Burgund, S. 72. 
mit der wiederholten Bitte um die Intervention Herzog Johanns bei seinen Untertanen ${ }^{217}$.

Johann aber konnte oder wollte in dieser Angelegenheit die burgundischen Interessen nicht mit Nachdruck durchsetzen, obwohl Karl am 11. Mai sogar seinen Sekretär Thibault Barradot an Johann absandte, um auf der Herausgabe der Pferde zu bestehen. Barradot erhielt den Auftrag, in der dringendsten Weise die Auslieferung zu verlangen und zu versichern, daß die Wirte keinerlei Verluste erleiden würden. Angesichts des herannahenden Reichsheers, des abgelaufenen Waffenstillstands mit Frankreich und der lothringischen Kriegserklärung konnte Karl seine Unruhe nicht verbergen. Barradot sollte Herzog Johann deutlich machen, daß seine Untertanen den Burgundern in der gegenwärtigen Lage keinen größeren Schaden zufügen könnten als durch die Rückhaltung der Pferde ${ }^{218}$. Daß die Sympathien der klevischen Untertanen nicht den Allianzen ihres Landesfürsten folgten, hatte sich zudem schon im August 1474 gezeigt, als Karl um die Unterbindung von Lebensmittellieferungen nach Köln bitten mußte ${ }^{219}$. Trotzdem wurden die Klever von den Kölnern als Feinde betrachtet, an denen man sich bei Gelegenheit schadlos hielt ${ }^{220}$.

\section{d) Deserteure und Waffenhilfe}

Die Anzahl der Desertionen aus dem burgundischen Heer stieg im Lauf der Belagerung beständig 221. Am 2. Dezember 1474 sah sich Karl gezwungen, Herzog Johann um Hilfe zu bitten: Es sei ihm zu Ohren gekommen, daß einige der burgundischen Kriegsleute die Flucht aus dem Lager vorbereiteten und dabei durch klevisches Gebiet ziehen wollten. Johann möge die Deserteure fangen, festsetzen und sie eher töten als entkommen lassen ${ }^{222}$. Zu einem ähnlichen Schreiben sah sich Karl erneut im März 1475 veranlaßt, als er Johann

217 Karl an Johann, 4.5.1475 Lager vor Neuss; Briefwechsel Nr. 3075. 8.5.1475 Lager vor Neuss; Briefwechsel Nr. 3077. Und 14.5.1475 Lager vor Neuss; Briefwechsel 3087. Alle HStA Düsseldorf, Kleve-Mark, Beziehungen zu Geldem 30 und 31, Dijon ACO, Papiers Henri STEIN. Vgl. Briefwechsel Nr. 3074.

${ }^{218}$ Karl an Barradot, 11.5.1475 Lager vor Neuss, HStA Düsseldorf, Kleve-Mark, Beziehungen zu Geldern 30, Dijon ACO, Papiers Henri STEIN; Briefwechsel Nr. 3085. Das gleichzeitige, von Barradot überbrachte Schreiben Karls an Johann ist nicht überliefert; Briefwechsel Nr. 3084.

${ }^{219} \mathrm{Karl}$ an Johann, 25.8.1474 Lager vor Neuss, HStA Düsseldorf, Kleve-Mark, Beziehungen zu Geldern 30, Dijon ACO, Papiers Henri STEN, Briefwechsel Nr. 2688.

${ }^{220}$ Karl an Johann, 25.10.1474 Lager vor Neuss, HStA Düsseldorf, Kleve-Mark, Beziehungen zu Geldern 34, Dijon ACO, Papiers Henri STEIN; Briefwechsel Nr. 2759.

221 Einige flohen, meist wegen ausbleibender Soldzahlung, in Mönchskleidung und gelangten teilweise bis Basel: Knebel, Diarium, Basler Chroniken, 2, S. 144f., 213.

$222 \mathrm{Karl}$ an Johann, 2.12.1474 Lager vor Neuss, HStA Düsseldorf, Kleve-Mark, Beziehungen zu Geldern 34, Dijon ACO, Papiers Henri STEn; Briefwechsel Nr. 2813. 
aufforderte, besonders den Amtsträgern in der Stadt Wesel zu befehlen, Deserteure aus dem burgundischen Lager abzufangen ${ }^{223}$.

Das Auslaufen des Waffenstillstandes von Compiègne zwischen Karl und Ludwig XI. am 1. Mai 1475 brachte den noch immer vor Neuss liegenden Herzog in weitere Bedrängnis. Der Kaiser rückte seit dem 6. Mai, wenn auch langsam, gemeinsam mit dem Reichsheer gegen Neuss, Ludwig XI. ließ Angriffe im burgundisch-französischen Grenzgebiet vortragen. Trotz seiner bereits im März dem Kaiser unterbreiteten Verhandlungsangebote ${ }^{224}$ mußte Karl mit einem Angriff des Reichsheers rechnen. In dieser Situation ließ er durch Thibault Barradot ein auf den 10. Mai 1475 datiertes Hilfeersuchen an Herzog Johann überbringen 225 . In dem Schreiben erwähnt er Vorgespräche, die bereits von seinem écuier de chambre und Vertrauten Simon de Quingey mit Johann geführt worden waren. Der Brief ist eine kuriose Mischung aus der Beschwörung eigener Stärke und der dringend vorgetragenen Bitte um klevische Hilfe. Zwar könne die burgundische Armee, so Karl, jederzeit alle Feinde allein schlagen, doch habe er die Herren aus den Grenzregionen, die nun von Ludwig XI. angegriffen würden, zur Verteidigung in die Heimat schicken müssen. Er erwarte bis Ende Mai die Landung einer englischen Armee, die gegen Frankreich ziehen werde, und habe deshalb diesem Heer seine englischen Kontingente zum Empfang entgegengesandt. Außerdem sei es nie seine Gewohnheit gewesen, seine Freunde und Alliierten um Hilfe anzugehen. Trotzdem gestand er jetzt ein, da $B$ er Herzog Johann für die Stellung eines klevischen Kontingents unter der Führung Johanns II. sehr dankbar wäre. Er wollte ihn für alle Kosten entschädigen, mußte ihn nur für den Moment doch bitten, die anfallenden Ausgaben selbst zu tragen.

Charakteristisch ist das Insistieren auf der eigenen Macht zur Wahrung von Ehre und Selbstbild, doch genügt der Vergleich mit dem hochfahrenden Ton des Schreibens vom August 1474, um die Verschlechterung der burgundischen Lage auch in Karls eigener Einschätzung zu erfassen. Am 9. Mai, also einen Tag vor Abfassung des Briefes an Johann, hatte der Herold Lothringen Karl den Absagebrief Herzog Renés überbracht. Luxemburg war unmittelbar bedroht226. Zwar ging Karl auf diese neue Herausforderung zunächst nicht ein,

${ }^{223}$ Karl an Johann, 18.3.1475 Lager vor Neuss, HStA Düsseldorf, Kleve-Mark, Beziehungen zu Geldern 31, Dijon ACO, Papiers Henri STEIN; Briefwechsel Nr. 2994.

224 VaUghaN, Charles, S. 342f.

${ }^{225}$ Karl an Johann, 10.5.1475 Lager vor Neuss, HStA Düsseldorf, Kleve-Mark, Beziehungen zu Geldern 30, Dijon ACO, Papiers Henri STEIN; Briefwechsel Nr. 3082; gekürzt gedruckt in Ulrich, Acten, Nr. 150, S. 107f. Vgl. J. LANGE, Pulchra Nussia. Die Belagerung der Stadt Neuss durch Herzog Karl den Kühnen von Burgund 1474-1475, in: Neuss, Burgund und das Reich, Neuss 1975, S. 9-190, hier S. 133.

${ }^{226}$ Nach dem Bericht in: Paris BNF Ms fr 6981 f.115r-116r empfing Karl den Herold am 9.5.1475 prachtvoll und beschenkte ihn reich. Englische Übersetzung in VAUGHAN, Charles, S. $308 f$. 
doch dürfte ihn die Kriegserklärung des Lothringers angesichts der noch nicht gelösten Neusser Frage zusätzlich beunruhigt haben.

Nach dem Abzug der burgundischen Armee von Neuss verlor die Korrespondenz zwischen Karl und Johann deutlich an Intensität. Von 1475 sind noch die Abschriften zweier weiterer Schreiben Karls erhalten, in denen er um zollfreien Durchgang für Rheinwein durch klevisches Gebiet bat, und zur Kapitelsitzung des Goldenen Vlieses nach Maastricht am 2. Mai des folgenden Jahres und Nennung möglicher neuer Mitglieder des Ordens einlud227. Für das Jahr 1476 sind vier Schreiben Karls an Johann und eines des Klevers an Karl überliefert. Das erste ist die bereits erwähnte Überschreibung der Pension des Vaters auf den Sohn vom 31. Januar 1476. Die anderen datieren beide vom 14. November des Jahres und enthalten die Bitte um freies und sicheres Geleit für den Bischof von Metz als Gesandtem Karls und Protonotar Georg Heßler als kaiserlichem Bevollmächtigtem, die auf dem Weg zu Maria nach Gent waren, um ihr Einverständnis zur Hochzeit mit Maximilian einzuholen. Im zweiten Schreiben dieses Datums verwandte sich Karl bei Herzog Johann für Heßler, der sich über Dekan und Kapitel von Xanten beklagt hatte, die ihm die Einkünfte der Stiftspropstei verweigerten ${ }^{228}$.

Das Hauptproblem im Verhältnis Karls zu Johann bestand in ihrer formalen Ranggleichheit als Reichsfürsten, die im Alltag aber vor der Übermacht des Burgunders verblaßte. Dieses Wissen spiegelt sich im Formular der Briefe wieder, wenn Johann Karl mit stres hault et tres puissant prince, mon tres chier et tres honnouré seigneur et cousin« ansprach, während Karl sich manchmal nur zu einem "Beau cousin « durchringen konnte, meist aber die Formel »Tres chier et tres amé cousin« verwandte ${ }^{229}$. Karl sah sich als Herr eines, wenn auch vornehmen, Vasalls. Als solcher hatte Johann militärische Hilfe zu leisten, während der Belagerung von Neuss den Nachschub zu sichern, aber keinesfalls eigenständige politische Vorstellungen zu entwickeln. Das Verdikt Vaughans von der klevischen Marionette muß also dahingehend modifiziert werden, daß es sich jedenfalls unter der Regierung Karls um eine Marionette wider Willen handelte. Und so freundschaftlich die Beziehungen

227 Karl an Johann, 24.9.1475 Schloß Bassonpierre, (Rheinwein): HStA Düsseldorf, KleveMark, Beziehungen zu Geldern 34, Dijon ACO, Papiers Henri STEn; u. 11.12.1475 Lager vor Nancy, HStA Düsseldorf, Kleve-Mark, Familien-Sachen Nr. 1, Dijon ACO, Papiers Henri STEIN; Briefwechsel Nr. 3244 u. 3298. Antwort Johanns, nach 11.12.1475, in: PARAVICINI, Kleve, Geldern und Burgund, S. 56 Anm. 32. Johann schlug folgende neue Ordensritter vor: Rudolf von Baden-Hachberg Markgraf von Rötteln, den Grafen von Vernenborch (=Virneburg?), Heinrich van Horne Herrn von Perwez, Johann von Glymes Herrn von Bergen-op-Zoom, Johann von Luxemburg, Adrian van Borselen, Claude de Toulongeon, Jean du Bos Herrn von Fiennes.

228 Karl an Johann, 14.11.1476 Lager vor Nancy, HStA Düsseldorf, Kleve-Mark, Beziehungen zu Geldern 34, Dijon ACO, Papiers Henri STEIN; Briefwechsel Nr. 3509.

229 PARAVICINI, Kleve, Geldern und Burgund, S. 74 Anm. 157. 
während der Herrschaft Philipps des Guten auch waren, bereits damals kündigte sich die unbedingte Unterordnung klevischer Interessen unter die burgundischen an. Unter Karl wurde das gewachsene Abhängigkeitsverhältnis Kleve beinahe zum Verhängnis, wobei sich Johann noch gezwungen sah, dem Burgunder bei der Einkreisung der eigenen Lande behilflich zu sein.

\section{Jülich-Berg}

\subsection{Familienbeziehungen und Vorgeschichte}

Auch mit dem Haus Berg traten die Herzöge von Burgund bereits zu Anfang des 15. Jahrhunderts in engere Beziehungen, ohne daß es zu vergleichbar engen Bindungen wie mit Kleve oder Geldern gekommen wäre. Es wurden keine Ehen zwischen den Fürstenhäusern geschlossen, und die Herzöge von Berg wählten ihre Gatten ausschließlich aus deutschen Familien.

Im Zuge der Auseinandersetzung mit dem Haus Egmond wurde Herzog Adolf von Berg 1425 von Kaiser Sigmund mit Jülich und Geldern belehnt, doch konnte er nur Jülich gegen den mit Burgund verbündeten Arnold von Egmond behaupten. Wenige Jahre später aber, 1427, schloß Herzog Adolf das erste Bündnis mit Philipp dem Guten und Bischof Rudolf von Utrecht gegen die Ansprüche Arnolds von Geldern auf Jülich-Berg. Diese Allianz wurde 1431 erneuert ${ }^{230}$. Adolf versprach nun gegen die Belehnung mit den von Brabant rührenden jülichschen Besitzungen, Philipp im Kampf gegen die Lütticher und bei der Behauptung seiner Ansprüche auf Luxemburg und die Landvogtei im Elsaß behilflich zu sein, wie ein $» L e h n s m a n n$ seinem Herrn ${ }^{231}$. Arnold von Geldern verband sich dagegen mit Herzog Adolf von Kleve, dessen Sohn Johann allerdings schon 1445 die Fronten wechselte und ebenfalls auf die Seite Gerhards, des neuen Herzogs von Jülich-Berg, trat.

1445 gründete Herzog Gerhard den Hubertusorden aus Anlaß des Sieges über Arnold von Geldern in der Schlacht von Linnich. Der Orden hatte seinen Sitz in der Christina-Kirche zu Nideggen und kann, trotz einiger Parallelen zum Goldenen Vlies, als Betonung jülichscher Eigenständigkeit gesehen werden, da die Jülicher nicht in den burgundischen Orden aufgenommen worden waren ${ }^{232}$. Doch auch das jülichsche Herzogspaar konnte sich der Anziehung des burgundischen Hofes nicht entziehen und sandte Jungherzog Wilhelm

${ }^{230}$ LACOMBLET, Rheinisches Urkundenbuch, 4, 1, S. 9 f.

231 LACOMBLET, Rheinisches Urkundenbuch, 4, 1, Nr. 204, S. 233-235; JAPPE ALBERTS, Geschiedenis, S. 101; PETR, Nordwestdeutschland, S. 86.

232 KRUSE, PARAVICINI, RANFT, Ritterorden und Adelsgesellschaften, S. 353-355. 
1469 dorthin zur Erziehung. Man wachte eifersüchtig darüber, daß ihm die gleichen Ehren zuteil wurden wie Johann II. von Kleve, war aber entsetzt über die finanziellen Belastungen, die der Aufenthalt mit sich brachte ${ }^{233}$. Vielleicht auf entsprechende Andeutungen hin hatte sich Karl zur Zahlung einer Pension an Wilhelm bereit gefunden, die für 1470 belegt ist. Wilhelm erhielt 3000 francs im Jahr ${ }^{234}$, also ebensoviel wie Johann II. von Kleve seit Oktober 1470. Auch hier mag auf strenge Parität geachtet worden sein. Wilhelm kehrte spätestens vor Beginn der Belagerung von Neuss, wenn nicht schon vor der Eroberung Gelderns, an den elterlichen Hof zurück. Auch zu den unmittelbaren Vertrauten Karls pflegte man enge Beziehungen, wie an der Patenschaft Jungherzog Wilhelms für ein im Januar 1476 geborenes Kind des Statthalters von Geldern, Guy de Brimeu, sichtbar wird ${ }^{235}$. In der von Herzog Wilhelm erlassenen Hofordnung von 1479 zeigt sich schließlich, daß der burgundische Hof trotz des vergleichsweise kühlen gegenseitigen Verhältnisses Vorbildfunktion auch für Jülich besaß236.

Nach dem Tode Philipps des Guten brachten ab 1468 und 1469 der Erbfolgestreit um die Grafschaft Blankenheim und der Prozeß Herzog Gerhards und Herzogin Sophies gegen Anton von Palant um die Herrschaft Monschau ${ }^{237}$ vor dem Gericht des Herzogs von Burgund die Fürstenhäuser wieder in unmittelbaren Kontakt. Im Konflikt um Blankenheim griff Herzog Karl vermittelnd ein und konnte im Mai 1469 in Maastricht eine Einigung zwischen den Ansprüchen der Marie de Croÿ, der Witwe des verstorbenen Grafen von Blankenheim und den Manderscheider Grafen, die seit kurzem von den Herzögen von Jülich unterstützt wurden, herbeiführen ${ }^{238}$. Im Kampf um Monschau hatte

233 Severin CORSTEN, Die Residenzen des Herzogtums Jülich, in: Territorium und Residenz am Niederrhein, S. 97-117, hier S. 110; Brigitte KASTEN, Die Hofhaltung in Jülich und Berg im 15. und beginnenden 16. Jahrhundert, in: ebd., S. 171-187, hier S. 171f., wieder in: Wilhelm G. BUSSE (Hg.), Burg und Schloss als Lebensorte in Mittelalter und Renaissance, Düsseldorf 1995, S. 35-82, mit Abdruck der Hofordnungen von 1479 und 1480 S. 58-82; Anton GAIL, Die burgundische Ausdehnungspolitik und das Herzogtum Jülich im 14. und 15. Jahrhundert, in: Aus Mittelalter und Neuzeit, Festschrift Gerhard Kallen, Bonn 1957, S. 145-153.

234 Lille ADN B 2079, o. Fol.

235 Der Jungherzog ließ dazu in Köln Silbergeschirr für 200 fl.rh. kaufen, PARAVICINI, Brimeu, S. 438 m. Anm. 162.

236 KASTEN, Die Hofhaltung in Jülich und Berg, S. 173f.

237 Zur Auseinandersetzung um Monschau siehe insgesamt Werner PARAVICINI, Rasse de la Rivière, Antoine de Palant et la place de Montjoie, in: Annuaire d'Histoire Liégeoise 39/15 (1974) S. 130-135. Paravicini, Brimeu, S. 257f. Anm. 38, S. 715; W. STÜWER, Jülich, Limburg, Schönforst und Burgund im Kampf um Montjoie, in: H. PRÜMMER (Hg.), Das Monschauer Land historisch und geographisch gesehen, Monschau 1955, S. 58-75.

238 Peter NEU, Geschichte und Struktur der Eifelterritorien des Hauses Manderscheid, Bonn 1972, S. 56f. In der sich an den Konflikt um das Blankenheimer Erbe anschließenden Fehde zwischen den Manderscheidern und den Herzögen von Jülich waren auch die Herren von Arenberg verwickelt, die sich seit den 1460er Jahren eng an Burgund angeschlossen hatten. 
Anton von Palant zusammen mit seinem Vetter Friedrich von Wittem die Burg besetzt und gegen eine jülichsche Belagerung verteidigt, doch wurden die kriegerischen Handlungen Ende September 1469 auf die Initiative Karls hin eingestellt und der Streit vor den burgundischen herzoglichen Rat gebracht. Die entsandten jülichschen Räte entfalteten bis in den Dezember 1469 die gewöhnlichen Aktivitäten zur Beeinflussung der wichtigen Mitglieder des Hofes. Guillaume Bisches erhielt eine bedeutende Zuwendung, außerdem bat man den am Hof anwesenden Herzog Johann von Kleve, Johann von Sechtingen und Bastard Anton um Unterstützung der jülichschen Position ${ }^{239}$. Anton von Palant verweigerte zunächst die Übergabe der Burg an Guy de Brimeu als Beauftragten Herzog Karls, mußte Monschau 1472 aber dem Herzog von Jülich übereignen, der Herzog Karl dafür huldigte. Trotz ihres Widerstandes verloren weder Anton von Palant noch Friedrich von Wittem die Gnade Karls, sondern dienten ihm weiter in militärischen Ämtern.

Noch während die Monschauer Affaire in Brüssel anhängig war, wurde 1470 mit der Entsendung Jungherzog Wilhelms an den Hof Karls eine permanente Vertretung jülichscher Interessen geschaffen ${ }^{240}$. Im November 1470 nahm diese Annäherung konkrete Formen an im Abschluß eines neuen Bündnisses zwischen den Herzögen Karl und Gerhard. In der in Düsseldorf auf den 6. November 1470 datierten jülichschen Urkunde versprach Herzog Gerhard in Erneuerung alter Verträge, dem Herzog von Burgund gegen jedermann mit 400 Mann zu dienen; in Brabant, Limburg, Namur, Hennegau und Luxemburg mit 1000 Mann. Ausgenommen waren von dieser Verpflichtung der Kaiser, die rheinischen Erzbischöfe, die Bischöfe von Metz und Münster, der Pfalzgraf, Herzog Johann von Kleve und die Stadt Köln ${ }^{241}$. Karl bestätigte das Bündnis am 8. Dezember in Hesdin, also zu eben der Zeit, als er Adolf von Geldern bereits mehr oder weniger gewaltsam zum Nachgeben gegenüber den Forderungen seines Vaters gezwungen hatte und dessen Befreiung vorbereitet wurde. Karl verpflichtete sich gleichfalls und mit denselben Ausnahmen, Gerhard mit 400 Mann zu Hilfe zu kommen ${ }^{242}$. Am selben Tag gestand Karl Herzog Gerhard außerdem zu, daß er während der Dauer seines Waffenstillstands mit Geldern gegen dieses nicht aufgeboten werde ${ }^{243}$. Gleichzeitig erinnerte

Als Feinde der Manderscheider traten die Arenberger trotz ihrer vielfältigen Bindungen an den Herzog von Burgund auf die Seite der Jülicher, Peter NEU, Die Arenberger und das Arenberger Land, 1, Koblenz 1989, S. 89-91, 117-120.

${ }^{239}$ STÜWER, Jülich, Limburg, Schönforst und Burgund, S. 67f. Anwesenheit der jülichschen Gesandten bei Hof: GODEFROY, Itinerar, Oktober bis Dezember 1469.

240 STÜWER, Jülich, Limburg, Schönforst und Burgund, S. 67, sieht die Entsendung des Jungherzogs in direktem Zusammenhang mit dem Prozeß um Monschau.

241 Lille ADN B 335/16 194.

242 Düsseldorf HStA Jülich-Berg I Nr. 1173 nach GRÜNEISEN RTA-Material. Vgl. VAUGHAN, Charles, S. 241, ohne Kenntnis der jülichschen Ausfertigung vom November.

${ }^{243}$ Düsseldorf HStA, Jülich-Berg I Nr. 1174, nach GRÜNEISEN RTA-Material. 
sich Jülich angesichts der Eskalation der geldrischen Krise seiner Ansprüche auf Geldern. Herzogin Sophie sandte ihren auf Burgund spezialisierten Rat Meister Wyger, Propst von Kerpen, im Dezember nach Hesdin, um dort gemeinsam mit Jungherzog Wilhelm mithilfe einer Denkschrift das jülichsche Erbrecht auf Geldern darzulegen ${ }^{244}$.

\subsection{Die Eroberung Gelderns}

Der zeitliche Ablauf der burgundisch-jülichschen Verhandlungen zeigt, daß Karl dem Erwerb der jülichschen Rechte auf Geldern nur vergleichsweise geringe juristische Bedeutung beimaß. Der Feldzug gegen Geldern begann am 10. Juni 1473; am 19. Juni schrieb Karl an Johann von Kleve, daß er von Jülich Hilfstruppen in Form von 200 Pionieren erhalten habe ${ }^{245}$. Erst auf den 20. Juni datieren die beiderseitigen Erklärungen zur Zession der Rechte des Hauses Jülich auf Geldern und Zutphen an Karl gegen 80000 fl.rh. Die Städte Löwen, Brüssel, Antwerpen, 's-Hertogenbosch und Mecheln mußten für die Summe bürgen. Die Gültigkeit der Transaktion wurde unter den Vorbehalt der kaiserlichen Zustimmung gestellt. Diese Zustimmung erfolgte im Sommer 1473, als der Sekretär Nicolas Ruter sich von August bis September des Jahres zu Herzogin Sophie begab, um von ihr Abschriften der kaiserlichen Briefe zu erhalten ${ }^{246}$.

Der Einmarsch in Geldern war also bereits in vollem Gang, bevor die Verhandlungen mit Jülich zum Abschluß kamen und Karl sich nach dieser Seite rechtlich abgesichert hatte. Nach der Übertragung Gelderns durch Arnold war die Zustimmung Jülichs zweitrangig, und die Zahlung der 80000 fl.rh. wurde nicht allzu zügig in Angriff genommen. Erst im Dezember 1474 erging der Befehl Karls an seine Domänenschatzmeister, die Anweisung der 80000 fl.rh. an den Herzog von Jülich so rasch wie möglich zu prüfen und zurückzusenden. Die Finanzierung sollte über die Nijmegen und Arnheim auferlegten Reparationszahlungen erfolgen, doch diese Städte erklärten sich für zahlungsunfähig. Die Jülicher mußten daher weiter auf ihr Geld warten und sahen sich im Juni 1475 zu einer Mahnung an Karl mit dem Hinweis auf die Belastung ihrer

244 Denkschrift in: Lille ADN B 1427/15 754; Absage Herzogin Sophies betreffend den zuerst angesetzten Tag von Brüssel, 22.12.1470 Düsseldorf, Düsseldorf HStA Jülich-Berg I Nr. 143, nach GRÜNEISEN RTA-Material.

245 PARAVICINI, Kleve, Geldern und Burgund, S. 61; Karl an Johann, Lager bei Venlo, 19.6.1473, ebd., S. 77f. Nr. 3.

246 Ausfertigung Jülich: Nideggen, 20.6.1473: Lille ADN B 18842/29 459. Die burgundischen Urkunden wurden am selben Tag in Utrecht ausgestellt, LACOMBLET, Rheinisches Urkundenbuch, 4, 1, Nr. 367, S. 460-462. Am folgenden Tag gewährte Karl Jülich in einer eigenen Abmachung seinen Schutz und regelte den Verkehr zwischen den Untertanen, Utrecht, 21.6.1473: ebd. Mission Ruters: Lille ADN B 2115 f.103r-v. 
Lande durch den Neusser Krieg veranlaßt, ohne aber eine Antwort zu erhalten. Dies ist umso erstaunlicher, als Karl im Mai seinem Gouverneur von Nijmegen, Hermann von Bronckhorst-Batenburg, dringend befohlen hatte, die Städte zur Zahlung zu zwingen und dann sofort das Geld an Herzog Gerhard weiterzuleiten, "en consideration des bons termes qu'il nous tient à l'encontre de l'Empereur«. Schließlich sandten die Herzöge Propst Wyger zu Karl, um nähere Auskunft zu erhalten, woran sich weitere Korrespondenz unter anderem mit Guy de Brimeu anschlo ${ }^{247}$. Noch 1477 standen aber beinahe 50000 fl.rh., also mehr als die Hälfte der Kaufsumme, aus ${ }^{248}$.

Im weiteren Verlauf der Eroberung Gelderns drängte Karl die Jülicher eher nebenbei in die Rolle eines abhängigen Territoriums, dessen Integrität es nicht allzu peinlich zu beachten galt: Venloer Geiseln waren in die jülichschen Orte Bracht und Brüggen, letzteres jülichscher Pfandbesitz des Grafen von Moers, geführt worden. Später wurden Venloer Bürger, die in Brüggen ansässig waren, von burgundischen Amtleuten zur Beteiligung an der von Venlo zu zahlenden Kriegsentschädigung gezwungen, ebenso wie die Herrschaften BornSittard-Susteren und Brüggen ${ }^{249}$. Noch im August 1474 wurde über die Entschädigung jülichscher Untertanen für die Verluste verhandelt, die sie während des geldrischen Krieges erlitten hatten ${ }^{250}$. Ähnlich wie in Kleve empfand man sich daher auch in Jülich-Berg als burgundisch wider Willen, wie es von einem Rat Herzog Gerhard hieß: "...der doch seines herrn halb auch burgundisch ist, aber im hertzen nit.«251.

\subsection{Die Belagerung von Neuss}

In noch wesentlich größere Konflikte als der Herzog von Kleve gerieten die Herzöge von Jülich-Berg während des Kölner Stiftskrieges. Als Reichsfürsten mit traditionell guten Beziehungen zur Stadt Köln einerseits, als relativ

${ }^{247}$ Karl an die Domänenschatzmeister, 10.12.1474 Neuss: Lille ADN B 17 713. Die Herzöge von Jülich-Berg an Karl, 18.6.1475 Burg, Düsseldorf HStA, Jülich-Berg, I Nr. 255, f.36r, nach GRUNEISEN RTA-Material; Briefwechsel Nr. 3130. Karl an Hermann von BronckhorstBatenburg, 9.5.1475 Lager vor Neuss, HStA Düsseldorf, Kleve-Mark, Beziehungen zu Geldern 31, Dijon ACO, Papiers Henri STEIN; Briefwechsel Nr. 3078. Die Herzöge von JülichBerg an ihre Räte in Düsseldorf, 28.6.1475 Burg, Düsseldorf HStA, Jülich-Berg, I Nr. 255, f.38r, nach GRÜNEISEN RTA-Material.

248 PARAVICINI, Brimeu, S. 349 m. Anm.433.

249 JAPPE ALBERTS, De Eerste Bourgondische Bezetting van Gelre, S. 55f.; PARAVICINI, Brimeu, S. 388f. m. S. 269 Anm. 72a.

${ }^{250}$ Die Herzöge von Jülich-Berg an Präsident und Rat des Herzogs von Burgund in Geldern, 14.8.1474, Düsseldorf HStA Jülich-Berg I, Nr. 320 f.18r, nach GRÜNEISEN RTA-Material, Regest in: UlRICH, Acten, Nr. 34, S. 19. Vgl. auch ebd., Nr. 35.

251 Schreiben eines Unbekannten, 18.9.1473 Udenheim: JANSSEN, Reichskorrespondenz, 2, Nr. 459, S. 302. 
schwache Verbündete des Herzogs von Burgund andererseits mußten sie sich in diesem Konflikt auf eine äußerst prekäre Neutralität zurückziehen ${ }^{252}$.

Als sich im Mai 1474 die burgundische Bedrohung immer deutlicher abzeichnete, erbat die Stadt Köln von den Herzögen eine Stellungnahme hinsichtlich der Haltung, die sie im Fall eines Angriffs durch Karl einzunehmen gedächten. Die in Köln erschienenen jülichschen Räte schilderten die Reaktion der Herzöge in bewegter Weise, beide hätten geschworen, die Stadt mit aller Macht zu unterstützen. Sie wollten sich bei Karl um eine gütliche Beilegung bemühen und wenn dies nicht helfe, sogar militärische Hilfe gegen den Burgunder stellen. Sie verwiesen darauf, da $B$ in ihrem Bündnis mit Karl die Stadt Köln ausdrücklich ausgenommen sei. Noch im Oktober war ein Mainzer Domherr der Ansicht, die Herzöge von Jülich würden sich einem vom Kaiser geführten Reichsheer gegen den Burgunder anschließen ${ }^{253}$. Die Herzöge mögen gehofft haben, daß sich in der Kölner Frage doch noch eine gütliche Einigung finden lassen würde und unterschätzten sicherlich die Entschlossenheit Karls, ihr Land ganz den Bedürfnissen seiner Armee dienstbar zu machen.

Die kölnische Bitte um Hilfe ließ nach der deutlichen Parteinahme vom Mai nicht lange auf sich warten. Am 29. und 30. Juli bat Köln um die Stellung von 100 Mann und 30 Wagen und warnte vor einem bevorstehenden Durchzug der Burgunder ${ }^{254}$. Letzteres kann für die Herzöge keine Neuigkeit mehr gewesen sein, da burgundischerseits am 27. und am 31. Juli Briefe an Gerhard und Wilhelm ergingen, in denen Karl ihnen Nachrichten von der Belagerung übermittelte und sie darum bat, in ihren Landen für günstige Konditionen zur Verproviantierung des Heeres zu sorgen. Köln teilten die Herzöge darauf mit, sie hätten die Bitte Karls abschlägig beschieden, da ihre Untertanen ohnehin bereits sehr unter den burgundischen Truppen gelitten hätten ${ }^{255}$. Der entsprechende Brief an Herzog Karl ist nicht überliefert, ebensowenig die Antwort Karls darauf. Es kann vermutet werden, daß dem Burgunder gegenüber die Ablehnung seines Ansinnens gemäßigter formuliert wurde, um allzu heftige Reaktionen zu vermeiden. Die erbetene Hilfe an die Kölner wurde offenbar ebensowenig geleistet.

252 Vgl. dazu die Bemerkung Knebels, Diarium, Basler Chroniken, 2, S. 212: " ... dux et filius ejus dominus comes Juliacensis neutralizantes ob metum ducis Burgundie et formidando eciam civitatem Coloniensem ob confinitatem et multa beneficia prestita ......

${ }^{253}$ Die jülichschen Räte wurden am 6.5.1474 in Köln empfangen, Beschlüsse des Rates der Stadt Köln, 1, Nr. 39, S. $518 f$. Hinzu kam, daß die Herzöge von Jülich-Berg Außenedelbürger der Stadt waren, H. J. DOMSTA, Die Kölner Außenbürger. Untersuchungen zur Politik und Verfassung der Stadt Köln von der Mitte des 15. bis zur Mitte des 16. Jahrhunderts, Bonn 1973, S. 33f., S. 162. Knebel, Diarium, Basler Chroniken, 2, S. $136 f$.

254 UlRICH, Acten, Nr. 23, S. 16, Nr. 25, S. $16 \mathrm{f}$.

255 Boten vom 27.7.1474 und 31.7.1474: Lille ADN B 2105/67 598; der in Briefwechsel Nr. 2666 »1474 vor Aug.1.« genannte Brief wird mit dem am 31.7.1474 abgefertigten identisch sein, der die Bitte um Versorgungsgüter für die Armee enthielt. Die Herzöge von Jülich-Berg an Köln, 1.8.1474 Burg: UlRICH, Acten, Nr. 28, S. 17. 
Am 25. August forderte Karl die Herzöge ebenso wie Johann von Kleve auf, in ihren Landen jede Zufuhr von Lebensmitteln und anderen Gütern nach Köln zu untersagen ${ }^{256}$. Die jülich-bergischen Untertanen werden sich wie die Klever und auch einige Kölner die lukrativen Kriegsgeschäfte nicht haben entgehen lassen ${ }^{257}$. Von kaiserlicher Seite erging im Januar und Februar 1475 der entgegengesetzte Befehl, keine Lieferungen an das burgundische Heer zuzulassen, worüber es zu Anfang des Jahres zwischen kölnischen Söldnern und jülichschen Amtleuten zu handgreiflichen Auseinandersetzungen gekommen war. Die Jülicher hatten offenbar nach der Erneuerung des Bündnisses mit Karl Anweisung, sich den burgundischen Wünschen nach Verproviantierung zu fügen $^{258}$. Zu noch weitergehenden Schritten waren die Herzöge gezwungen, als sich kölnische Truppen "auf den Steinen« gegenüber von Neuss auf jülichschem Gebiet festsetzten. In einem anscheinend sehr unfreundlichen Schreiben befahl Karl den Herzögen, diesen Zustand sofort zu beenden, andernfalls werde er Jülich besetzen. Die Herzöge sahen keinen anderen Ausweg, als sich schriftlich an die Kölner zu wenden und sie um den Abzug zu bitten. Außerdem sollten sie beim Kaiser um Verständnis für diese Maßnahmen werben. Die Hilf- und Ausweglosigkeit der Jülicher ist hier mit Händen zu greifen. Natürlich zogen die Kölner nicht ab, sondern sandten den jülichschen Brief an den Kaiser weiter, der sich äußerst befremdet zeigte und ein entsprechendes Schreiben an die Herzöge ankündigte ${ }^{259}$.

Seit dem Sommer 1474 trugen sich die Herzöge, ebenso wie Johann von Kleve, mit dem Gedanken einer Vermittlung zwischen den Kriegsparteien. Nur eine friedliche Lösung konnte sie aus dem Dilemma der widerstreitenden Loyalitäten befreien. Am 11. August baten sie die Stadt Köln, sie als Vermittler anzuerkennen und wandten sich mit dem selben Anliegen auch an Landgraf Hermann und das Stift ${ }^{260}$. Erst im Oktober kam dann ein Tag zustande, allerdings ohne die Beteiligung Burgunds und des Erzbischofs ${ }^{261}$. Im Frühjahr 1475 versuchte Herzog Gerhard teilweise gemeinsam mit König Christian von

${ }^{256}$ Lille ADN B 2105/67 597; der Brief an Johann in Briefwechsel Nr. 2688; das Schreiben an die Herzöge von Jülich-Berg nicht in Briefwechsel.

${ }^{257} \mathrm{Zu}$ Geschäften Kölner Kaufleute mit dem burgundischen Heer siehe z.B. Knebel, Diarium, Basler Chroniken, 2, S. 235.

${ }^{258}$ Friedrich III. an Gerhard und Wilhelm von Jülich-Berg, 18.1.1475 Andernach: CHMEL, Aktenstücke, 1, 1, Nr. 149; ders. an dies., 26.1.1475 Andernach: ebd., Nr. 150; ders. an dies., 6.2.1475 Andernach: Regesten Friedrich III., 7, bearb. v. Th. KRAUS, Nr. 440, S. 234f. Zu den Proviantlieferungen LANGE, Pulchra Nussia, S. 84, nach UlRICH, Acten, Nr.86, 93, mit unzutreffender Einschätzung der Motive der Herzöge von Jülich-Berg.

${ }^{259} \mathrm{Karl}$ an Gerhard von Jülich, vor 22.2.1475 Lager vor Neuss, Briefwechsel Nr. 2956, nach Auszug in PRIEBATSCH, Politische Correspondenz, 2, Nr. 95, S. 137. Friedrich III. an die Stadt Köln, 25.2.1475 Andernach: Regesten Friedrich III., 7, bearb. v. Th. KRAUS, Nr. 447, S. 237f.

${ }^{260}$ Gerhard und Wilhelm an die Stadt Köln, 11.8.1474 Burg: ULRICH, Acten, Nr. 32, S. $18 \mathrm{f}$.

${ }^{261}$ Gerhard und Wilhelm an die Stadt Köln, 11.10.1474, ULRICH, Acten, Nr. 45, S. $30 \mathrm{f}$. 
Dänemark, einen Ausgleich zwischen Kaiser und Burgund zu stiften. Zur ersten Zusammenkunft zwischen Karl und Christian auf dem Rhein bei Düsseldorf im November 1474 hatten die Herzöge eines ihrer Schiffe zur Verfügung gestellt, sich aber durch Räte vertreten lassen. Auch später blieben sie ständig mit dem König und dem päpstlichen Legaten bezüglich eines Ausgleichs in Kontakt ${ }^{262}$. Guy de Brimeu spielte als enger Vertrauter und Statthalter Karls in Geldern eine zentrale Rolle in den jülichschen Vermittlungsbemühungen, die auch nach dem Abzug des burgundischen Heeres zur Versöhnung der streitenden Kölner Parteien andauerten ${ }^{263}$.

Zum Ende des Jahres 1474 begann sich das Ringen zwischen Burgund und dem Kaiser um die Jülicher zuzuspitzen. Karl besaß mit seiner Armee das stärkere Druckmittel als der Kaiser, der auf Androhung und Eröffnung eines Ächtungsprozesses zurückgreifen mußte. Folgerichtig gelang es Karl am 31. Dezember 1474, sein Bündnis mit Gerhard und Wilhelm vom 21. Juni 1473 zu erneuern. Darin verpflichtete er sich, den Herzögen bei einem mit ihrer burgundischen Allianz begründeten Angriff durch Kaiser und Reich Hilfe zu leisten. Außerdem stellte er Schadensersatz für durch den Krieg erlittene Verluste in Aussicht ${ }^{264}$. Friedrich III. forderte Gerhard und Wilhelm am 26. Januar 1475 von Andernach aus feierlich auf, als Fürsten des Reiches gegen den Herzog von Burgund Truppen zu stellen ${ }^{265}$. Noch während seit Mitte März eine neue Verhandlungsinitiative der Jülicher im Gang war, leitete der Kaiser von Köln aus den Prozess zur Verhängung der Reichsacht über die Herzöge ein. Am 2. April rief er die jülichschen Untertanen auf, ihre Fürsten gegen Burgund zum Anschluß an das Reich zu bewegen, andernfalls würde gegen sie das Verfahren eröffnet ${ }^{266}$. Nur zwei Tage später saß Friedrich III. dann tatsächlich im Kölner Gürzenich über den Erzbischof von Köln und die Herzöge von Jülich-Berg zu Gericht. Dem Erzbischof wurden die Regalien aberkannt, insbesondere die Verfügung über die Gerichtsbarkeit in Stift und Stadt von Köln. Als darauf auch die Absetzung Herzogs Gerhards und seines Sohnes erfolgen sollte, warf sich nach einem Straßburgischen Bericht ein jülichscher Rat dem Kaiser zu Füßen und erwirkte einen Aufschub des Urteils

262 Brimeu an jülichsche Räte, 9.4.1475 Lager vor Neuss, ULRICH, Acten, Nr. 131, S. 88f; Karl an die Herzöge von Jülich-Berg, 22.4.1475 Lager vor Neuss, ULRICH, Acten, Nr. 142, S. 100-102; Briefwechsel Nr. 3038. BACHMANN, Deutsche Reichsgeschichte, 2, S. 496 m. Anm. 2. Paravicini, Brimeu, S. 473f. m. Anm. 84.

${ }^{263} \mathrm{Zu}$ der Korrespondenz Humbercourts mit Herzog Wilhelm seit dem Sommer 1475 siehe PARAVICINI, Brimeu, S. 475 Anm. 87-89.

${ }^{264}$ LACOMBLET, Rheinisches Urkundenbuch, 4, 1, Nr. 379, S. 473f.

${ }^{265}$ Friedrich III. an Gerhard und Wilhelm, 26.1.1475 Andernach: CHMEL, Aktenstïcke 1, 1, Nr. 150, S. 429f.

266 Vermittlung: sächsische Hauptleute an Herzog Wilhelm von Sachsen, 12.3.1475: PRIEBATSCH, Politische Correspondenz, 2, S. 124 zu Nr. 73. Friedrich III. an die Untertanen von Jülich-Berg, 2.4.1475 Köln: ebd., Nr. 91, S. 134. 
um eine Woche. Die Absetzung wurde vorerst nur angedroht, die persönliche Unterwerfung, die Öffnung der jülichschen Schlösser und die Unterstützung der vor Neuss befindlichen Kölner Truppen gefordert ${ }^{267}$.

Zwischen dem 4. und dem 8. April erschien Jungherzog Wilhelm persönlich in Köln vor dem Kaiser. Die gewünschten Zusagen, vor allem militärische Hilfe, brachte er nicht, sondern bot nur ein weiteres Mal die Vermittlung zwischen Burgund und dem Kaiser an ${ }^{268}$. Folgerichtig betrachtete der Kaiser die Jülicher weiterhin als ungehorsam und ließ sie am 14. April drei Mal vor der Tür des Gürzenich als den angedrohten Strafen verfallen erklären, sollten sie nicht bis zum 24. April vor ihm erscheinen ${ }^{269}$. An eine Durchsetzung des Urteils gegen Jülich war unter den gegenwärtigen Bedingungen allerdings nicht zu denken. Der in Köln weilende Offizial des Basler Bischofs, Matthias Müller, schätzte das zukünftige Verhalten der Jülicher als entscheidend für den Ausgang des Krieges ein. Sollten sie sich zum Reich schlagen und dem burgundischen Heer den Nachschub abschneiden, werde Herzog Karl sehr schnell besiegt sein. Schlössen sie sich aber Burgund an, so würden die Kämpfe noch lange weitergehen, $» d e n n$ der hertzog von Berg ist mechtig und vermag vil volks « ${ }^{270}$.

Obwohl Jungherzog Wilhelm die Neutralität seines Landes nicht aufgegeben und sich zu keinerlei Hilfe für die Kaiserlichen verpflichtet hatte, löste sein Besuch in Köln auf burgundischer Seite heftige Reaktionen aus. Vom 9. April datieren zwei Schreiben Karls und eines Guy de Brimeus an die Herzöge bzw. die herzoglichen Räte. Karl muß am 8. oder 9. April durch den Propst von Kerpen von den angedrohten kaiserlichen Strafen und der Reise Wilhelms nach Köln unterrichtet worden sein. In seiner Antwort verurteilte Karl das Vorgehen Wilhelms scharf und forderte die Herzöge auf, ihrem Bündnis treu zu bleiben. Sein eigenes Handeln sei durch die Übertragung der Vogtei gerechtfertigt. Auch versagte er sich den Hinweis nicht, daß ihnen die Allianz mit dem Kaiser keinerlei materielle Vorteile bringe, wie sie an dem fruchtlosen Prozess gegen Geldern hätten erfahren müssen ${ }^{271}$. Am selben Tag wandten sich Karl und Guy de Brimeu, letzterer nach eigenem Bekunden un-

267 PRIEBATSCH, Politische Correspondenz, 2, Nr. 95, S. 138f. u. ebd. Nr. 92, S. 135, Albrecht Achilles an Kurfürst Ernst von Sachsen, 5.4.1475 Köln. Herzog Magnus von Mecklenburg, der eigentlich der burgundfreundlichen Partei um König Christian von Dänemark angehörte, war unter den über die Jülicher bestellten Richtern: CHMEL, Aktenstücke, 1, 1, Nr. 154, S. 433-438.

268 Asmus von Eberstein an Herzog Wilhelm von Sachsen, 12.4.1475 Köln, PRIEBATSCH, Politische Correspondenz, 2, Nr. 94, S. 136.

269 Beschlüsse des Rates der Stadt Köln, 1, Nr. 21, S. 537.

270 Brief in: Knebel, Basler Chroniken, 2, S. 231, vgl. auch ebd., S. 240: 1 ... et si dux Montensis non permitteret alimenta sibi [Karls] per suam patria vehere, tunc non posset ibi manere.«

271 Karl an Gerhard und Wilhelm, 9.4.1475 Lager vor Neuss, UlRICH, Acten, Nr. 132, S. 89ff.; Briefwechsel Nr. 3014. 
abhängig von seinem Herzog, an die jülichschen Räte in Düsseldorf. Ihnen wurde unzweideutig geraten, ihre Herren zu einer offenen Allianz mit Burgund zu bewegen, da sie sonst ihr eigenes und das Wohlergehen ihrer Länder leichtfertig gefährdeten ${ }^{272}$. Gleich am folgenden Tag antwortete Jungherzog Wilhelm noch aus Köln mit der Bitte um Verständnis für sein Vorgehen, da er im Hinblick auf die kaiserlichen Strafandrohungen nicht anders habe handeln können ${ }^{273}$.

An der tatsächlichen Lage Jülichs änderte sich durch diese Vorgänge nichts, doch zeigt sich in der harten Reaktion Karls neben seiner hochfahrenden Art auch die Angst, die wichtige Basis der jülich-bergischen Länder zu verlieren, als der Aufmarsch des Reichsheers zu einer ernsthaften Bedrohung wurde. Die Kaiser und Stadt Köln umfassende Exemtionsklausel des Bündnisses von 1473, die in der Bekräftigung von 1474 nicht gestrichen worden war, wurde auf burgundischer Seite wohlweislich nicht mehr erwähnt. Denn Karl konnte sich den Herzögen gegenüber nicht auf ein Versprechen ähnlich dem Johanns von Kleve berufen, ihm gegen jedermann, auch gegen den Kaiser, dienen zu wollen. Neutralität war offensichtlich die äußerste und einzige Position, die Jülich mit Berufung auf die Ausnahmen des Bündnisvertrages einnehmen konnte. Im Juni wurden noch einmal Pläne des Kaisers bekannt, nach einem Sieg über Karl die Herzöge von Jülich und von Kleve für die unterlassene Hilfeleistung zu bestrafen ${ }^{274}$.

Da der Kaiser nach Verstreichen des Ultimatums vom 24. April weiterhin mit Acht und Konfiskation drohte und sich die gesamtpolitische Lage Karls zunehmend verschlechterte, versuchte der Burgunder, die Herzöge durch das Schreckgespenst eines bevorstehenden kaiserlichen Angriffs auf. Jülich doch noch für ein offensives Bündnis zu gewinnen. Wie an Kleve erging daher sofort nach dem Eintreffen der Kriegserklärung Herzog Renés von Lothringen die Aufforderung an Jülich, sich in Kriegsbereitschaft gegen Ludwig XI. zu versetzen, der nach Ablauf des Waffenstillstands die burgundischen Grenzen bedrohte 275 . Ebensowenig wie Kleve stellte Jülich die gewünschten Truppen und wurde genau wie Herzog Johann im Juli gebeten, Guy de Brimeu in Ab-

272 Karl an die Räte, 9.4.1475 Lager vor Neuss, ULRICH, Acten Nr. 130, S. 87f.; Briefwechsel Nr. 3015. Brimeu an die Räte: UlRICH, Acten, Nr. 131, S. 88f.

273 Jungherzog Wilhelm an Karl, 10.4.1475 Köln: ULRICH, Acten, Nr. 134, S. 92 (Regest), Düsseldorf HStA, Jülich-Berg I, Nr. 255 f.23r, nach GRÜNEISEN RTA-Material; Briefwechsel Nr. 3018.

${ }^{274}$ Herzog Wilhelm von Sachsen an Herzog Albrecht von Sachsen, Juni 1475: PRIEBATSCH, Politische Correspondenz, 2, Nr. 128, S. 163.

${ }^{275} \mathrm{Karl}$ an Gerhard und Wilhelm von Jülich, 9.5.1475 Lager vor Neuss: ULRICH, Acten, Nr. 147, S. 105f.; Briefwechsel Nr. 3079. Ders. an dies., 18.5.1475 Lager vor Neuss: UlRICH, Acten, Nr. 157, S. 112-114, Briefwechsel Nr. 3088. Vgl. LANGE, Pulchra Nussia, S. 134. 
wesenheit Karls beim Schutze Gelderns beizustehen ${ }^{276}$. Im Juni ersuchte Jungherzog Wilhelm den Burgunder, seine Lande beim Rückzug der Truppen zu schonen, da sie schon zu sehr unter dem Krieg gelitten hatten. Die Bitte war vergeblich, denn einen Monat später sahen sich die Herzöge zu einer Beschwerde über die Gewalttätigkeiten der durchziehenden burgundischen Söldner veranlaßt277. Im November 1476 sicherte Erzbischof Ruprecht in Ersatz der Schäden die Summe von 5000 Gulden zu ${ }^{278}$.

Der kaiserliche Unwille über die Nichtachtung des Reichsaufgebotes äußerte sich in der Rücknahme der Belehnung mit Jülich-Berg und der Übertragung der Grafschaft Blankenheim und der Herrschaft Gerolstein aus dem Erbe Graf Wilhelms von Loon und Blankenheim an den Grafen von Moers. Die Jülicher, die mit den übrigen Besitzungen Graf Wilhelms im März 1469 von Friedrich belehnt worden waren, hatten die Ansprüche der Grafen von ManderscheidSchleiden auf diese Herrschaften unterstützt; Graf Vinzenz seinerseits beanspruchte ein Viertel des Herzogtums Jülich als Erbe des Grafen von Blankenheim $^{279}$. Erst nach seinem Engagement in der Schlichtung zwischen Erzbischof Ruprecht und Hermann von Hessen und der Truppenhilfe für die Habsburger im Krieg gegen Frankreich nach 1477 gelang es Herzog Wilhelm von Jülich, die kaiserliche Belehnung mit dem väterlichen Erbe zu erlangen.

Der Niederrhein schien in seiner Gesamtheit bis zum Kölner Stiftskrieg als nahezu wehrloses Objekt burgundischer Expansion. Aus der Korrespondenz Karls wird deutlich, wie wirksam die Mischung aus Allianzen, Geld und Gewalt zur Anbindung oder Unterwerfung der nordöstlichen Nachbarn war. Weder Kleve, Geldern noch Jülich-Berg waren allein in der Lage, dem Burgunder Widerstand zu leisten. Vor Neuss scheiterte der Herzog am Durchhaltewillen der Stadt und der gänzlich unerwarteten Mobilisierung des Reichsaufgebotes. Sobald das divide et impera in einer traditionell von Partikularinteressen bestimmten Landschaft nicht mehr griff, war der Burgunder der Übermacht der verbündeten Reichsglieder nicht gewachsen. In diesem Sinne war Karl Auslöser einer Manifestation der Verdichtung des Reiches und scheiterte gleichzei-

${ }^{276}$ Karl an Gerhard von Jülich, 4.7.1475 Lager bei Heerlen: ULRICH, Acten Nr. 192, S. 138; Briefwechsel Nr. 3154. Dazu PaRavicINI, Brimeu, S. 351 Anm. 438.

277 Jungherzog Wilhelm an Karl, 7.6.1475 Düsseldorf: Düsseldorf HStA Jülich-Berg I, Nr. 255 f.34r, nach GRÜNEISEN RTA-Material; Briefwechsel Nr. 3106. Gerhard und Willhelm von Jülich an Karl, 3.7.1475 Burg: Düsseldorf HStA Jülich-Berg I, Nr. 255 f.40r, nach GRÜNEISEN RTA-Material; Briefwechsel Nr. 3151.

278 25.1 1.1476: LACOMBLET, Rheinisches Urkundenbuch, 4, 1, Nr. 390, S. 484.

279 CHMEL, Regesta Friderici III., 2, Nr. 5536, S. 553; PARAVICINI, Moers, Croy, Burgund, S. 50. Auch Graf Johann von Nassau machte 1469 für seine Gemahlin Marie von Loon Ansprüche auf das Jülicher Viertel geltend, deren Verhandlung mit dem jülicher Herzogspaar sich mindestens bis 1472 hinzog: HStA Düsseldorf Jülich-Berg I, Nr. 376, nach GRÜNEISEN RTA-Material. 
tig an ihr. $\mathrm{Daß}$ er sie nicht vorhergesehen hat, kann ihm nicht zugerechnet werden, wohl aber seine mangelnde Flexibilität in der Reaktion auf diese Entwicklungen.

Im Bewußtsein seiner königgleichen Stellung, deren Anerkennung ihm noch vor kurzem vom Kaiser verweigert worden war, sah Karl die Gefolgschaft der Herzöge von Kleve und Jülich-Berg als selbstverständlich an. Da er selbst als Reichsfürst gegen das Reichsoberhaupt Krieg führte, wogen die faktischen Machtkonstellationen in seinen Augen allemal schwerer als Rücksichtnahmen auf die Zugehörigkeit zu einem politischen Gebilde, dessen Führung und Macht er geringschätzte. Der Handlungsspielraum Johanns von Kleve war seit der Eroberung Gelderns fast vollständig verloren. Die Herrschaftsübernahme Karls auch im Kölner Stift hätte den Klever endgültig aller verbliebenen Selbständigkeit beraubt. Obwohl er wie Jülich-Berg durch die Verweigerung der Truppenhilfe den Zorn des Kaisers auf sich zog, profitierten beide Häuser von der geschickten und zähen Abwehr der Neusser und dem Aufmarsch des Reichsheeres fast ebenso sehr wie das Erzstift selbst.

\section{Köln und die Hanse: Burgund als Schiedsinstanz}

\subsection{Köln, Lübeck und die Niederlande}

Am Niederrhein waren neben den weltlichen Fürstentümern Kleve, Geldern und Jülich-Berg das Erzstift ${ }^{280}$ und die Stadt Köln die bedeutendsten Nachbarn der Herzöge von Burgund. Die Stadt Köln verfügte traditionell über intensive Handelsbeziehungen zu den holländischen und flandrischen Städten, die sie im Lauf des 15. Jahrhunderts durch die restriktive Politik vor allem der wendischen Hansestädte unter Führung Lübecks gefährdet sah. Um den eigenen Handel vor Schaden zu bewahren, weigerte sich Köln, die von Lübeck betriebenen Zwangsmaßnahmen gegen die aufstrebenden holländischen Städte und Kaufleute mitzutragen ${ }^{281}$.

${ }^{280} \mathrm{Zu}$ den Beziehungen Philipps des Guten zu Erzbischof Dietrich von Moers vgl. S. 37-46.

281 Zum Kölner Handel mit Flandern und den Niederlanden siehe Gunther HIRSCHFELDER, Die Kölner Handelsbeziehungen im Spätmittelalter, Köln 1994, S. 332-340; Franz IRSIGLER, Die Kölner Handelsbeziehungen im Spätmittelalter, Wiesbaden 1979; Hans POHL, Köln und Antwerpen um 1500, in: Köln, das Reich und Europa, Köln 1971, S. 469-552; Philippe DOLlINGER, Die Hanse, Stuttgart ${ }^{4} 1989$, S. 384f.; Dieter SEIFERT, Alte Bindungen, neue Zwänge: die Krise der niederländischen Hansepolitik, in: Jörg BRACKER (Hg.), Die Hanse Lebenswirklichkeit und Mythos, Lübeck ${ }^{2} 1998$, S. 151-161; DERS., Kompagnons und Konkurrenten. Holland und die Hanse im späten Mittelalter, Köln, Weimar, Wien 1997, S. 17- 
Hatte es der Partikularismus der niederländischen Städte bis zum Anfang des 15. Jahrhunderts den Hansekaufleuten, oder »Osterlingen«, wie sie gemeinhin genannt wurden und sich selbst nannten ${ }^{282}$, noch erleichtert, mithilfe des Kontors zu Brügge, ${ }^{283} \mathrm{dem}$ »Deutschen Kaufmann«, ihre Monopolstellung fuir den Handel nach Norden und Osten zu behaupten, so sah man sich seit dem Erwerb Brabants, Hollands und Seelands durch Philipp den Guten einer übergreifenden Interessenvertretung durch den Herzog und seinen Rat gegenüber. In Flandern hatte diese Entwicklung schon unter Philipp dem Kühnen in Nachfolge seines Schwiegervaters eingesetzt ${ }^{284}$. Auch war es nun wesentlich schwieriger, eine Stadt gezielt durch Handelsblockaden oder andere Maßnahmen unter Druck zu setzen, da damit auch immer der Herzog als Landesherr getroffen wurde ${ }^{285}$. Die Macht der flandrischen Städte, namentlich der Vier Leden, ging zugleich in dem Maße zurück, wie die herzogliche Verwaltung an Durchsetzungskraft gewann ${ }^{286}$. Zur Zeit des Regierungsantritts Karls waren

21; knapper Überblick bei Hermann M. WOLLSCHLAEGER, Hansestadt Köln. Die Geschichte einer europäischen Handelsmetropole, Köln 1988, S. 34-39.

282 Vgl. zum Problem der Verfassung und des Selbstverständnisses der hansischen Städte und Kaufleute Thomas BEHRMANN, >Hansekaufmann,, 'Hansestadtc, 'Deutsche Hanser? Über hansische Terminologie und hansisches Selbstverständnis im späten Mittelalter, in: Th. SCHARFF, Thomas BEHRMANN (Hg.), Bene vivere in communitate. Beiträge zum italienischen und deutschen Mittelalter. H. Keller zum 60. Geburtstag, Münster, New York, München, Berlin 1997, S. 155-176; Rolf HAMMEL-KIESOW, Die Hanse, München 2000, S. 6896; zuletzt und erhellend: Ernst PITZ, Bürgereinung und Städteeinung. Studien zur Verfassungsgeschichte der Hansestädte und der Deutschen Hanse, Köln, Weimar, Wien 2001.

283 Zum Brügger Kontor Volker HENN, Über die Anfänge des Brügger Hansekontors, in: HGBIl 107 (1989) S. 43-66. Zur Konfliktregelung zwischen Hansekaufleuten und den flandrischen Städten Renée RöSSNER, Hansische Geschichtsbilder. Das Brügger Kontor, in: Thomas HILl, Dietrich W. POECK (Hg.), Gemeinschaft und Geschichtsbilder im Hanseraum, Frankfurt a. M. 2000, S. 27-44, mit Literatur zum Brügger Kontor. Demnächst zu einem Einzelbeispiel: Werner PARAVICINI, Ungeliebte Freunde. Der Hansenmord in Sluis zu Trinitatis 1436 (im Druck). Zur Geschichte der Beziehungen zwischen der Hanse und Holland bis etwa 1450 und besonders zum Konflikt von 1438-1441: SEIFERT, Kompagnons, S. 233-320, und DERS., Der Hollandhandel und seine Träger im 14. und 15. Jahrhundert, in: HGBll 113 (1995) S. 71-91. Siehe demnächst die Habilitationsschrift von Thomas BEHRMANN, Herrscher und Hansestädte. Studien zum diplomatischen Verkehr im Spätmittelalter, Typoskript Münster 1995.

284 Dietrich W. POECK, Kontorverlegung als Mittel hansischer Diplomatie, in: Nils JöRN, Werner PARAVICINI, Horst WERNICKE (Hg.), Hansekaufleute in Brügge, Teil 4: Beiträge der Internationalen Tagung in Brügge April 1996, Frankfurt a. M., Berlin, Bern u.a. 2000, S. 33 53, hier 44f., 50-53.

285 Walther STEIN, Die Burgunderherzöge und die Hanse, in: HGBll 10 (1901) S. 9-26, hier S. $14 f$.

286 PITZ, Bürgereinung, S. 37-40; Marc BooNE, Gent en de Bourgondische Hertogen ca. 1384-ca. 1453. Een sociaal-politieke Studie van een Staatsvormingprocess, Brüssel 1990, S. 163-235. DERS., Geld en Macht. De Gentse stadsfinanciën en de Bourgondische staatsvorming (1384-1453), Gent 1990, passim, zeigt den Zusammenhang zwischen dem Verlust politischer Macht und der Verfügungsgewalt über die städtischen finanziellen Ressourcen auf. Zur nachlassenden Bedeutung der diplomatischen Aktivitäten der Leden im 
aus den faktisch autonomen Handelsstädten Untertanen des Fürsten geworden, die an die Weisung seiner Amtsträger gebunden waren. Der organisatorisch nur schwer faßbare Verband der Hansestädte, der auch mit Lübeck über kein festes Oberhaupt verfügte und zudem keinem Fürsten unterstellt war, hob sich gegen diese zentralistischen Tendenzen umso deutlicher $a b^{287}$.

Schon im 14. Jahrhundert hatten unter lübischer Führung Bemühungen eingesetzt, die Autorität des Brügger Kontors auch auf die nichtflandrischen Gebiete der Niederlande auszudehnen. Dabei kamen der Entrichtung des Schosses, einer zunächst auf Flandern beschränkten Abgabe hansischer Kaufleute an das Brügger Kontor, auch in Brabant, Holland und Seeland, und dem Stapelzwang in Brügge entscheidende Bedeutung zu. Beide Punkte wurden auf dem Hansetag zu Lübeck 1447 beschlossen und stießen auf den erbitterten Widerstand Kölns, das sich jeder Machterweiterung des von Lübeck dominierten Kontors widersetzte ${ }^{288}$. Die anschließenden Verhandlungen mit Herzog Philipp und den Leden Flanderns verliefen ergebnislos, denn der Herzog sah keinen Grund, die wirtschaftlichen Anliegen der Deutschen, die den Stapel auch für die Holländer verpflichtend machen wollten, gegen die eigenen Untertanen zu vertreten. Lübeck reagierte mit wiederholten Versuchen, den Stapel aus Flandern und dem burgundischen Territorium heraus zu verlegen. Die Anweisung an die Kaufleute, den Handel nach Deventer zu verlegen, fand 1451 kaum Gehör; vor allem Köln hielt sich nicht an die Vorschrift. Als die Verlegung des Stapels 1455 nach Utrecht von den Kaufleuten weit besser befolgt wurde, ließ Herzog Philipp die Einrichtung gewaltsam entfernen. In den anschließenden Verhandlungen mußten sich die Hansekaufleute zur Rückkehr nach Brügge bereit erklären, ohne nennenswerte Konzessionen errungen zu haben. Brügge verlor dauerhaft seine Vormachtstellung, denn auch nach der Aufhebung der Handelssperre bestanden die von Hansekaufleuten eingerichteten »wilden Lager« vor allem in Amsterdam und Antwerpen fort ${ }^{289}$. Die Städte und Leden Flanderns waren als Verhandlungspartner gänzlich hinter den herzoglichen Amtsträgern zurückgetreten, während durch die Ausdehnung des

15. Jahrhundert: Wim BLOCKMANS, De Volksvertegenwoording in Vlaanderen in de Overgang van Middeleeuwen naar Nieuwe Tijden (1384-1506), Brüssel 1978, S. 174f.

287 BEHRMANN, ,Hansekaufmann', S. 167-169; Volker HENN, Was war die Hanse?, in: J. BRACKER (Hg.), Die Hanse. Lebenswirklichkeit und Mythos, 1, Hamburg 1989, S. 15-21.

288 In den drei hansischen Dritteln, von denen die Älterleute des Brügger Kontors gestellt wurden, waren die rheinischen Städte nicht vertreten, HUB, 9, S. XXI; siehe zu den verfassungsrechtlichen Aspekten der Auseinandersetzung PITZ, Bürgereinung, S. 316-321, 386389.

289 Stuart JeNKS, England, die Hanse und Preußen - Handel und Diplomatie 1377-1474, Bd. 3, Köln, Wien 1992, S. 710-719; Dollinger, Hanse, S. 388f.; DAENELl, Blütezeit, S. 81; Paul THERSTAPPEN, Köln und die niederrheinischen Städte in ihrem Verhältnis zur Hanse in der 2. Hälfte des 15. Jahrhunderts, (Diss. phil. Marburg) 1901, S. 75-78. 
Machtbereichs der burgundischen Herzöge die Verlegung des Kontors kein geeignetes diplomatisches Druckmittel mehr war ${ }^{290}$.

Angesichts der zurückgehenden Bedeutung Brügges und des flandrischen Handels hoffte Köln, dem Kontor und damit der lübischen Vormacht durch die Beschränkung seiner Privilegien auf Flandern allmählich die ökonomische Grundlage zu entziehen ${ }^{291}$. Gegen die Erhebung des Schosses führte die Stadt das ihr 1251 von Herzog Heinrich von Brabant gewährte Handelsprivileg an und bestritt außerdem die Jurisdiktion des Brügger Kontors über kölnische Kaufleute in Flandern. Die Konfrontation wurde unvermeidlich, als Köln 1458 zum ersten Mal bewußt gegen den hansischen Grundsatz, in interne Auseinandersetzungen keine außerhansischen Mächte einzuschalten, verstieß, indem es den Herzog um Schutzbriefe für Kölner Kaufleute anging, die den Herbstmarkt in Antwerpen aufsuchen wollten. Zusätzlich brachte Köln in den sechziger Jahren die süderseeischen und niederrheinischen Hansestädte durch seine Feindschaft zu Geldern und die Weigerung gegen sich auf, sich mit Deventer im Konflikt mit den Holländern um die Deventer Messen solidarisch zu zeigen $^{292}$.

Der Schoßstreit zwischen Köln und dem Kontor flammte 1465 durch die Erneuerung des Schoßgebotes auf dem Hansetag zu Hamburg wieder auf. Das Kontor forderte, den Verkauf aller in Flandern hergestellten Tuche ausschließlich in Brügge, Ypern und Thourout zu erlauben, um den holländischen Handel mit flandrischen Tuchen zu untergraben. Gegen diese Einmischung in die wirtschaftlichen Belange der Niederen Lande wandte sich namentlich Antwerpen, das die völlige Abschaffung des Stapelzwanges auch für hansische Waren verlangte. Diese Frontstellung Antwerpens wirkte sich auf dem Pfingstmarkt der Stadt 1466 sofort zum Vorteil der Kölner aus. Als sie den Schoß verweigerten und das Kontor sie arrestieren lassen wollte, schlug sich die Antwerpener Obrigkeit auf die Seite der Kölner. Der Streit gelangte schließlich durch den Appell des Hansetages von Lübeck im Juli 1466 vor das herzogliche Gericht ${ }^{293}$. Nachdem der herzogliche Große Rat zunächst gegen Antwerpen entschieden und die Stadt dagegen appelliert hatte, berief Herzog Philipp Köln und das Brügger Kontor zu einer erneuten Verhandlung vor sein Gericht, die im Januar 1467 beginnen sollte ${ }^{294}$. Der Streit wurde damit durch den Hansetag selbst zu einer Angelegenheit des Herzogs von Burgund.

290 POECK, Kontorverlegung, S. 50-53.

${ }^{291} \mathrm{Zu}$ Brügge siehe Georg ASMUSSEN, Die Lübecker Flandernfahrer in der zweiten Hälfte des 14. Jahrhunderts (1358-1408), in: Werner PARAVICINI (Hg.), Hansekaufleute in Brügge, Frankfurt a.M. u.a., 1999, S. 38-81; DAENELL, Blütezeit, S. 69 f.

${ }^{292}$ HR, 2, 5, Einleitung zu Tag von Hamburg, S. 458. DAENELL, Blütezeit, S. 73-76, 84f.

293 HUB, 9, Nr. 319.

294 THERSTAPPEN, Köln und die niederrheinischen Städte, S. 78. 
Die Entsendung Johann Zeuwelgins ${ }^{295}$, Propst von St. Andreas zu Köln, an den burgundischen Hof zur Vertretung der kölnischen Interessen fiel damit in den Beginn der Regierungszeit Herzog Karls. Seine Berichte stehen im Mittelpunkt der folgenden Abschnitte und geben Aufschlüsse über die Parteien am burgundischen Hof, die sich um die Entscheidung im Schoßprozeß formierten, und die in ganz ähnlicher Zusammensetzung auch in anderen Fragen der herzoglichen Reichspolitik wiederbegegnen ${ }^{296}$. Diese Beobachtungen werden ergänzt durch die Akten der Verhandlungen zwischen den holländischen und hansischen Städten in Utrecht von 1473/74. Sie geben Aufschlüsse über ein grundsätzliches Problem der Burgunder im Umgang mit dem Reich, namentlich die Verunsicherung einer auf den Herzog hingeordneten Verwaltung gegenüber einer Vielzahl von Ansprechpartnern im Reich, die teilweise, wie der Verbund der Hansestädte, nur zweifelhaft legitimiert schienen und nicht hierarchisch einer Machtzentrale untergeordnet waren.

\subsection{Der Schoßstreit vor dem herzoglichen Rat}

Zeuwelgin hielt sich von Juni 1467 bis Januar 1468 als eine Art von ständigem Vertreter am Hof in Brüssel auf. Bereits vor seiner offiziellen Beauftragung durch die Stadt im April 1467 hatte er ihre Anliegen beim Grafen von Charolais gefördert. Ziel seiner Mission war es, den Prozeß dem herzoglichen Rat wieder entziehen und vor einen Hansetag verweisen zu lassen ${ }^{297}$. Köln dachte dabei jedoch nicht an eine allgemeine Versammlung der Hansestädte, sondern an das Gremium eines »kölnischen Drittels«, das in dieser Form gar nicht existierte und keinesfalls die Zustimmung der übrigen Städte finden würde ${ }^{298}$. Der Propst sollte sich außerdem um eine einvernehmliche, außergerichtliche Lösung mit dem Kontor bemühen ${ }^{299}$. Der Große Rat jedoch, der auf das lukrative Druckmittel auf Köln, die übrigen Hansestädte und das Kontor nicht verzichten wollte, verweigerte die Zurückweisung des Prozesses an einen Hansetag 300 . Köln entschloß sich angesichts der Unterstützung Antwerpens und der ermuti-

295 Die Familie Zeuwelgin war in Köln alteingesessen. Arnold und Hermann Zeuwelgin waren 1375/76, 1394 und 1396, bzw. 1394 und 1396 Mitglieder des weiten Rates der Stadt. 1430 und $1434 \mathrm{saß}$ Arnold Zeuwelgin für das Schwarzhaus im Rat der Stadt: Wolfgang HERBORN, Die politische Führungsschicht der Stadt Köln im Spätmittelalter, Bonn 1977, S. 496, 611 .

296 Der Ablauf der Prozesse ist anhand der Hanserezesse und des Hansischen Urkundenbuches bereits ausführlich dargestellt in THERSTAPPEN, Köln und die niederrheinischen Städte; DOLLINGER, Hanse, S. 394-404; HUB, 9, Einleitung S. XXIX-XXXI, XLI.

297 HUB, 9, Nr. 359; Vollmachten der Stadt Köln für Zeuwelgin, 13.6.1467, HUB, 9, Nr. 373, 375.

298 HUB, 9, Nr. 389.

299 HUB, 9 , Nr. 375.

${ }^{300}$ HUB, 9 , Nr. $340,343,359,364,370,372-75$. 
genden Berichte Zeuwelgins zu einer unnachgiebigen Haltung, obwohl sich das Kontor mit einer Ablösung der Kölner Schoßpflicht durch die jährliche Entrichtung von 4-500 Gulden einverstanden erklärte ${ }^{301}$. Im November 1467 kam es schließlich in Köln im Lauf der Gesandtschaft des Kontorssekretärs Goswin von Coesfeld nach beleidigenden Äußerungen einiger Kölner Ratsherren zum endgültigen Bruch ${ }^{302}$.

Für die Mitglieder des herzoglichen Rates und die übrigen Hofangehörigen war das Eintreten für oder gegen die Kölner Anliegen von politischen Erwägungen bestimmt. Die Unterstützung Kölns bedeutete gleichzeitig, sich auf die Seite Herzog Johanns von Kleve und der Herzöge von Jülich und Berg und gegen Erzbischof Ruprecht von Köln und Herzog Adolf von Geldern zu stellen. Die Konstellationen Kurköln und Geldern gegen das von Burgund gestützte Kleve war bereits aus den Soester und Münsterschen Fehden überkommen und die Förderung stadtkölnischer Anliegen daher traditionell eine burgundische Priorität ${ }^{303}$. Weiterhin spielte in die wenig zuvorkommenden Behandlung des Kontors zu Brügge der Unwillen der herzoglichen Verwaltung über die hansische Einmischung in die wirtschaftlichen Belange der Niederlande hinein.

Zeuwelgin verstand es in dem guten halben Jahr von April 1467 bis zum Januar 1468, das er in kölnischem Auftrag am Hof verbrachte, sich das Vertrauen des Herzogs aus der früheren Bekanntschaft zu erhalten und es zu nutzen, um Zugang $\mathrm{zu}$ den wichtigen Informationsquellen und den entscheidenden Mitgliedern des Großen Rates zu erlangen. Karl zeigte sich dem Kölner für alle sichtbar geneigt, indem er ihm Zutritt zu seinen Privaträumen, dem »heymlich gemach«, zu seinem levé und zur morgendlichen Messe im Oratorium gewährte ${ }^{304}$. Wiederholt führte es der Propst auf seine Anwesenheit in der »Kammer« zurück, daß er geheime Informationen über den Prozeßverlauf und die Entwicklung im Krieg gegen den Erzbischof und Geldern an die Stadt weiterleiten konnte. In der Hofordonnanz von 1469 weist Karl sein Oratorium und seine chambre als privilegierten Ort des Zugangs zum Herrscher aus ${ }^{305}$. Dies sollte sich vor allem angesichts der schwachen rechtlichen Position Kölns auszahlen, aus der das Kontor aufgrund seiner eigenen schlechten Verbindungen zu Hofangehörigen kaum Kapital schlagen konnte ${ }^{306}$.

301 DAENELL, Blütezeit, S. 88f.

302 HUB, 9, Nr. 399, 402, 408 u S. XXXIII.

${ }^{303}$ JANSSEN, Kleve-Mark-Berg-Ravensberg 1400-1600, S. 24-30.

304 HUB, 9, Nr. 399, 423. Zeuwelgin verstand Französisch, auch wenn er es offenbar nicht fließend sprach, HUB, 9, Nr. 405.

305 HUB, 9, Nr. 399, 400, 420, 423. Werner PARAVICINI, Ordre et règle. Charles le Téméraire et ses ordonannces de l'hôtel, in: Académie des Inscriptions et Belles-Lettres. Comptes rendus des séances, Paris 1999, S. 311-359, hier S. 333f.

${ }^{306} \mathrm{Vgl}$. Thomas BEHRMANN, Hansische Gesandte an Herrscherhöfen: Beobachtungen zum Zeremoniell, in: Werner Paravicini (Hg.), Zeremoniell und Raum. 4. Symposium der Resi- 
Sein Zugang zu den innersten Zirkeln der höfischen Entscheidungsträger versetzte Zeuwelgin in die Lage, dort Kontakte zu pflegen und die jeweils anstehenden Urteile durch Bitten, Versprechungen und Geschenke zugunsten Kölns zu beeinflussen. Die Lektüre seiner Berichte läßt dabei nach und nach ein umfassendes Bild der kölnfreundlichen Fraktion am Hof entstehen. Die ersten und wichtigsten Verbindungen knüpfte Zeuwelgin zu Pierre de Goux, Kanzler Burgunds, den Karl aus der Regierung seines Vaters übernommen hatte, und zu Karls Günstling Guillaume Bische. Beide wurden von Köln im August mit eigenen Bittschreiben bedacht, die zunächst einen Aufschub der Verhandlungen auf den 15 . September bewirkten ${ }^{307}$. Wenige Tage nach Beginn des Prozesses stellte der Propst dann fest, daß er mit den allgemein erwarteten Geschenken zur Beförderung der eigenen Anliegen bereits beinahe in Verzug war. Schleunig holte er daher von seinen Auftraggebern die Erlaubnis ein, dem Kanzler und Bische jeweils zwei vergoldete Kannen im Wert von 120 fl.rh. zukommen zu lassen ${ }^{308}$. Mit Jehan Gros d. J., dem ersten Sekretär Karls ${ }^{309}$, gab sich ein weiterer enger Vertrauter des Herzogs als Befürworter der kölnischen Sache zu erkennen. Zeuwelgin sprach von ihm als dem »allerheymlichste[n] secretarius «, dessen Einfluß die Stadt mit einer Anerkennung (»reverencie«) von einem halben Dutzend Schalen im Wert von etwa 40 Gulden honorieren sollte ${ }^{310}, 1469$ sprachen die kölnischen Gesandten von Gros als dem »audiencierre, der guet frunt is « ${ }^{311}$.

Köln bedurfte dieser Hilfsmittel auch dringend, denn die Schwäche seiner Rechtsposition war klar zutage getreten, als der Kontorssekretär Gerhard Bruns $^{312}$ am 15. September vor dem Großen Rat die Siegel der Hansestädte vorlegte, die dem Schoß zugestimmt hatten. Unter den präsentierten Dokumenten befand sich auch ein einschlägiges Schreiben Kölns. Der Kanzler nahm Zeuwelgin nach Ansicht dieser Briefe beiseite und riet dringend zu einem gütlichen Ausgleich mit dem Kontor. Goux wies ausdrücklich darauf hin, $\mathrm{da} ß \mathrm{ihm}$ durch die Inkonsistenz des kölnischen Verhaltens eine der Stadt genehme Entscheidung so gut wie unmöglich gemacht werde. Zeuwelgin setzte

denzen-Kommission der Akademie der Wissenschaften in Göttingen, Sigmaringen 1997, S. 97-111, hier S. 110 .

${ }^{307}$ HUB, 9, Nr. 376, 390 u. Anm. 3, Nr. 393.

${ }^{308}$ HUB, 9, Nr. 399, 405.

309 Gros war audiencier des Großen Siegels und des Sekretsiegels, und Erster Sekretär, Cockshaw, Le personnel, S. 64, 67.

310 HUB, 9, Nr. 420.

311 HUB, 9, Nr. $613 \$ \$ 59,60$.

312 Siehe zu Bruns H. LELOUX, Een Deventer kanunnik secretaris van de oosterlingen te Brugge in Vlaanderen, in: Verslagen en Mededelingen van de Vereniging tot Beoefening van Overijsselsche Recht en Geschiedenis 88 (1973) S. 3-23, und DERS., Nog eens Gerard Bruens van Deventer, in: ebd. 89 (1974) S. 48-50. 
trotzdem weiterhin auf die Konfirmierung des Privilegs von 1251, die er durch die Intervention Guillaume Bisches erreichen wollte ${ }^{313}$.

Neben Goux, Bische und Gros versicherte eine Vielzahl weiterer Herren die Kölner ihrer Unterstützung. Traditionell der Stadt Köln verbunden war die Familie Looz-Blankenheim, die 1467 am burgundischen Hof durch den Sohn Graf Wilhelms und seiner Frau Marie de Croÿ vertreten war ${ }^{314}$. Gemeinsam mit Eberhard von der Marck hatte der Junker von Blankenheim Zeuwelgin die Etablierung bei Hof überhaupt ermöglicht ${ }^{315}$. Unter anderem vermittelten sie dem Gesandten eine Unterredung mit Adolf von Kleve-Ravenstein, der sich bei Karl für Köln einzusetzen versprach ${ }^{316}$. Im Januar 1468 berichtete Zeuwelgin, daß sich auch Johann von Luxemburg, Graf von Marle, Köln wohlgesonnen zeige und sich gemeinsam mit Goux und Bische dem Rat der Stadt empfehlen ließ. Johann von Luxemburg stellte in den Augen des Propstes einen bedeutenden Zugewinn dar, da er jede Nacht in der Kammer des Herzogs schlief und daher direkten Zugang zu dessen Ohr versprach ${ }^{317}$. Mit Bastard Anton gab sich noch ein weiteres Mitglied des höchsten Hofadels als »Freund der Stadt« zu erkennen, und Zeuwelgin konnte schließlich so gut wie alle groBen Herren bei Hof zu seinen Gönnern zählen ${ }^{318}$.

Angesichts dieser erdrückenden Übermacht der kölnfreundlichen Partei, die sich ganz in den Bahnen der burgundischen Politik unter Herzog Philipp bewegte und ihren Platz in den Konflikten mit dem Erzbischof und Geldern fand, ist die kleine Gruppe derjenigen, die sich gegen Köln auf die Seite des Brügger Kontors schlugen, von besonderem Interesse. Namentlich zu identifizieren sind Pierre Bladelin, Generalrentmeister Herzog Philipps, den Zeuwelgin als Protektor des Kaufmanns zu Brügge ausmachte ${ }^{319}$, Peter von Hagenbach und Antoine Haneron.

Bei Bladelin, der selbst als Kaufmann tätig war, bevor er in den herzoglichen Dienst übertrat, wird der Grund für die Stützung des Brügger Kontors in seinen persönlichen wirtschaftlichen Verflechtungen gelegen haben ${ }^{320}$. Aus der Perspektive der weiteren Reichspolitik Karls ist er im übrigen von untergeordneter Bedeutung. Anders sind in dieser Hinsicht Hagenbach und Haneron zu beurteilen, deren Zusammenwirken in Reichsangelegenheiten sich hier

313 HUB, 9, Nr. 399.

${ }^{314}$ Siehe PARAVICINI, Moers, Croy, Burgund, S. 23 m. Anm. 67.

315 HUB, 9, Nr. 420. Zeuwelgin hatte den Auftrag, sich des Wohlwollens Blankenheims als Fürsprecher beim Großen Rat zu versichern. An Blankenheim erging ein Schreiben Kölns in gleichem Sinn, HUB, 9, Nr. 374.

316 HUB, 9, Nr. 420, Zeuwelgin an Köln, 30.12.1467. Antwort des Rates: ebd., Nr. 422, 4.1.1468.

${ }^{317}$ HUB, 9, Nr. 423, Zeuwelgin an Köln, 4.1.1468.

318 HUB, 9, Nr. 425, Zeuwelgin an Köln, 17.1.1468.

${ }^{319}$ HUB, 9, Nr. 376, Zeuwelgin an Köln, 15.6.1467.

${ }^{320}$ BARTIER, Légistes et gens de finances, S. 62 Anm. 5. 
zum ersten Mal nachweisen läßt ${ }^{321}$. Auch bei Haneron könnten wirtschaftliche oder andere persönliche Verbindungen zum Brügger Kontor seine Haltung beeinflußt haben, da er seit Dezember 1467 mit der Propstei von Saint-Donat in Brügge bepfründet war ${ }^{322}$. Hagenbachs Abneigung gegen die stadtkölnische Politik wird sich aus seinen Verbindungen zum pfalzgräflichen Haus, dem auch Erzbischof Ruprecht entstammte, erklären lassen. 1453 soll er bereits dem Pfalzgrafen als Kammerherr am burgundischen Hof gedient haben. Spätestens aber seit der Aushandlung der burgundischen Allianz mit Pfalzgraf Friedrich von 1465 war er dem Pfalzgrafen persönlich bekannt ${ }^{323}$. Haneron und Hagenbach machten sich damit sehr früh zu Anwälten einer städtefeindlichen Politik, die sie mit unterschiedlichen Akzenten in den 1470er Jahren gegen die oberrheinischen Städte und die Eidgenossen vertraten.

Herzog Karl widmete sich allerdings erst nach der Besetzung Gelderns den Streitigkeiten innerhalb des Erzstiftes und wechselte zu Beginn des Jahres 1474 tatsächlich gegen burgundisches Herkommen in das erzbischöfliche Lager. Im Januar 1468 aber war er noch weit davon entfernt und ließ Dr. Georg Heßler, zu diesem Zeitpunkt Propst zu Xanten und Kanzler Erbischof Ruprechts, mehr als eine Woche auf eine Audienz warten, obwohl sich Haneron und Hagenbach wiederholt bei Karl für ihn verwandten ${ }^{324}$.

Noch aber war der Schoßstreit zu keiner Klärung gekommen, sondern erhielt im Gegenteil 1469 neue Nahrung, als sich das Kontor entschloß, auf dem Ostermarkt zu Bergen-op-Zoom und in Antwerpen gegen die Kaufleute vorzugehen, die den Schoß verweigerten. Da die Kölner über herzogliche Schutzbriefe verfügten, wurde der Fall wieder vor den Großen Rat gezogen, wo er am 1. August 1469 verhandelt werden sollte ${ }^{325}$. Köln ließ sich durch Bürgermeister Heinrich Suderman, Doktor Johann Bareyt van den Bosch, Stadtsekretär Mathias Krayn und die Kaufleute Peter von Ercklenz und Paul Rode vertreten. Am 4. August empfing sie der Herzog in Middelburg (Walcheren, Seeland) in Anwesenheit Herzog Johanns von Kleve, Adolfs von KleveRavenstein und des Kanzlers. Die lateinische Rede Dr. Bareyts wurde freundlich aufgenommen und eine schnelle Behandlung des Falls versprochen ${ }^{326}$.

321 Siehe unten S. 224-227, 245f., 265-268.

322 Henri STEIN, Un diplomate bourguignon du XV $\mathrm{XV}^{e}$ siècle, Antoine Haneron, in: BEC 98 (1937) S. 283-348, hier S. 293.

323 BRAUER-GRAMM, Hagenbach, S. 15f., 21.

324 HUB, 9, Nr. 425. Die Mission Heßlers fällt in die Anfänge der Vermittlungsversuche Karls im Streit des Kölner Erzbischofs mit seinem Stift, Leonhard ENNEN, Geschichte der Stadt Köln, 3,1, Köln 1869, S. 465f., 479.

${ }^{325}$ HUB, 9, Nr. 598. Vgl. die Schreiben Kölns an Karl, 17.5.1469, HR, 2, 6, Nr. 256 u. 21.6.1469, ibid., Nr. 259. Siehe zu den Einzelheiten des Prozesses THERSTAPPEN, Köln und die niederrheinischen Städte, S. 91-94.

${ }^{326}$ HUB, 9, Nr. 613, $\S 1-4$. Vollmacht der Stadt Köln HR 2 VI, Nr. 262, 24.7.1469. Die Gesandtschaft reiste mit 15 Pferden. 
Der Prozeß begann am 11. August 1469 in Den Haag in Anwesenheit der kölnischen Gesandten, des Advokaten und des Prokuratoren der beklagten Kölner Kaufleute, sowie Goswins von Coesfeld und Gerhard Bruns, Sekretäre des Kaufmanns zu Brügge und ihrer Anwälte ${ }^{327}$. Sehr schnell zeigte sich einmal mehr die Schwäche der kölnischen Rechtsposition, als die Gesandten lediglich von zwei weiteren Städten neben Köln, Wesel und Duisburg, förmliche Protesterklärungen gegen den Schoß beibringen konnten ${ }^{328}$. Die Älterleute des Kontors dagegen legten zur Untermauerung ihrer Ansprüche eine Fülle von Dokumenten vor. Wieder flüchteten sich die Kölner in die Bitte, das Privileg von 1251 zu bestätigen, woraufhin zunächst eine Prüfung des Privilegs durch Kanzler und Rat von Brabant angeordnet wurde ${ }^{329}$.

Als aber der Große Rat am 5. September beschloß, den Kölner Kaufleuten in Antwerpen bis zur endgültigen Entscheidung zu einer Aufstellung ihrer schoßpflichtigen Waren zu befehlen, wußten die kölnischen Gesandten, an wen sie ihren Protest zu richten hatten. Sie teilten dem Kanzler mit, daß sie diese Maßnahme als Benachteiligung ansähen und verweigerten ihre Zustimmung. Goux hob daraufhin eigenmächtig den vom Rat verkündeten Beschluß auf. Selbst der Bericht der Kölner gestand ein, daß der Kanzler dies "mit guten Worten« den Kontorsvertretern habe plausibel machen müssen, da er es nach seinen eigenen Worten $»$ myt rechte...nyet doin mochte ${ }^{330}$. Im Oktober 1469 untersagte der Kanzler auf die Klage der Kölner den Brügger Älterleuten, kölnische Kaufleute auf dem Markt in Bergen-op-Zoom festnehmen zu lassen, da der Prozeß noch schwebe und die Kölner in Antwerpen Sicherheiten geleistet hätten ${ }^{331}$. Das Privileg von 1215 wurde schließlich im November in Brüssel bestätigt ${ }^{332}$.

Nun galt es aber für Köln weiterhin, das immer noch ausstehende endgültige Urteil des Herzogs zum Schoß zu erwirken ${ }^{333}$. Zu diesem Zweck blieb Dr. Bareyt am burgundischen Hof zurück. Seine Berichte vom Januar 1470 demonstrieren einmal mehr, in welchem Umfang der Hof sich hinter die kölnischen Anliegen stellte. Guillaume de Rochefort, seit Ende November Berichterstatter im ProzeB, der Kanzler Goux und Antoine de Montjeu sagten ihre Unterstützung zu. Bareyt versicherte ihnen, da $B$ die Stadt sich erkenntlich zeigen werde ${ }^{334}$. Die für den 19. Februar 1470 angesetzte Anhörung vor dem Großen Rat nahm Bareyt zum Anlaß, »die heren von den rait, die man vur

${ }^{327}$ HUB, 9, Nr. 613, $\$ 1$.

${ }^{328}$ HUB, 9, Nr. 613, §§10-11.

${ }^{329}$ HUB, 9, Nr. 613, $\$ 18-20$. Der entsprechende Befehl an Kanzler und Rat von Brabant wurde durch den Sekretär Jan Schoonhove ausgefertigt: ibid., Nr. 630.

330 HUB, 9, Nr. $613 \$ 26$.

331 HUB, 9, Nr. $613 \S 55$.

332 HUB, 9, Nr. $613 \S 58$.

333 THERSTAPPEN, Köln und die niederrheinischen Städte, S. 104-106.

334 HUB, 9, Nr. $613 \S \S 81,77-79$. 
guede vrunde der stat Colne acht «, mit einer Informationsschrift zu bedenken, die den Kölner Standpunkt zusammenfaßte. Zu diesem Kreis rechnete der Gesandte den Protonotar Arthur de Bourbon, Gerard Vurry, Präsident des Rates von Luxemburg, Jehan Carondelet, Antoine de Montjeu und Meister Volpart von Amerongen ${ }^{335}$. In der Anhörung selbst sprach sich Rochefort wie erwartet ganz zugunsten Kölns aus. Seine Darlegungen wurden angenommen und verabschiedet, so daß nur noch das eigentliche Urteil durch den Herzog ergehen mußte, das am 6. März 1470 in Brügge ausgesprochen und am 29. März besiegelt wurde 336 .

Doch auch nach diesem Urteil war ein Ende des Rechtsstreits nicht abzusehen, denn im Mai 1470 legte das Brügger Kontor Protest ein und der Prozeß wurde erneut eröffnet ${ }^{337}$. Als Rechtsvertreter Kölns fungierte nun Heinrich van Kandry, Licentiat des römischen Rechts, der einen Aufschub des Prozesses auf den 8. Januar 1471 erwirkte ${ }^{338}$. Er berichtete nach Köln, daß sich nun besonders Guillaume Hugonet, bailli von Charolais, den er als seinen Gönner hervorhob, Jehan de Poitiers Herr von Arcey (Arcis-sur-Aube), Markgraf von Antwerpen, und Jehan de Rubempré Herr von Bièvres, für die Belange der Stadt einsetzten ${ }^{339}$. Auch das Urteil des Rates vom 6. September 1471, das der Herzog am 16. September konfirmierte, erkannte zugunsten Kölns. Die Stadt erhielt die Freistellung von allen Schoßzahlungen, während dem Kontor die Zahlung der Kosten des Prozesses und die Rückerstattung des von Köln auBerhalb Flanderns gezahlten Schosses auferlegt wurde ${ }^{340}$.

Die Entscheidung über die Grundfrage des Schosses fiel schließlich 1476 auf einem Hansetag in Bremen. Köln mußte nach den durch burgundische Räte vermittelten Verträgen von Utrecht, die den Streit der wendischen Hansestädte mit England beilegten, einlenken. Die 1471 gegen die Stadt ausgesprochene Verhansung wurde jedoch aufgehoben und auch von den Schoßzahlungen blieb Köln auf Dauer ausgenommen ${ }^{341}$.

335 HUB, 9, Nr. $613 \S 90$.

336 Anhörung: HUB, 9, Nr. $613 \S \S 93,94,96,97$; Urteil ibid., Nr. 710. Die Meinung DAENELLs, Blütezeit, S. 92f., daß Karl das Urteil auch aufgrund seines soeben übernommenen Engagements am Oberrhein habe ergehen lassen, kann nicht zutreffen, da der Vertrag von Saint-Omer mit Herzog Sigmund erst am 9.5.1469 geschlossen wurde und die Verhandlungen erst am 22.3.1467 begannen, siehe VAUGHAN, Charles, S. 86.

337 Siehe HR, 2, 6, S. 261.

${ }^{338}$ HUB, 9, Nr. 784.

${ }^{339} \mathrm{Zu}$ Hugonet: L. LAROCHE, Le baillage comtal et le baillage des cas royaux de Charolais, AB 5, 1933, S. 147. Hugonet war von 1469 bis 1471 bailli des Charolais. HUB, 9, Nr. 784.

${ }^{340}$ HUB, X, Nr. 52, 60; HR, 2, 6 Nr. 465 §6, Nr. 467-469, 533.

341 THERSTAPPEN, Köln und die niederrheinischen Städte, S. 116-120. 


\subsection{Utrecht $1473 / 1474$}

Eine der Ursachen des Schoßstreites, die lose Organisation der Hanse und die offen ausgetragenen Interessenkonflikte ihrer Mitglieder, sorgte auch während der Verhandlungen der Hansevertreter mit den holländischen Städten in Utrecht 1473/1474 ${ }^{342}$ unter der Leitung herzoglicher Räte für Irritationen. Diese Verhandlungen illustrieren in aller Deutlichkeit die Beobachtungen von Behrmann zu Struktur und Selbstwahrnehmung der Hansekaufleute und -städte ${ }^{343}$. Nach Außen, den burgundischen Verhandlungspartnern gegenüber, gebärdete man sich zunächst als homogener Bund, der die Interessen aller "Hansestädte« vertrat. Gleichzeitig aber erwies sich immer wieder an juristischen Detailfragen, dass die Städte weder gewillt noch fähig waren, als einheitliches Rechtssubjekt aufzutreten, das seine Mitglieder verpflichtend binden konnte. Den Burgundern war zwar eben erst in den Auseinandersetzungen Kölns mit dem Brügger Kontor vor Augen geführt worden, daß die Hanse eben nicht eine einheitliche Korporation unter der unbestrittenen Führung einer Stadt, geschweige denn eines Fürsten war, doch hatten sie trotzdem Schwierigkeiten, diese Vorstellung in ihre Rechtsauffassung zu integrieren.

Für den Herzog saßen in Utrecht im wesentlichen Gerd von Assendelft, Jean de Halewin und Lambert van der Ee den Gesprächen vor. Die ebenfalls bevollmächtigten Ludwig von Brügge, Herr von Gruuthuse, Guillaume de Clugny und Jehan Gros nahmen wegen anderer Verpflichtungen gar nicht oder nur kurz an den Verhandlungen teil ${ }^{344}$.

Am 21. Juli 1473 entspann sich zum ersten Mal die danach in immer neuen Varianten wiederholte Diskussion um die Verfassung der Hanse. Die Burgunder bestanden darauf, die Hanse als einen »corpus« anzusehen, dessen Glieder gegenüber Dritten zur Gesamthaftung verpflichtet seien. Dem entgegneten die Sendboten, daß die Hanse eine Körperschaft ausschließlich in ihren Privilegi-

$342 \mathrm{Vgl}$. zu den Verhandlungen von Utrecht allgemein JENKS, England, S. 719-736; Terence Henry LLOYD, England and the German Hanse, 1157-1611, Cambridge 1991, S. 209-216; G. NEUMANN, Hansische Politik und Politiker bei den Utrechter Friedensverhandlungen, in: Klaus FRIEDLAND, Frühformen englisch-deutscher Handelspartnerschaft, Köln, Wien 1976, S. 25-59; zuletzt Nils JORN, "With Money and Blooder. Der Londoner Stalhof im Spannungsfeld der englisch-hansischen Beziehungen im 15. und 16. Jahrhundert, Köln, Weimar, Wien 2000, S. 66-88.

343 BEHRMANN, ,Hansekaufmann', passim.

344 Siehe zu Assendelft, Halewin, Clugny und Ee unten S. 221, 227, 241f., 249f; zu Gruuthuse Mario DAMEN, De staat van dienst. De gewestelijke ambtenaren van Holland en Zeeland in de Bourgondische periode (1425-1482), Hilversum 2000, S. 464; und Maximilian MARTENS, Louis de Bruges, seigneur de Gruuthuse, in: de SMEDT (Hg.), Les Chevaliers de l'Ordre de la Toison d'or, Nr. 61, S. 148-151. HR 2, 7, Nr. 24, Vollmacht vom 9.6.1473; HR 2, 7, Nr. $35 \$ \$ 1,5$. 
en sei, die, wenn nötig, gemeinsam verteidigt würden ${ }^{345}$. Doch auch die Burgunder hielten nicht konsequent an der Auffassung von der Hanse als Korporation fest. Im Zusammenhang eines Schreibens der Hanse an den Rat von Holland, das mit dem Lübecker Stadtsiegel besiegelt war, bezweifelten sie, daß dieses im Namen aller Hansestädte ergangen sei. Damit machten sie sich das Argument zu eigen, mit dem die Hansen die Eigenständigkeit ihrer Mitglieder zu belegen pflegten, nämlich das fehlende gemeinsame Siegel. Wenig später bemühte dann aber auch Halewin die Benutzung des Lübecker Stadtsiegels im Namen aller Städte als Beweis für deren Zusammengehörigkeit ${ }^{346}$.

Die Verfassung des amorphen Städtebundes bereitete den herzoglichen Räten auch im Zusammenhang der Prokurationen Verständnisschwierigkeiten. $\mathrm{Zu}$ Beginn der Verhandlungen im November und Dezember 1473 bemängelten sie, daß aus den Vollmachten der Ratssendboten nur die Bevollmächtigung durch Lübeck und die Wendischen Städte hervorgehe, nicht aber durch die anderen Hansestädte, gegen die man ebenfalls Ansprüche erhob. Zudem besäßen die Sendboten keine Vollmacht von den fürstlichen Stadtherren, wie beispielsweise des Grafen von Holstein ${ }^{347}$. Während die Ratssendboten betonten, daß die Tagfahrt ohnehin nur eine Angelegenheit der Wendischen Städte sei, wiesen sie die Behauptung, zu ihren Verhandlungen mit auswärtigen Mächten die Vollmacht eines Fürsten zu benötigen, entschieden zurück: „dat wii des neyn behoeff en hadden jeniger fursten macht to hebbende, wente de stede bii sick mechtich weren « ${ }^{348}$.

Dem unbedingten Souveränitätsanspruch des Herzogs gemäß waren die holländischen Städte im Gegenteil ängstlich bemüht, jeden Anschein eigenständigen Handelns zu vermeiden ${ }^{349}$. Jedes die Städte betreffende Verhandlungsergebnis mußte immer zuerst durch den Herzog gutgeheißen werden, neben der Vollmacht der städtischen Regierung benötigten deren Deputierte stets eine weitere des Herzogs.

345 HR 2, 7, Nr. $34 \S 10$, Nr. $35 \S \S 33-37,41,43$. Otto MELTZING, Tommaso Portinari und sein Konflikt mit der Hanse, in: HGBll 12 (1906) S. 101-123, hier S. 110. Zu der parallel gelagerten Auseinandersetzung der Hansestädte mit England um die Verfassung der Hanse siehe PITZ, Bürgereinung, S. 21 f.

${ }^{346}$ HR 2, 7, Nr. 35 §§6-28. Fehlende gemeinsame Siegel und Kasse als Zeichen für die Unabhängigkeit der einzelnen Glieder der Hanse, ibid., §77. Argumentation Halewins ibid., §78. Siehe dazu BEHRMANN, ,Hansekaufmann', S. 169.

${ }^{347}$ HR 2, 7, Nr. 79 § 18.

348 HR 2, 7, Nr. $79 \$ 34$.

349 HR 2, 7, Nr. $139 \S 232$. 
Der Gegensatz zu den Verhältnissen des römisch-deutschen Reiches hätte deutlicher nicht sein können. Für die Hansestädte war es eine Selbstverständlichkeit, ohne die Bevollmächtigung der ihnen reichsrechtlich übergeordneten Fürsten und des Kaisers oder auch nur in Abstimmung mit diesen Verträge mit auswärtigen Mächten zu schließen. Den Burgundern begegnete hier so etwas wie ein Abbild des Reiches in verkleinertem Maßstab, mit dem sie in ihrem zentralistisch geschulten Denken ebensolche Probleme hatten wie mit der pluralen Verfassung des gesamten Reiches. 
